P.F. Maeder, J. Kestin, D.A. Dickinson,

R. DiPippo and H. Olia

\author{
University of California \\ Los Alamos National Laboratory \\ LASL4-X60-6306P-1
}




\section{DISCLAIMER}

This report was prepared as an account of work sponsored by an agency of the United States Government. Neither the United States Government nor any agency Thereof, nor any of their employees, makes any warranty, express or implied, or assumes any legal liability or responsibility for the accuracy, completeness, or usefulness of any information, apparatus, product, or process disclosed, or represents that its use would not infringe privately owned rights. Reference herein to any specific commercial product, process, or service by trade name, trademark, manufacturer, or otherwise does not necessarily constitute or imply its endorsement, recommendation, or favoring by the United States Government or any agency thereof. The views and opinions of authors expressed herein do not necessarily state or reflect those of the United States Government or any agency thereof. 


\section{DISCLAIMER}

Portions of this document may be illegible in electronic image products. Images are produced from the best available original document. 


\title{
DESIGN AND OPERATION OF A \\ TWO-PHASE FLOW RESEARCH FACILITY
}

\section{by}

\author{
P. F. Maeder, J. Kestin \\ D. A. Dickinson, R. DiPippo ${ }^{(1)}$, and H. O1ia
}

Division of Engineering
Brown University
Providence, Rhode Island 02912

May 1982

(1) A1so, Mechanical Engineering Department, Southeastern Massachusetts University, North Dartmouth, Massachusetts 02747. 


\section{ABSTRACT}

In this report we describe the new two-phase flow facility that has been constructed at Brown University. Included is the design philosophy that led us to select a blow-down, Freon tunnel as the means of studying the flow of a pure substance undergoing liquid-vapor phase changes. Each component is discussed from the initial design considerations, through sizing calculations, to actual system specifications. Special emphasis is placed on the instrumentation and automatic data acquisition and processing system. Finally a sampling of results obtained so far is presented.

Section 1 gives the reasons for the construction of the facility and lists some of the uses and objectives of its operation. The reader can gain a good overview of the facility from Section 2 without a great deal of detail. In Section 3 we present the rationale for the particular design choices that were made and give details about the selection and sizing of a11 major components except the instrumentation. The latter subject is treated in Section 4 where we discuss the temperature and pressure probes, mass flow rate measurement, and other instrumentation. Section 5 is devoted to the test section proper where all the two-phase flow measurements and observations take place. The electronic data acquisition and facility contro1 system is the subject of Section 6. Results on two-phase friction factors and flow pattern observations in a horizontal pipe are given in Section 7 along with the ranges of flow that have been covered so far.

In capsule summary, the two-phase flow test facility is operational and has demonstrated a wide range of flow conditions from purely liquid to purely vapor through a variety of two-phase situations. Only horizontal flows have been studied so far, but the test section has been designed to operate in inclined positions up to fully vertical. The instrumentation performs very well as does the fully automatic control system. We believe the test facility is capable of yielding highly reliable and accurate data on two-phase flows which will be of great value in practice and in validating the various theories that have been put forth to describe this phenomenon. 


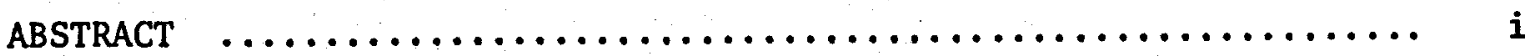

LIST OF FIGURES $\ldots \ldots \ldots \ldots \ldots \ldots \ldots \ldots \ldots \ldots \ldots \ldots \ldots \ldots \ldots \ldots \ldots \ldots$

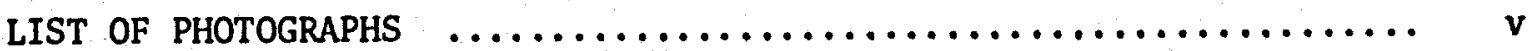

LIST OF SYMBOLS $\ldots \ldots \ldots \ldots \ldots \ldots \ldots \ldots \ldots \ldots \ldots \ldots \ldots \ldots \ldots \ldots \ldots \ldots$

1. INTRODUCTION $\ldots \ldots \ldots \ldots \ldots \ldots \ldots \ldots \ldots \ldots \ldots \ldots \ldots \ldots \ldots \ldots \ldots$

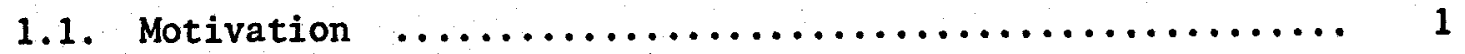

1.2. Objectives $\ldots \ldots \ldots \ldots \ldots \ldots \ldots \ldots \ldots \ldots \ldots \ldots \ldots \ldots \ldots \ldots, 3$

2. GENERAL DESCRIPTION OF THE FACILITY $\ldots \ldots \ldots \ldots \ldots \ldots \ldots \ldots \ldots \ldots .5$

2.1. Physical Arrangement $\ldots \ldots \ldots \ldots \ldots \ldots \ldots \ldots \ldots \ldots \ldots \ldots \ldots$

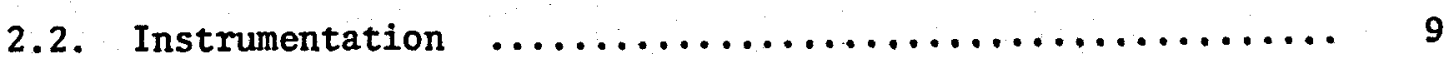

2.2.1. Monitoring and Control Instrumentation ....... 13

2.2.2. Data Acquisition Instrumentation ............ 14

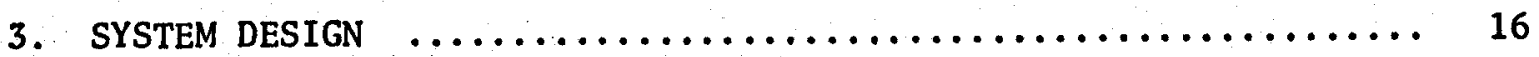

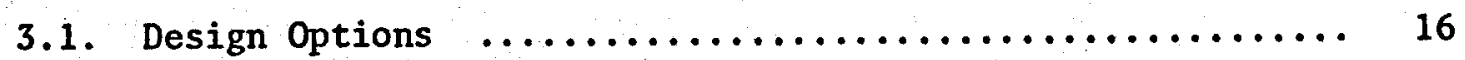

3.2. Sizing and Selection of Components $\ldots \ldots \ldots \ldots \ldots \ldots \ldots \ldots$

3.2.1. Design of Tanks for Freon System $\ldots \ldots \ldots \ldots \ldots \ldots 21$

3.2.2. Design of Condenser, Coolant Storage Tank,
Chiller, Heaters and Pumps $\ldots \ldots \ldots \ldots \ldots \ldots \ldots 28$

3.2.3. Design of Test Section ................ 34

3.2.4. Miscellaneous Hardware ............... 35

3.3. Equipment Specification List $\ldots \ldots \ldots \ldots \ldots \ldots \ldots \ldots \ldots \ldots \ldots \ldots \ldots \ldots \ldots \ldots$

4. INSTRUMENTATION $\ldots \ldots \ldots \ldots \ldots \ldots \ldots \ldots \ldots \ldots \ldots \ldots \ldots \ldots \ldots \ldots \ldots \ldots \ldots$

4.1. Instrumentation for Experimental Data $\ldots \ldots \ldots \ldots \ldots \ldots \ldots 38$

4.1.1. Temperature Measurement $\ldots \ldots \ldots \ldots \ldots \ldots \ldots \ldots$

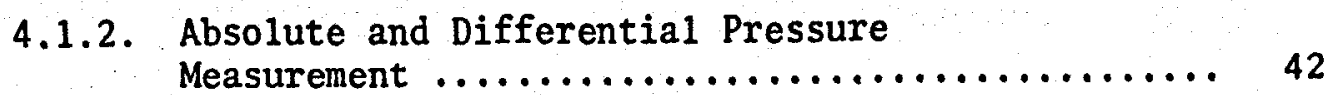

4.1.3. Mass Flow Rate Measurement ............. 45 
4.2. Instrumentation for Monitoring and Control $\ldots \ldots \ldots \ldots \ldots \ldots 50$

4.3. Instrumentation Specification List $\ldots \ldots \ldots \ldots \ldots \ldots \ldots \ldots$

5. TEST SECTION ARRANGEMENT $\ldots \ldots \ldots \ldots \ldots \ldots \ldots \ldots \ldots \ldots \ldots \ldots \ldots \ldots \ldots$

5.1. General Arrangement $\ldots \ldots \ldots \ldots \ldots \ldots \ldots \ldots \ldots \ldots \ldots \ldots \ldots$

5.2. Accommodation of Probes and Transducers $\ldots \ldots \ldots \ldots \ldots . . .57$

5.3. Flow Control $\ldots \ldots \ldots \ldots \ldots \ldots \ldots \ldots \ldots \ldots \ldots \ldots \ldots \ldots \ldots$

6. MONITORING, SET-UP, AND DATA ACQUISITION $\ldots \ldots \ldots \ldots \ldots \ldots \ldots \ldots$

6.1. Selection of Basic System and Functions $\ldots \ldots \ldots \ldots \ldots \ldots, 63$

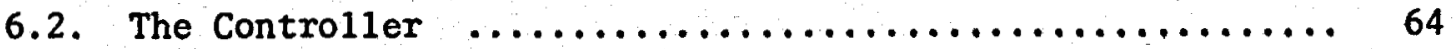

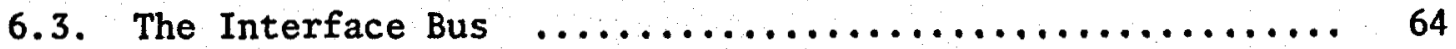

6.4. The Multiprogrammer and Its Cards $\ldots \ldots \ldots \ldots \ldots \ldots \ldots \ldots, 65$

7. PRELIMINARY RESULTS OF PRESENT OPERATIONS $\ldots \ldots \ldots \ldots \ldots \ldots \ldots \ldots .69$

7.1. Range of Operation $\ldots \ldots \ldots \ldots \ldots \ldots \ldots \ldots \ldots \ldots \ldots \ldots, 69$

7.2. Two-Phase Friction Factors $\ldots \ldots \ldots \ldots \ldots \ldots \ldots \ldots \ldots . \ldots 6$

7.3. Flow-Pattern observations $\ldots \ldots \ldots \ldots \ldots \ldots \ldots \ldots \ldots \ldots \ldots$

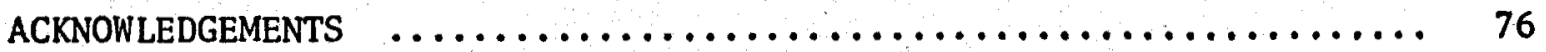

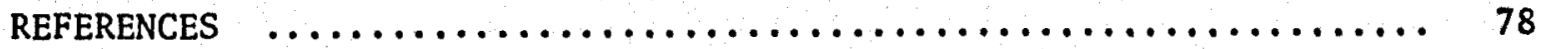


LIST OF FIGURES

page

Fig. 1 Simplified line diagram of flow facility ............. . 6

Fig. 2 Simplified schematic of test section $\ldots \ldots \ldots \ldots \ldots \ldots \ldots \ldots .8$

Fig. 3 Plan layout of facility $\ldots \ldots \ldots \ldots \ldots \ldots \ldots \ldots \ldots \ldots \ldots \ldots \ldots$

Fig. 4 Elevation section (see Fig. 3) $\ldots \ldots \ldots \ldots \ldots \ldots \ldots \ldots \ldots \ldots \ldots 11$

Fig. 5 Saturation curves for several refrigerants $\ldots \ldots \ldots \ldots \ldots \ldots \ldots 17$

Fig. 6 Fanno-1ine characteristic for $R-114 \ldots \ldots \ldots \ldots \ldots \ldots \ldots \ldots \ldots 19$

Fig. 7 Critical pressure ratio versus mass flux for several stagnation temperatures $\ldots \ldots \ldots \ldots \ldots \ldots \ldots \ldots \ldots \ldots \ldots . \ldots \ldots$

Fig. 8 Pressure rise in dump tank as a function of the liquid volume fraction in the tank $\ldots \ldots \ldots \ldots \ldots \ldots \ldots \ldots \ldots, 23$

Fig. 9 Time to choking versus mass flux for several stagnation temperatures $\ldots \ldots \ldots \ldots \ldots \ldots \ldots \ldots \ldots \ldots \ldots \ldots \ldots . \ldots \ldots$

Fig. 10 Pressure fall-off in accumulator as a function of the vapor volume fraction in the tank $\ldots \ldots \ldots \ldots \ldots \ldots \ldots \ldots \ldots . \ldots . \ldots 26$

Fig. 11 Volume ratio versus pressure ratio, accumulator/booster tanks $\ldots \ldots \ldots \ldots \ldots \ldots \ldots \ldots \ldots \ldots \ldots \ldots$

Fig. 12 Thermistor arrangement $\ldots \ldots \ldots \ldots \ldots \ldots \ldots \ldots \ldots \ldots \ldots \ldots \ldots$

Fig. 13 Sample calibration for (a) temperature and

(b) pressure transducers $\ldots \ldots \ldots \ldots \ldots \ldots \ldots \ldots \ldots \ldots \ldots \ldots \ldots 43$

Fig. 14 Pressure transducer mounting arrangement $\ldots \ldots \ldots \ldots \ldots \ldots \ldots .44$

Fig. 15 Venturi flow meter $\ldots \ldots \ldots \ldots \ldots \ldots \ldots \ldots \ldots \ldots \ldots \ldots \ldots \ldots \ldots .49$

Fig. 16 Delrin inserts for temperature and pressure ${ }_{\text {probe attachments } \ldots \ldots \ldots \ldots \ldots \ldots \ldots \ldots \ldots \ldots \ldots \ldots \ldots \ldots \ldots \ldots}$

Fig. 17 Throttle plate and holder $\ldots \ldots \ldots \ldots \ldots \ldots \ldots \ldots \ldots \ldots \ldots \ldots 60 \ldots \ldots \ldots \ldots \ldots$

Fig. 18 Boost pressure versus mass flow rate for several equivalent nozzle diameters $\ldots \ldots \ldots \ldots \ldots \ldots \ldots \ldots \ldots \ldots \ldots . \ldots 6$

Fig. 19 Automatic data acquisition and processing system $\ldots \ldots \ldots \ldots 67$

Fig. 20 Pressure drop as a function of distance along the pipe for pure liquid flow $\ldots \ldots \ldots \ldots \ldots \ldots \ldots \ldots \ldots \ldots \ldots \ldots$

Fig. 21 Fanno-curve for typical flow conditions $\ldots \ldots \ldots \ldots \ldots \ldots \ldots 72$

Fig. 22 Friction effects as a function of volume ratio $\ldots \ldots \ldots \ldots \ldots 74$

Fig. 23 Two-phase flow patterns $\ldots \ldots \ldots \ldots \ldots \ldots \ldots \ldots \ldots \ldots \ldots \ldots$ 


\section{$-\mathrm{v}-$ \\ LIST OF PHOTOGRAPHS}

page

Photo 1 Test section area of flow facility. Transparent tubes form the test section; large pipe at left is the return line. Note support beam beneath test section, and pivot support in right foreground that allows operation with the test section in a vertical or inclined position.

Photo 2 Booster tank (1eft center), accumulator tank (right center), and test section. Booster heater housing is at the bottom of the booster tank. Note locations of pressure and temperature probes along test section.

Photo 3 Condenser (top) and dump tank (bottom); basement leve1 of facility.

Photo 4 Coolant storage tank and circulating pump. Condenser partially visible at upper left; chiller in far background at right.

Photo 5 Chiller unit; prepackaged, commercial system.

Photo 6 Typical measuring station. Thermistor probe is at upper left, pressure probe is at right side of Delrin insert. Note connecting flanges for glass pipe sections.

Photo 7 Venturi flow meter. Located in downcomer beneath accumulator tank; shown before insulation was attached.

Photo 8 Venturi flow meter showing differential pressure transducer.

Photo 9 Freon-oil interface. U-tube has freon vapor in the left cylinder, oil in the right cylinder, and mercury in the connecting tube. Also shown is dial pressure gauge; instruments shown at top of booster tank.

Photo 10 Upstream valve. Note pneumatic actuator and settling chamber instruments. 
$-v i-$

\section{LIST OF PHOTOGRAPHS}

page

Photo 11 Downstream valves. The throttling control valve (gate valve) is in the 2 -in diameter section; the isolation valve (butterfly valve) is in the 5 -in diameter section. Both are automatically controlled.

Photo 12 Electronic interface between measuring instruments 66 and $\mathrm{HP}-85$ computer.

Note: All photographs by R. DiPippo. 


\section{LIST OF SYMBOLS}

Latin letters

A

$\mathrm{A}_{0}$

$\mathrm{a}^{*}$

D

Fr

f

$f_{0}$

g

$\mathrm{h}$

$\mathrm{h}_{\mathrm{f}}$

$\ell$

$\mathrm{Ma}$

$\dot{\mathrm{m}}$

$\dot{\mathrm{m}}_{0}$

P

$\mathrm{P}_{0}$

$\mathrm{P}_{\mathrm{A}}$

$P_{B}$

$P_{c}$

$P_{f}$

$P_{i}$

$P_{\text {sat }}$

Q

R cross-sectional area of test section

reference cross-sectional area of test section

local choking velocity

diameter of flow cross-sectional area

Froude number

general flow friction factor

pseudo single-phase friction factor

gravitational acceleration

specific enthalpy

saturated liquid specific enthalpy

test section unit length

pseudo Mach number

mass flow rate

reference mass flow rate

pressure

stagnation pressure

pressure in accumulator tank

initial pressure in booster tank

choking pressure

final accumulator tank pressure

initial accumulator tank pressure

saturation pressure

dynamic pressure

specific volume ratio 
-viii-

LIST OF SYMBOLS (CONT.)

$\overline{\mathbf{R}}$

$\operatorname{Re}$

$\mathbf{s}$

$\mathbf{s}_{\mathbf{f}}$

T

$T_{0}$

$t_{0}$

$t_{c}$

V

$V_{A}$

$\mathbf{V}_{\mathrm{B}}$

$v_{F}$

$\mathrm{V}_{\mathrm{F}_{0}}$

$\mathrm{V}_{\mathrm{g}}$

$v$

$\bar{v}$

w

Greek letters

$\alpha, \beta$

$\mu$

$\rho$ average specific volume ratio over a portion of test section

Reynolds number

specific entropy

saturated liquid specific entropy

temperature

stagnation temperature

reference time

run time with choked flow in test section

volume

volume of accumulator tank

volume of booster tank

volume of liquid in dump tank

reference volume of dump tank

volume of vapor

specific volume

average specific volume over a portion

of test section

velocity

constants characterizing resistance - temperature behavior of thermistor

viscosity

density

resistance (or voltage with known current applied) 


\section{INTRODUCTION}

\subsection{Motivation}

Techniques and laboratory facilities are widely available for the study of essentially incompressible fluids (water channels, wave tanks, etc.). Similar techniques were developed in the 1940s for the investigation of gas flows at speeds near and above the sonic velocity (wind tunnels, shock tubes, etc.). Instruments of these kinds are found routinely today in industrial and university laboratories, and play an important role in the design and engineering of a multitude of products. Furthermore, such installations have been valuable to the scientific community in gaining a fundamental understanding of various physical phenomena.

The situation is quite different with regard to the flow of two-phase fluids, particularly the flow of an evaporating or condensing medium, either in pure form or in the presence of contaminants. Two-phase flow facilities are not commonplace. In some cases because of the intended uses for the data, proprietary restrictions are placed on the dissemination of results.

The impetus behind the present effort at Brown University came from a desire to gain a better understanding of the phenomenon of geothermal fluid flow, particularly, but not limited to, the flow that takes place in geothermal wells. In practically all of the geothermal electric generating stations around the world, currently producing about $2500 \mathrm{MW}$, some form of flashing takes place in the geothermal reservoir, production wells or fluid gathering equipment [DiPippo, 1980]. It is, therefore, essential to have on hand a reliable, predictive theory in order to design a geothermal power plant. 
So far, what information exists on two-phase flow has been taken from either field measurements, which are severely limited in range and accuracy because of practical difficulties, or laboratory setups using small-diameter tubes of air-water mixtures (i.e., without phase changes). Other test rigs have been built by private companies to investigate rather narrow regimes of flow for specific design purposes, and the results are not generally available in the open literature. Where they are available, it turns out that the data are not of sufficient accuracy to be of use in the scientific sense [Bilicki et al., 1980].

Since 1976 the Brown University geothermal energy research group has been concerned with systems and techniques aimed at the production of electricity from geothermal energy. At first, this work was mainly theoretical and conceptual in nature, involving the design and analysis of hybrid fossil-geothermal energy conversion systems. (See, e.g., [Kestin et a1., 1978; DiPippo et a1., 1979; DiPippo and Avelar, 1979].) That effort culminated in the publication of two definitive books on geothermal power technology [Kestin, 1980; DiPippo, 1980]. Given the backgrounds of the members of the group (fluid and gas dynamics, thermodynamics, shock and wind tunnel design, prime-mover design and analysis, geothermal power technology), we decided to focus our attention on the design and construction of a twophase flow facility that would have capabilities beyond those presently in existence.

The test facility described in this report is suitable for a number of fundamental investigations in the field of two-phase flow. Its unique features make it an ideal tool to study such phenomena as: (i) cavitation; (ii) supersaturation; (iii) gravity effects; and (iv) fluctuations in 
turbulent flow. The high-quality data obtainable from the precision instrumentation and the inherent flexibility of the design should permit us to gain insights into these various phenomena. The application of this knowledge should lead to improved designs of piping, valves, separators, and related flow devices subject to two-phase flow. A proper technical understanding of this phenomenon is crucial, for instance, in the design of emergency core cooling systems for nuclear reactors where there may be an excessive limitation on the flow rate of the water should it be subject to choking in two-phase flow.

We believe that the research facility is capable of yielding data that will lead to a better understanding of these and related flow phenomena such as flooding in vertical pipes, thermosiphons, jets, and the flow of cryogenic fluids such as liquid hydrogen and oxygen.

\subsection{Objectives}

The general objective of our experimental effort is to build and operate a test facility that will permit us to generate, observe, and measure a wide range of two-phase flows under carefully controlled conditions. From the observations we hope to be able to check various theories of two-phase flow, and therefore we demand high accuracy and precision in our data. To facilitate the construction and operation of the apparatus, we have chosen a working fluid with convenient thermophysical properties, yet one that will allow us to extend our results to other fluids using the principle of similarity.

Since gravity plays an important role in all two-phase flows, the experimental set-up is flexible enough to allow fluid flow in horizontal, vertical and inclined directions. 
Our specific objectives for the initial phase of operation include the visual observation of flow patterns and the determination of the frictional pressure losses in a wide range of flows from purely liquid through two-phase flows of varying quality to pure vapor flow. We can generate flows in which the fluid is choked at either end of the test section. From these results we aim to check the reliability and applicability of various two-phase flow models, beginning with the relatively simple homogeneous equilibrium model [Bilicki and Kestin, 1982], and including other ones that incorporate various corrective features [Maeder and Michaelides, 1980; Bilicki and Kestin, 1980; Maeder et al., 1981; Bataille and Kestin, 1981]. Many other studies could be cited (see Bilicki et a1., 1980), but our intention in this report is to cover only the design and operation of the experimental facility. 


\section{GENERAL DESCRIPTION OF THE FACILITY}

\subsection{Physical Arrangement}

The research facility which has been constructed and is presently in full operation at Brown University is a highly versatile one, allowing the study and analysis of a wide variety of phenomena involving the flow of a fluid at or near its saturation point as well as in the two-phase region. An important feature of the facility, setting it apart from others, is that it is dedicated to two-phase flow of a single substance as opposed to the case of two-component, two-phase flow (i.e., the flow of air and water). The fluid presently used is dichlorotetrafluoroethane (designated Refrigerant-114 or simply, R-114); this allows two-phase experiments to be carried out at manageable temperatures and pressures, namely, between 0 and $60^{\circ} \mathrm{C}$, and up to $10 \mathrm{bar}$. The reasons for the selection of this fluid are given in Section 3.1. The design of the facility incorporates provisions to substitute other suitable working fluids as desired,

A simplified schematic diagram of the system is given in Figure 1 which shows only the main fluid path; auxiliary piping, control systems and the like have been omitted for the sake of clarity. The main circuit consists of the vessels, $A, B, C$ and $D$, and the piping indicated by solid lines. The components are arranged in a closed loop containing R-114 in either its liquid or vapor state. When the system is not in operation, the bulk of the R-114 is stored in tank (D) as a saturated liquid at room temperature, with vapor filling the rest of the system. The storage tank, and hence the working fluid, can easily be interchanged with another.

The system operates as a "blowdown", or intermittent, tunnel, rather than as a continuous, steady-state 10op. A typical experimental run lasts 


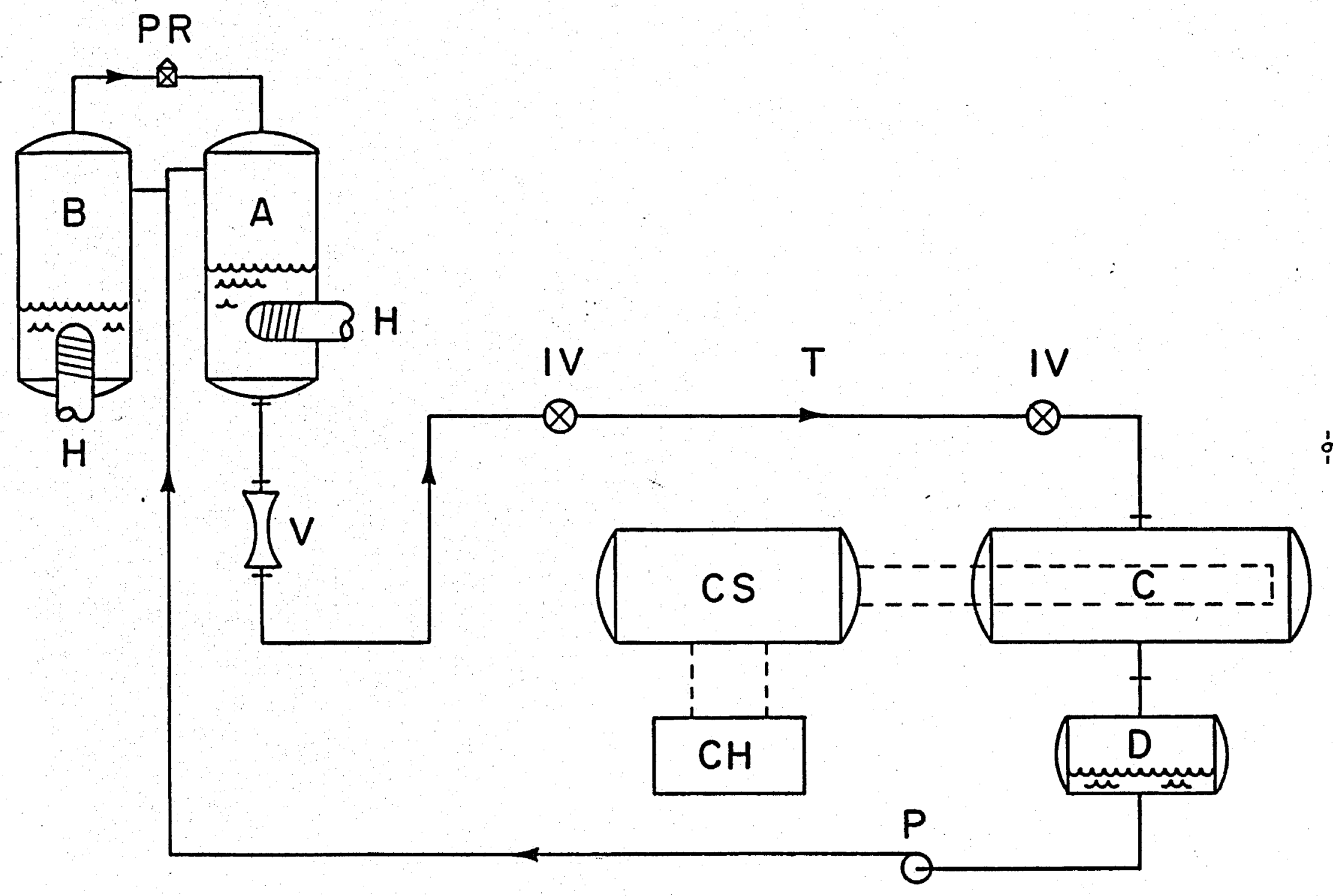

Fig, 1. SIMPLIFIED LINE DIAGRAM OF FLOW FACILITY 


\section{$-7-$}

approximately three minutes, with about three hours required for preparation between runs.

At the beginning of a run, liquid is pumped from the storage tank (D) to the accumulator tank (A) and the booster tank (B), and is heated to the desired initial conditions by means of electric immersion heaters $(H)$. Since the tanks contain saturated liquid and vapor, the pressure is adjusted solely by setting the fluid temperature by means of the heaters. The run is started by opening the isolation valves (IV). Liquid then flows from the accumulator (A) down through a venturi flow meter $(V)$ and enters the test section (T). The function of the booster tank (B) is to provide vapor to the accumulator (A) through a pressure regulating valve (PR) so as to maintain a predetermined accumulator pressure and thus compressed liquid in the accumulator. Measurements are carried out in the test section (T) as the flow develops from single-phase to two-phase because of throttling and pressure losses. The mixture is converted back to the liquid phase in the condenser (C) and finally collects in the storage (or "dump") tank (D). The condenser is provided with a stream of a methano1-water solution (shown in the diagram by dashed lines) from a cold storage tank (CS) which is maintained at a predetermined temperature (approximately $-20^{\circ} \mathrm{C}$ ) by a standard refrigeration chiller $(\mathrm{CH})$. The chiller uses city water as its heat sink.

A simplified diagram of the test section is given in Figure 2 . The compressed liquid working fluid, close to saturation, enters the 2 -in diameter test section from a 5 -in settling chamber where its stagnation temperature and pressure are measured. Two-phase flow is produced in the test section by the natural decrease in pressure due to friction, or by an 


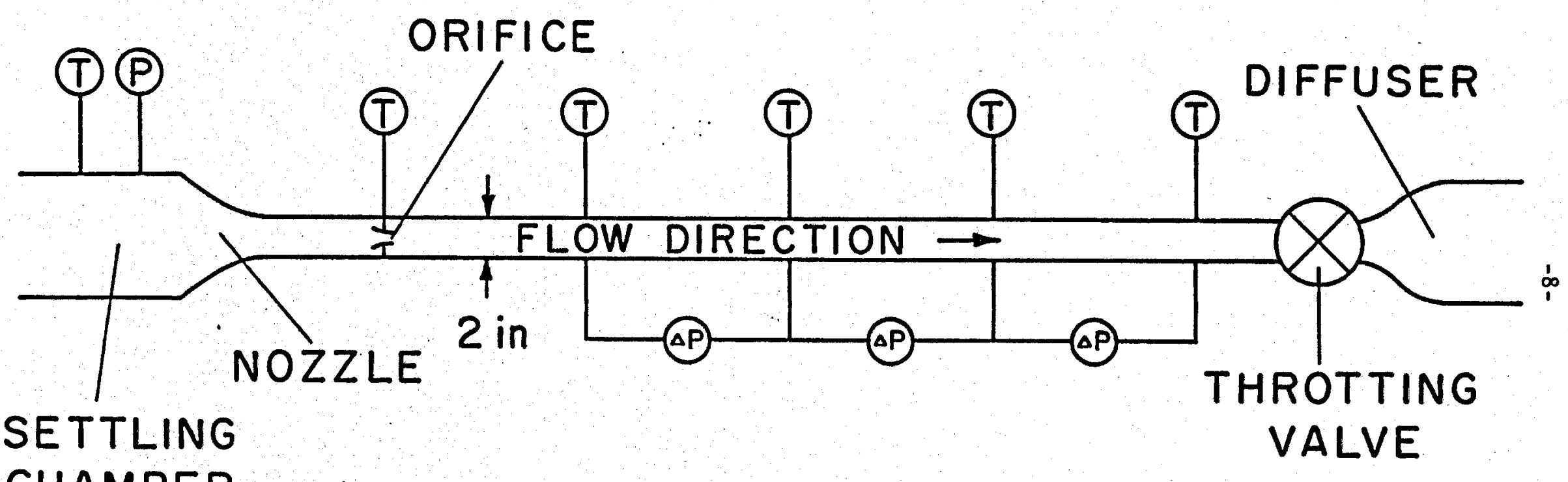

CHAMBER

Fig, 2, SIMPLIFIED SCHEMATIC OF TEST SECTION 
orifice plate if more throttling is required. Inclusion of the orifice also makes it possible to study two-phase nozzle flows. Temperature and differential pressure measurements are taken at successive stations along the test section, a typical arrangement being shown in Figure 2. At present, the entire 2-in portion is made of transparent Pyrex, thus allowing direct observation of the flow. The flow rate and conditions in the test section are controlled by the size of the orifice (if used) and the setting of the throttling valve (both normally operated at choked flow conditions). Finally, the fluid passes through a diffuser and into a return pipe which leads to the condenser.

The facility occupies portions of the basement and first floor of the Prince Engineering Laboratory. Plan views are given in Figure 3 for each level; an elevation view is shown in Figure 4. The test section and return pipe assembly can be pivoted about a common, horizontal axis, allowing orientation at any angle from horizontal $\left(0^{\circ}\right)$ to vertical $\left(90^{\circ}\right)$. The length of the test section is adjustable, and allowance has been made for the test section entrance to be located at the basement level with the test section extending to the ceiling of the upper level should the maximum, $10 \mathrm{~m}$ length be required for vertical operation.

A general view of the main floor of the facility is given in Photo 1.

\subsection{Instrumentation}

The present instrumentation may be classified into two groups:

(1) instruments used for monitoring and control of the system, and

(2) instruments used for the acquisition of experimental data. These are 


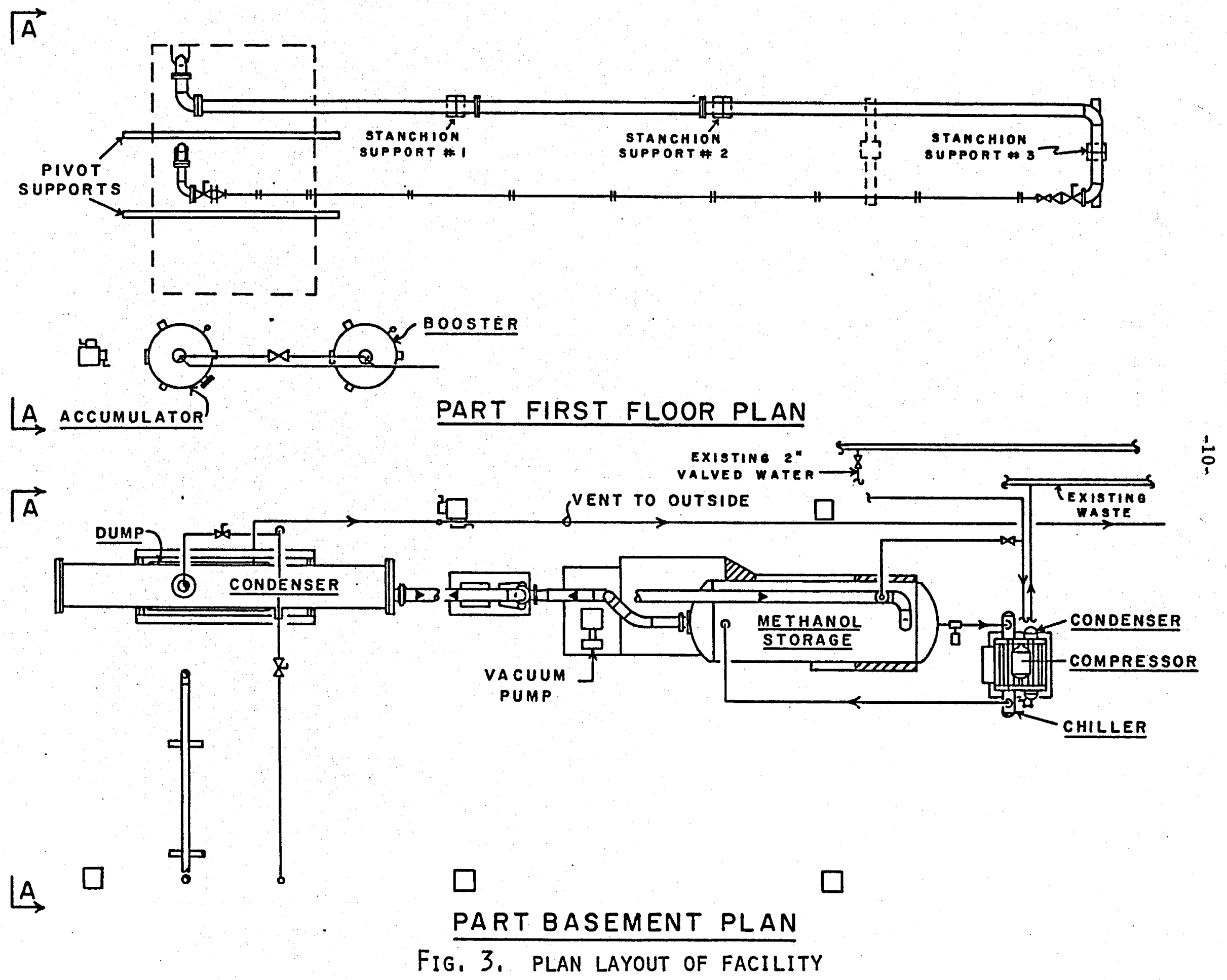




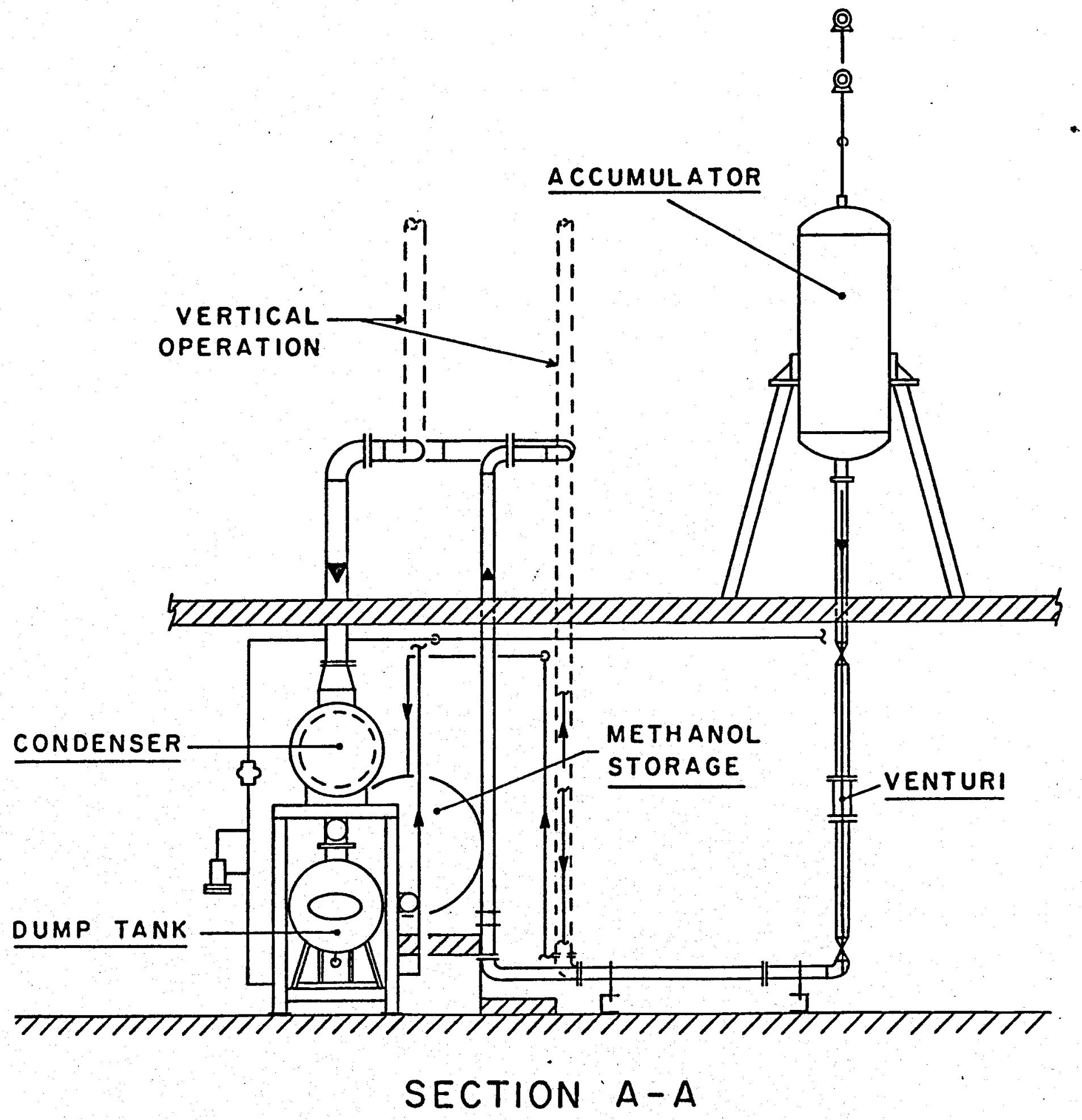

Fig, 4, elevation Section (See fig, 3) 


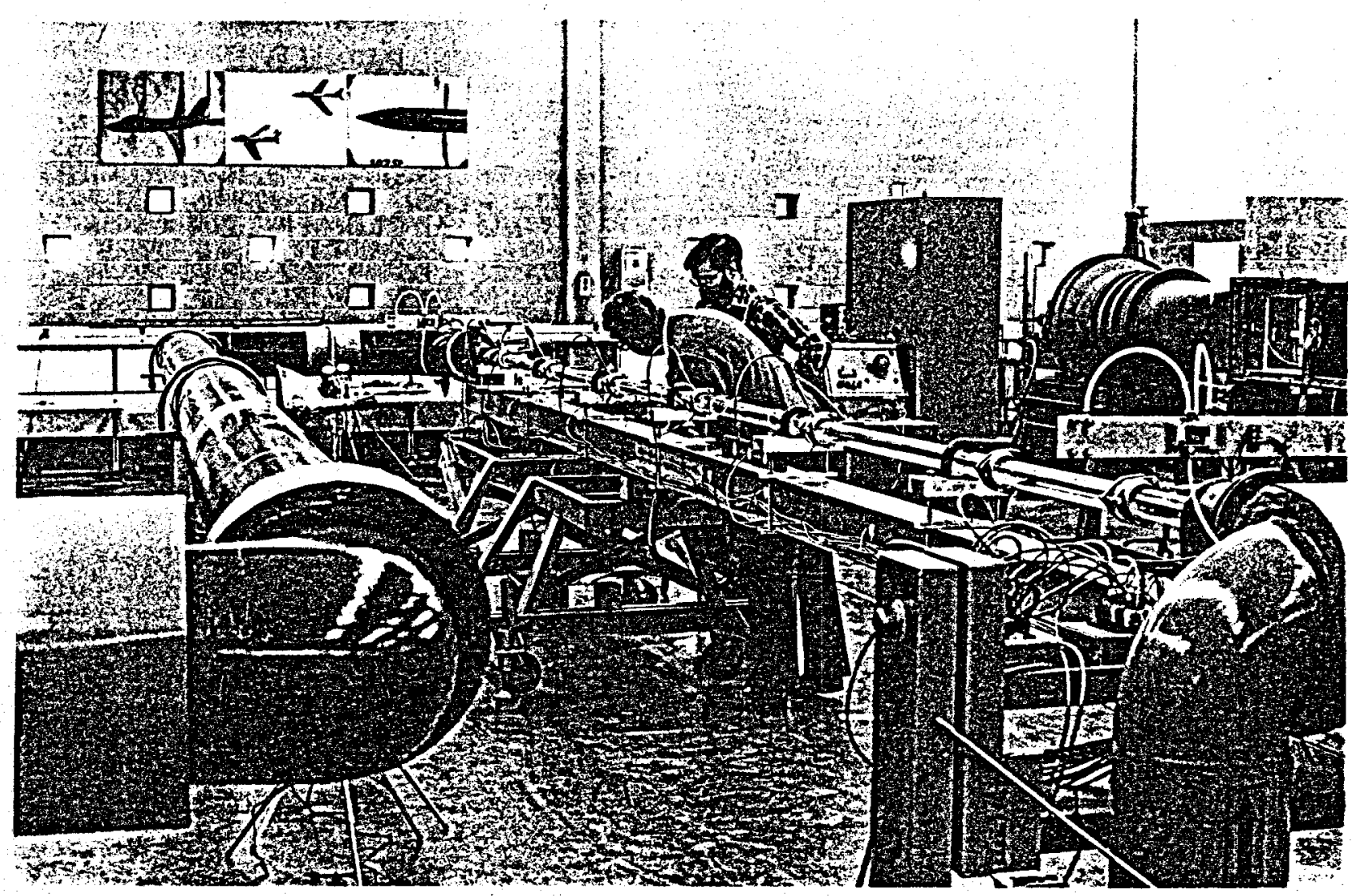

Photo 1.

Test section area of flow facility. Transparent tubes form the test section; large pipe at left is the return line. Note support beam beneath test section, and pivot support in right foreground that allows operation with the test in a vertical or inclined position. 
discussed separately below.

\subsubsection{Monitoring and Control Instrumentation}

During the time the facility is idle, conditions throughout

the system are continuously monitored by computer, a Hewlett-Packard HP-85 desk-top mode1. This machine is programmed to take action to maintain certain conditions, e.g., operation of the chiller to maintain the cold storage tank at the desired temperature.

During the time the system is being prepared for a test run, the preparation procedure is monitored and controlled by the same computer so that once the desired starting time for the run has been entered into the computer by the operator, all of the required steps will be initiated and controlled automatically (operation of valves, heaters, etc.) ensuring that the system will be ready for a run at the prescribed time.

The link between the controller (HP-85) and the physical system is provided by the HP-IB "Interface Bus" and the Hewlett-Packard Multi-Programmer. These devices allow the computer to read a number of instruments and take action, i.e., operate equipment, by switching relays. A detailed discussion of this process is given in Section 6 .

There are two types of measurements taken for automatic control and monitoring purposes: tank temperatures and liquid levels. Temperatures are measured using thermistors attached to the exterior wall of the tank, beneath the insulation. These are located on each of the tanks in the system, including the methanol cold storage tank. Liquid levels are determined by reading differential pressure transducers connected across the top and bottom of the tank to sense hydrostatic pressure, and 
hence liquid level.

In addition to the above, visual monitoring of temperatures, pressures, and liquid levels is possible, when needed, using standard mercury-in-glass thermometers, dial pressure gauges, and sight glasses.

\subsubsection{Data Acquisition Instrumentation}

The instrumentation for the experimental measurements consists of three types of sensors: temperature, absolute pressure, and differential pressure. The sensors are of the same basic types as used for the monitoring measurements, but are calibrated and mounted so as to produce the highest accuracy possible.

Although not located in the test section proper, the venturi meter allows us to measure the flow rate by means of a differential pressure transducer connected between the inlet and throat sections. Details on the test section instrumentation and the venturi are given later in Section 4.

Measurements are taken in the test section using the controller $(\mathrm{HP}-85)$. The computer scans all instruments in the test section (and the venturi) at pre-determined time intervals. It is also programmed to control the test run by operating the control valves, throttling valve, pressure regulating valve and condenser.

Data collected during a test run are stored in the memory of the HP-85 in real time. At the end of the run, the data can be printed in raw form directly, i.e., voltage measurements from each instrument as read in each scan, or in reduced form in units of temperature, pressure, and mass flow rate. 
Lastly, a set of programs has been developed to provide additional data reduction and graphic display for calculations made from the measurements, such as values for density ratios, friction factors, etc. 


\section{SYSTEM DESIGN: PHILOSOPHY AND EXECUTION}

\subsection{Design Options}

The overall design of the system was dictated by the type of experimental measurements desired. The goal was to produce a full range of two-phase flow regimes on a laboratory scale, with steady-state conditions existing for a sufficiently long period of time to allow certain basic measurements to be taken. Furthermore, it was our intention that these measurements and the resulting analysis be of use in certain practical applications where two-phase flow exists; the design of geothermal power plants, for example.

Many two-phase flow situations, including the case just cited, involve water substance operating in a temperature and pressure range that would be both difficult and dangerous to produce in the laboratory. Hence, the first step was to select a working fluid with which two-phase flow could be produced in a more convenient and manageable range. The fluorocarbon fluids used in refrigeration systems were obvious first candidates. Figure 5 shows the saturation pressure-temperature characteristics of a number of these. Based on its saturation characteristics, price and availability, Refrigerant-114 appeared to be the most desirable working fluid.

An additional important consideration was that the working fluid must meet the proper similarity requirements so that the results obtained on it will be more generally applicable for other fluids. It will be shown later that $\mathrm{R}-114$ is quite acceptable on these grounds as well. 


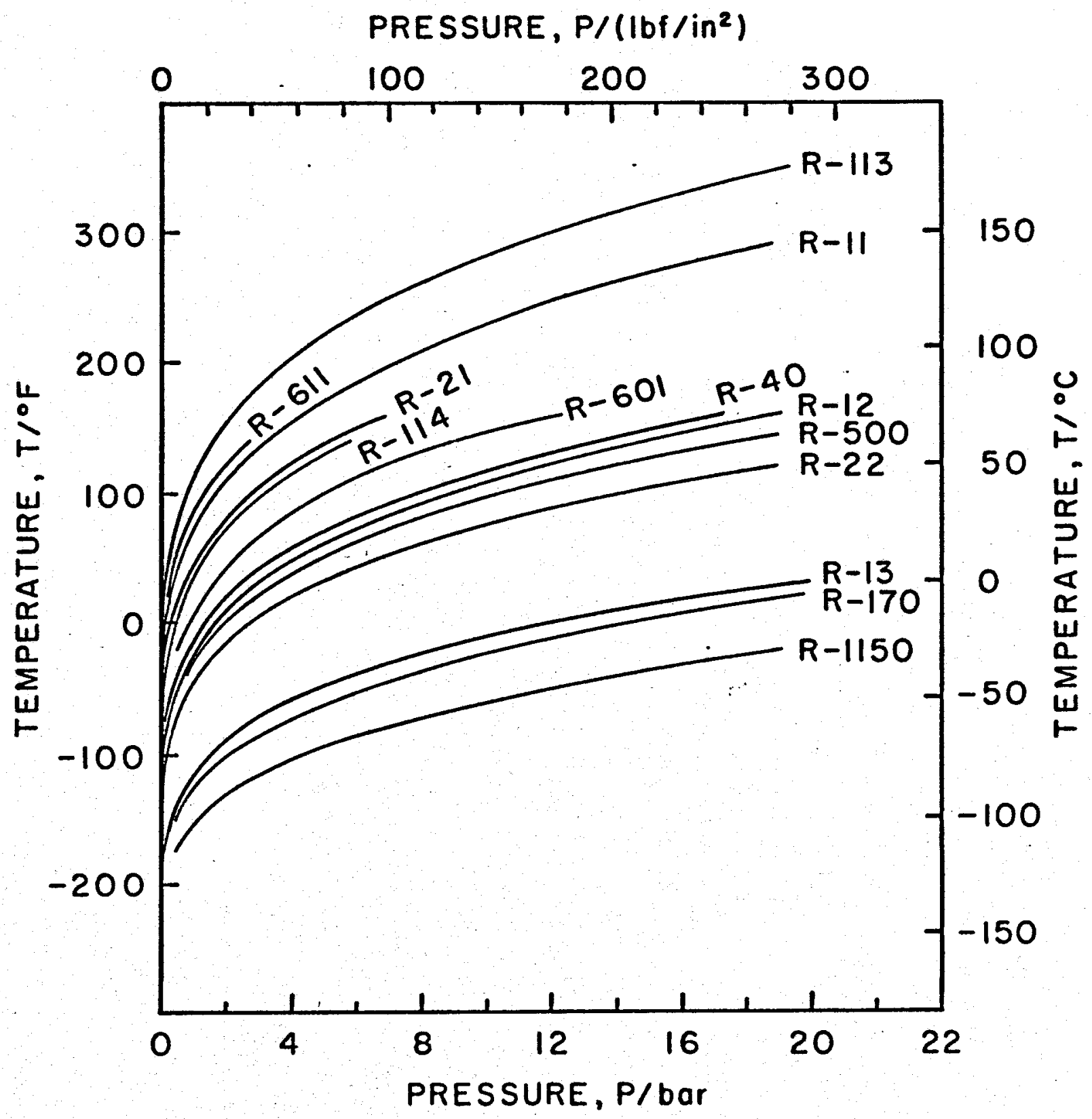

Fig. 5. SATURATION CURVES FOR SEVERAL REFRIGERANTS 
The next consideration was the actual physical size of the apparatus. The test section diameter determines the amount of fluid which flows and hence the size of many of the major mechanical components. It was necessary to select the diameter of the test section large enough to allow for instrumentation to be attached in a straightforward manner and for the flow to be observed easily, but small enough to keep the rest of the system manageable in size. Based on these considerations, a diameter of 2 inches was selected. Similarity studies indicate that experimental results using R-114 in a 2-in diameter tube will correspond to the case of water substance in a 10-in diameter pipe, which happens to be a case of practical interest in many different situations.

The pressure range of the working fluid in the system was selected as having a minimum of $0.5 \mathrm{~atm}\left(8^{\circ} \mathrm{F}\left(-13^{\circ} \mathrm{C}\right)\right.$ at saturation) and a maximum of $6.5 \mathrm{~atm}\left(150^{\circ} \mathrm{F}\left(66^{\circ} \mathrm{C}\right)\right.$ at saturation), since such a range allows standard design of tanks, pipes and fittings.

Figure 6 shows the Fanno-line characteristics of the fluid in the pressure range selected. It can be seen that a range of flows can be produced from fully liquid to fully choked two-phase flow with a mass flux of between $1000-4000 \mathrm{~kg} / \mathrm{m}^{2} \cdot \mathrm{s}$ in both horizontal and vertical modes. Thus, a maximum flow rate of $8.1 \mathrm{~kg} / \mathrm{s}$ will occur with a 2 -in diameter tube. Figure 7 gives the critical (choking) pressure ratio for R-114 with a range of stagnation conditions from room temperature to a maximum of approximately $150^{\circ} \mathrm{F}$ for both vertical and horizontal orientation of the test section. Note that the flow-rate is limited at lower temperatures when the tube is vertical.

The feasibility of operating the facility as a closed loop in a 


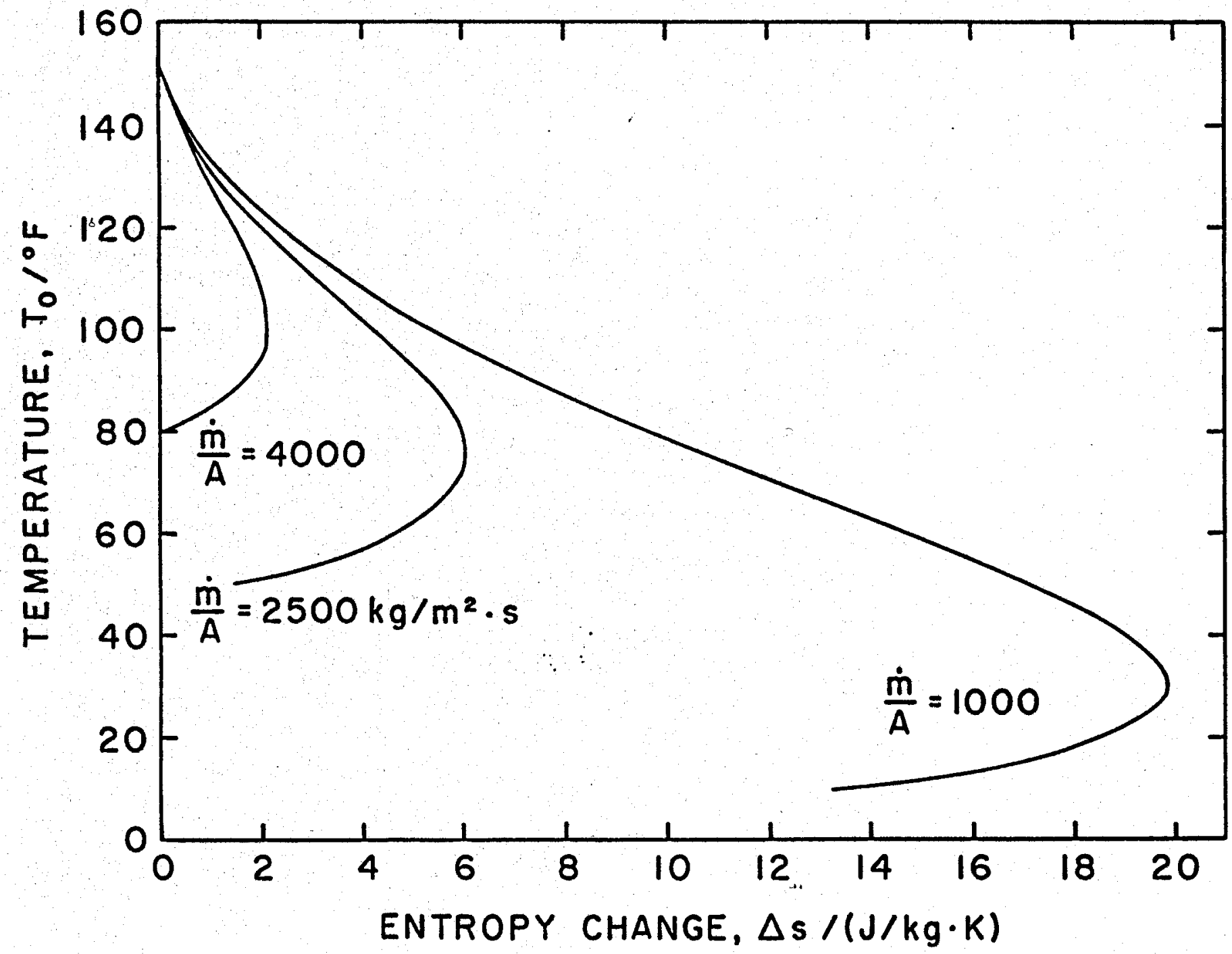

$\frac{1}{6}$

Fig. 6. FANNO-LINE CHARACTERISTIC FOR R-114 


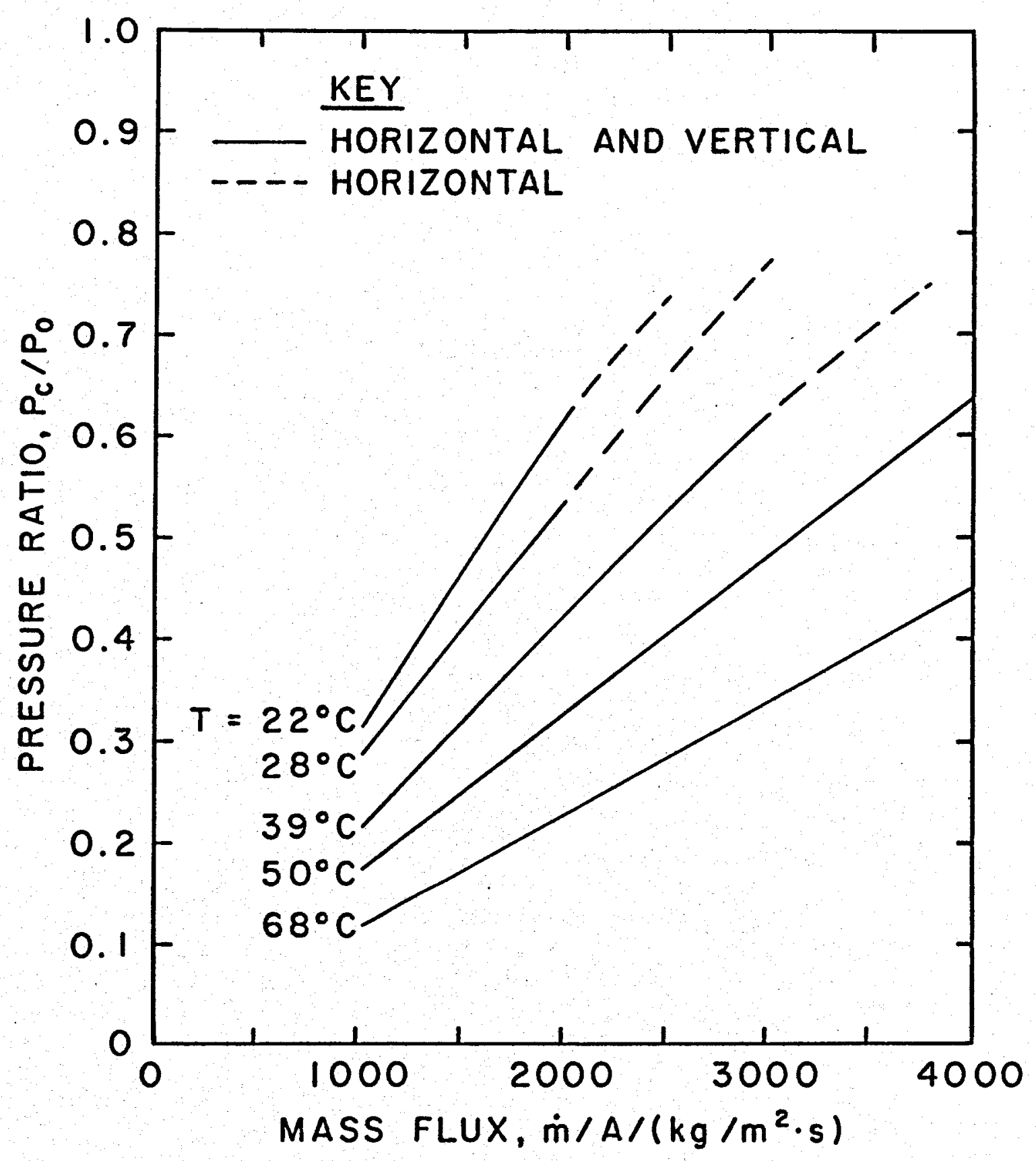

Fig, 7. CRITICAL PRESSURE RATIO VERSUS MASS FLUXX FOR SEVERAL STAGNATION TEMPERATURES 
continuous steady-state mode was examined. The exergy difference for liquid R-114 at saturation conditions between $P=0.5$ atm and 6.5 atm amounts to $2.6 \mathrm{~kJ} / \mathrm{kg}$. For the maximum mass flow rate given above, a maximum continuous mechanical power input of $21 \mathrm{~kW}(28 \mathrm{hp})$ would be required. Although the power is not unmanageable, the working fluid must also be pumped without contamination and with suitably steady conditions for experimentation. The cooling system for the plant would require a steady refrigeration capacity of 200 tons. This rate is prohibitive, and when coupled with the pumping problems, led us to conclude that continuous operation is not feasible.

Thus, it was decided to design the facility for intermittent (or blow-down) operation, permitting a smaller energy input, including refrigeration, applied over a longer preparation time and then expended during the time interval of a test run. As a consequence, the accumulator, dump tank, and other components must then be properly sized to allow a test run of sufficient time to gather the required data. We discuss the design of each of the major components in the following sections.

\subsection{Sizing and Selection of Components}

\subsubsection{Design of Tanks for Freon System}

The size of the dump tank is the first important consideration once the test section size has been selected as discussed in Section 3.1. As this tank fills with liquid from the condenser, the pressure will rise accordingly and after a certain length of time, this pressure rise will cause the flow in the test section to be no longer 
choked at the gate valve. In order to determine the size of this tank, it is assumed to be filled initially with saturated vapor at $P_{i}=0.5$ bar. The pressure rise is illustrated in Figure 8 which shows the ratio of the instantaneous pressure to the initial pressure, $P / P_{i}$, after a fraction of the volume, $V_{F} / V$, has been filled with liquid. This calculation is made assuming that the vapor is compressed by the entering fluid but is not cooled or condensed by it, (i.e., vapor lock occurs) resulting in the "worst case" tank pressure.

$$
\text { When } P / P_{i} \text { reaches a value corresponding to } P=P_{c} \text { for } a
$$
particular $\dot{\mathrm{m}} / \mathrm{A}$ (given in Figure 8), the flow will no longer be choked. The time required for this to occur, $t_{c}$, is the maximum worst case running time available. This time is plotted in Figure 9 for various stagnation and mass flux conditions. It can be seen that $t_{c}$ increases with $\dot{m} / A$ (since $P_{\text {c }}$ increases with $\left.\dot{m} / A\right)$ until it reaches a maximum as the higher $\dot{m}$ becomes dominant. The volume of the tank in this plot, $\mathrm{V}_{\mathrm{F}_{0}}$, is a reference volume selected as the volume of liquid which leaves the condenser under the reference conditions, $\dot{\mathrm{m}}_{0} / \mathrm{A}_{0}=4000 \mathrm{~kg} / \mathrm{m}^{2} \cdot \mathrm{s}, \mathrm{t}_{0}=1 \mathrm{~min}$, and test section area $A_{0}$ corresponding to a diameter of 2 inches; thus, $V_{F_{0}}=$ $0.31 \mathrm{~m}^{3}$. The available time $t_{c}$ can be lengthened by any amount simply by multiplying the tank volume by the factor desired.

Over the range of operating conditions which will be experienced, the minimum running time can be seen to be 0.6 minutes. This is about one third the minimum desirable time for our measurements, and hence the tank volume was selected as approximately $1.0 \mathrm{~m}^{3}$.

Also shown in Figure 9 is a dashed line corresponding to the time required to empty the accumulator, assuming that the tank is sized to hold that quantity of liquid which will flow in the time $t_{c}$ coresponding 


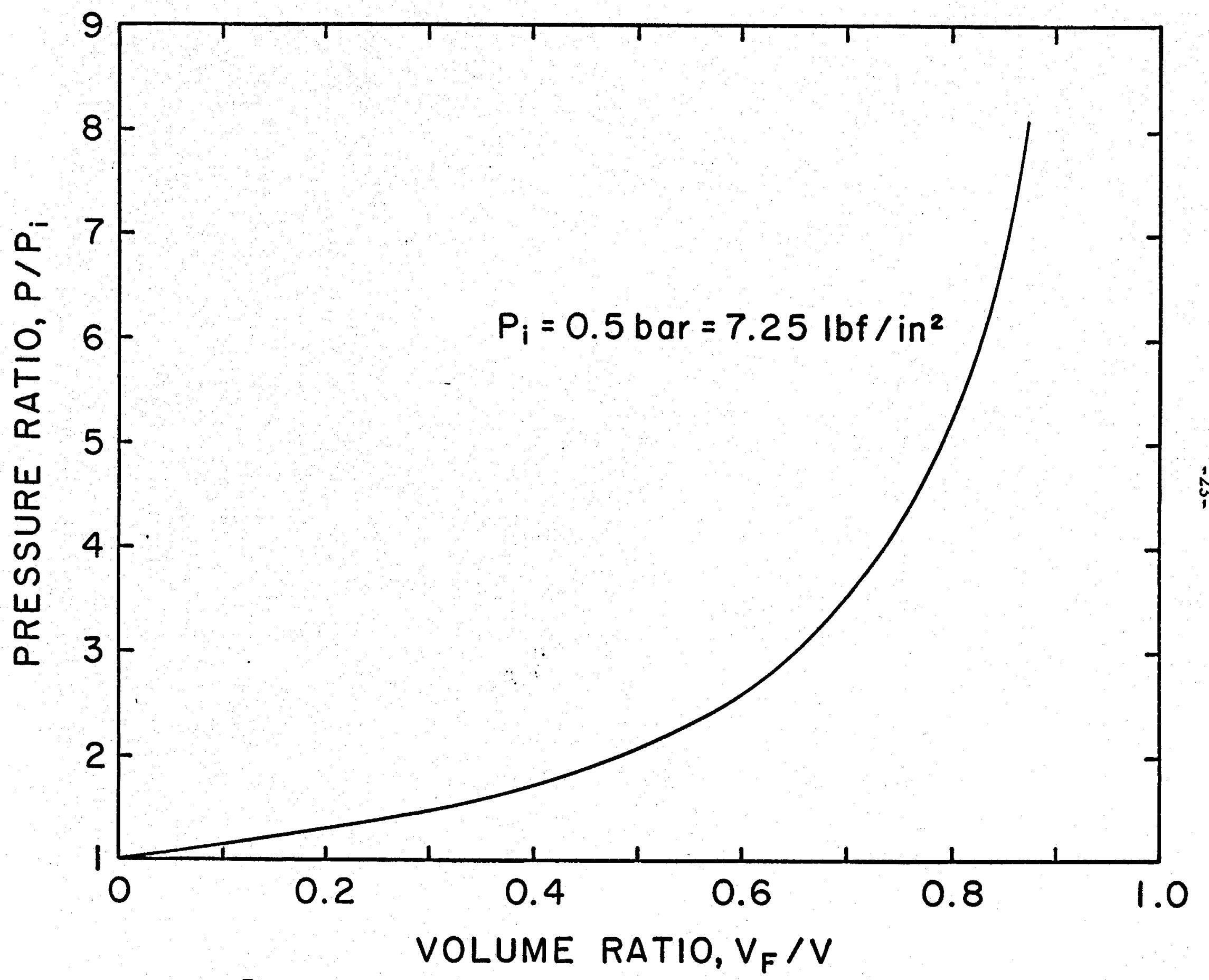

FIG, 8, PRESSURE RISE IN DUMP TANK AS A FUNCTION OF THE LIQUID VOLUME FRACTION IN THE TANK 


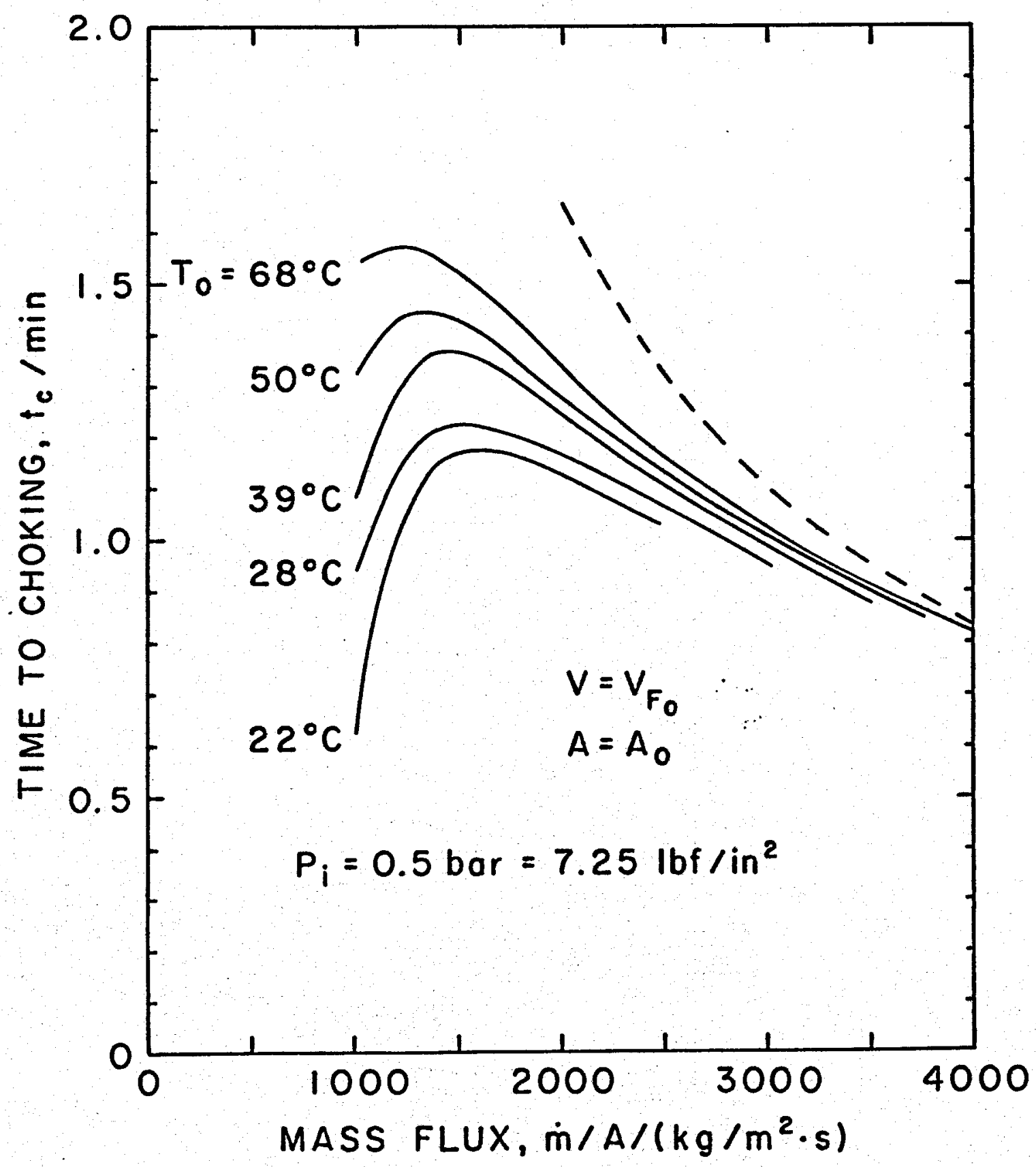

FIG. 9. TIME TO CHOKING VERSUS MASS FLUX FOR SEVERAL STAGNATION TEMPERATURES 
to $\dot{\mathrm{m}} / \mathrm{A}=\dot{\mathrm{m}}_{0} / \mathrm{A}_{0}$, i.e., the maximum amount. Hence the emptying time for the accumulator is always greater than or equal to $t_{c}$, ensuring an adequate supply of liquid under all conditions.

Another consideration in the design of the accumulator was the behavior of the saturated liquid in that tank as emptying occurred during a run. Of greatest concern was the drop in pressure which could be expected, since this would affect conditions in the test section. Figure 10 shows two extreme cases between which the real behavior would have to occur. The initial condition is taken as $v_{g} / V=\alpha=0.1, i . e ., 10 \%$ of the tank contains vapor, $90 \%$ contains liquid, in equilibrium at saturation conditions. In the case when both components remain in equilibrium and expand isentropically, the pressure decrease is small as the tank empties, i.e., $\mathrm{V}_{\mathrm{g}} / \mathrm{V}$ increases. However, if the tank drains quickly enough that evaporation of the liquid does not occur and the approximately isentropic expansion is limited to the vapor, then the pressure loss is much more severe, and in fact becomes unacceptable. This problem is avoided by the use of a booster tank which provides a supply of vapor to the accumulator. This allows the pressure in the accumulator to be held essentially constant by means of an adjustable pressure regulating valve. The use of such a valve also allows the accumulator pressure to be "boosted" above saturation conditions, thus creating compressed liquid at the inlet to the test section since condensation of initially superheated vapor from the booster occurs slowly. The graph in Figure 11 shows the volume ratio, $V_{B} / V_{A}$, which is required to maintain a pressure ratio, $P_{A} / P_{B}$, until the accumulator is completely empty, where $P_{A}$ is the constant pressure desired in the accumulator and $P_{B}$ is the initial pressure in the booster. It can be seen that if one selects equal volumes for the two tanks, a pressure ratio 


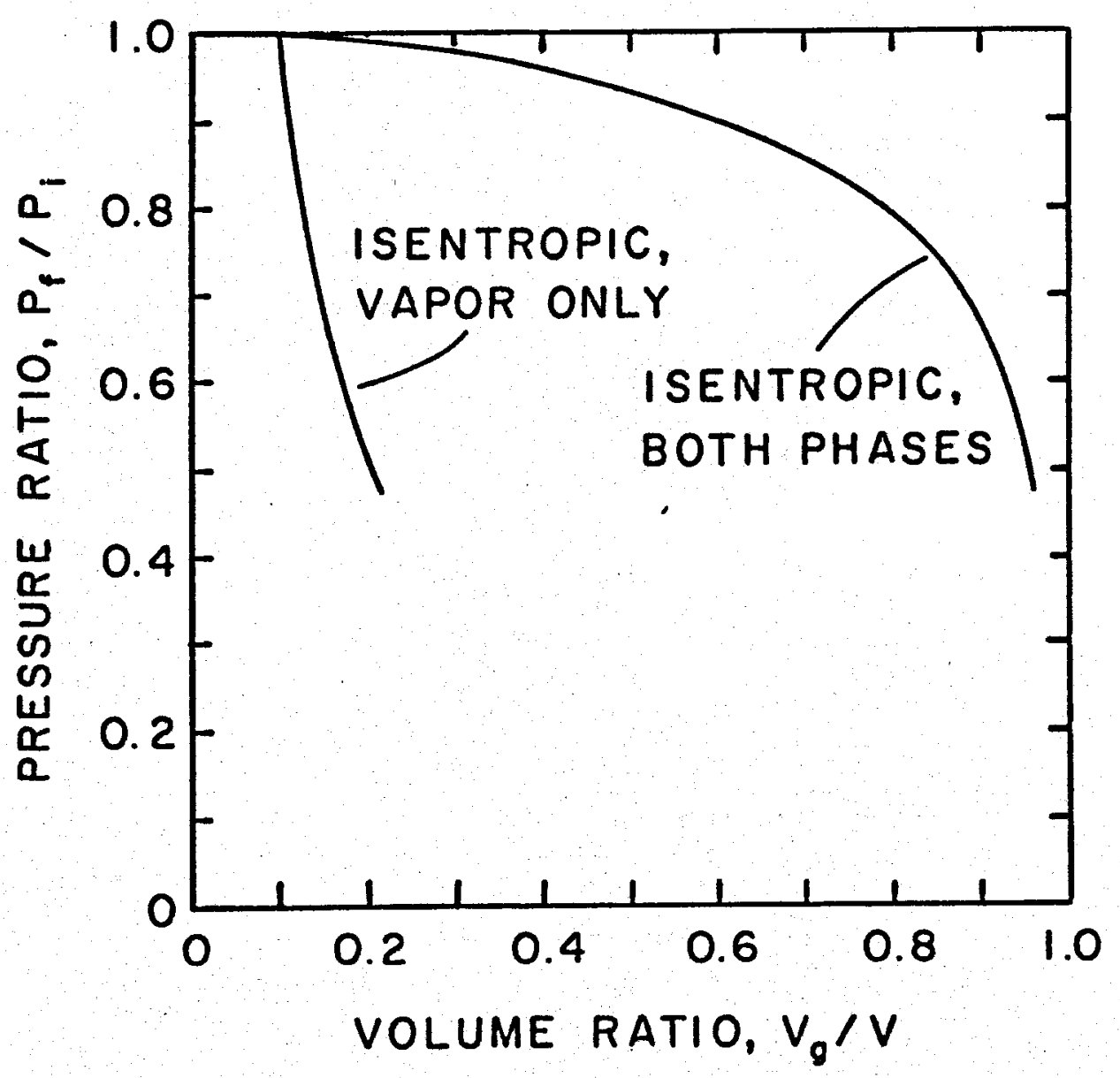

Fig, 10, PRESSURE FALL-OFF IN ACCUMULATOR AS A FUNCTION OF THE VAPOR VOLUME FRACTION IN THE TANK 


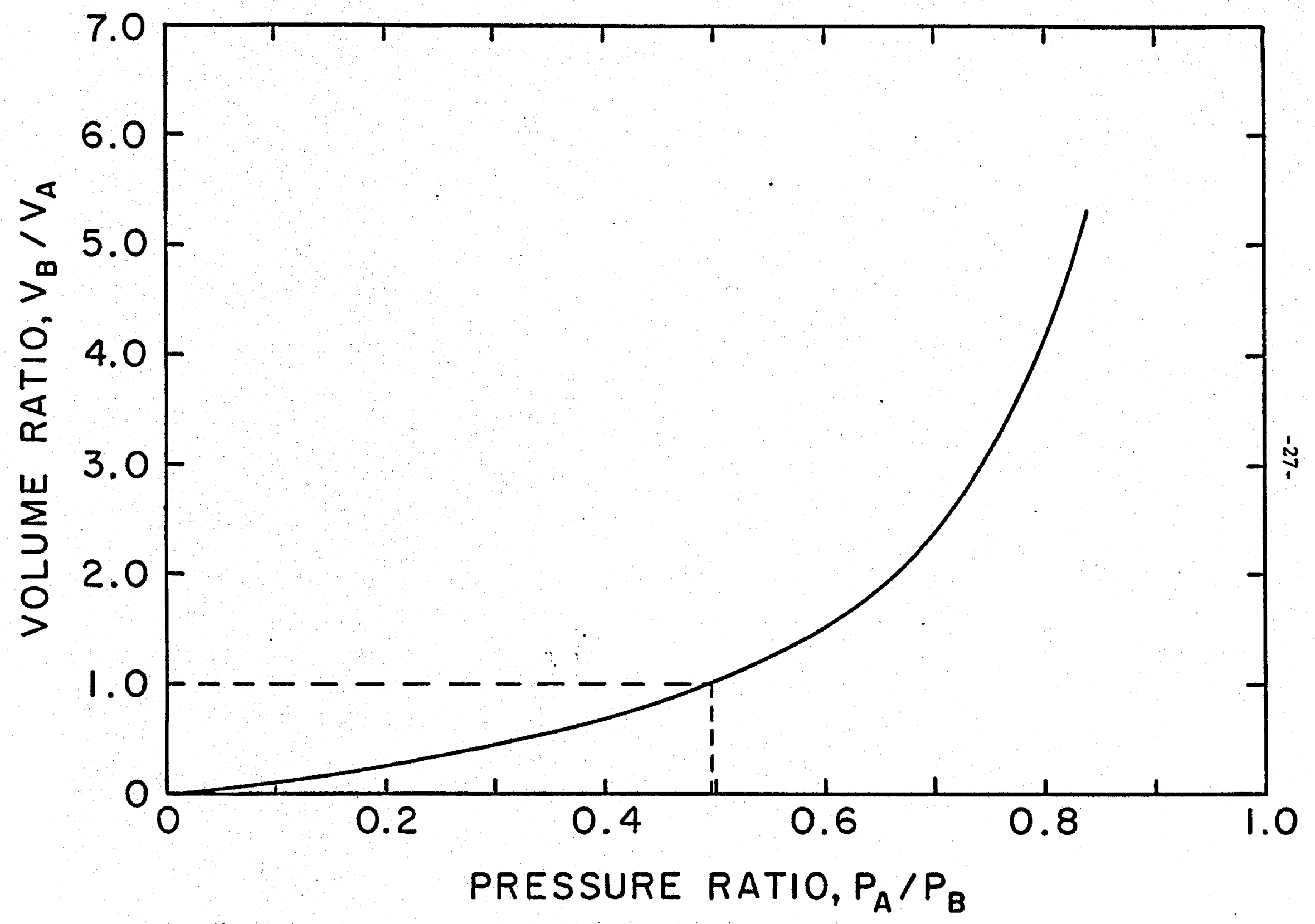

Fig, 11. VOLUME RATIO VERSUS PRESSURE RATIO, ACCUMULATOR/BOOSTER TANKS 
$P_{B} / P_{A}$ of approximately 2 is required. This corresponds to a manageable pressure, for design purposes, of 13 bar $\left(1901 \mathrm{bf} / \mathrm{in}^{2}\right)$ for the booster tank. This is the choice that was made.

Detailed specifications for each tank are given in the specification 1ist, Section 3.3. A view of the accumulator and booster tanks is shown in Photo 2.

\subsubsection{Design of Condenser, Coolant Storage Tank, Chiller, Heaters and Pumps}

The size of the condenser was determined on the basis of the dryness fraction and latent heat of the two-phase mixture as it leaves the test section, having undergone, essentially, an adiabatic throttling process. At the maximum mass flux, $\dot{\mathrm{m}}_{0} / \mathrm{A}_{0}$, with saturated liquid throttled from 6.5 bar to a dump tank pressure of 0.5 bar, the required cooling capacity for the condenser is 200 ton $(1$ ton $=200 \mathrm{Btu} / \mathrm{min}=3.5 \mathrm{~kJ} / \mathrm{s})$. The condenser is a standard shell and tube unit, cooled by circulation of a methanol-water solution from the coolant storage tank. This type solution is used since it allows the tank to be cooled to as low as $-40^{\circ} \mathrm{F}\left(-40^{\circ} \mathrm{C}\right)$ with a $40 \%$ methanol concentration. Methanol was selected over the more conventional ethylene-glycol because of better heat transfer, viscosity and specific heat properties for use in the condenser. A coolant circulation rate of $450 \mathrm{GPM}$ is required by the condenser, with a solution temperature of $-20^{\circ} \mathrm{F}\left(-29^{\circ} \mathrm{C}\right)$. The coolant pump was selected accordingly. The condenser and durn tank are shown in Photo 3.

The coolant storage tank must hold an adequate supply of solution to condense the quantity of vapor which leaves the test section 


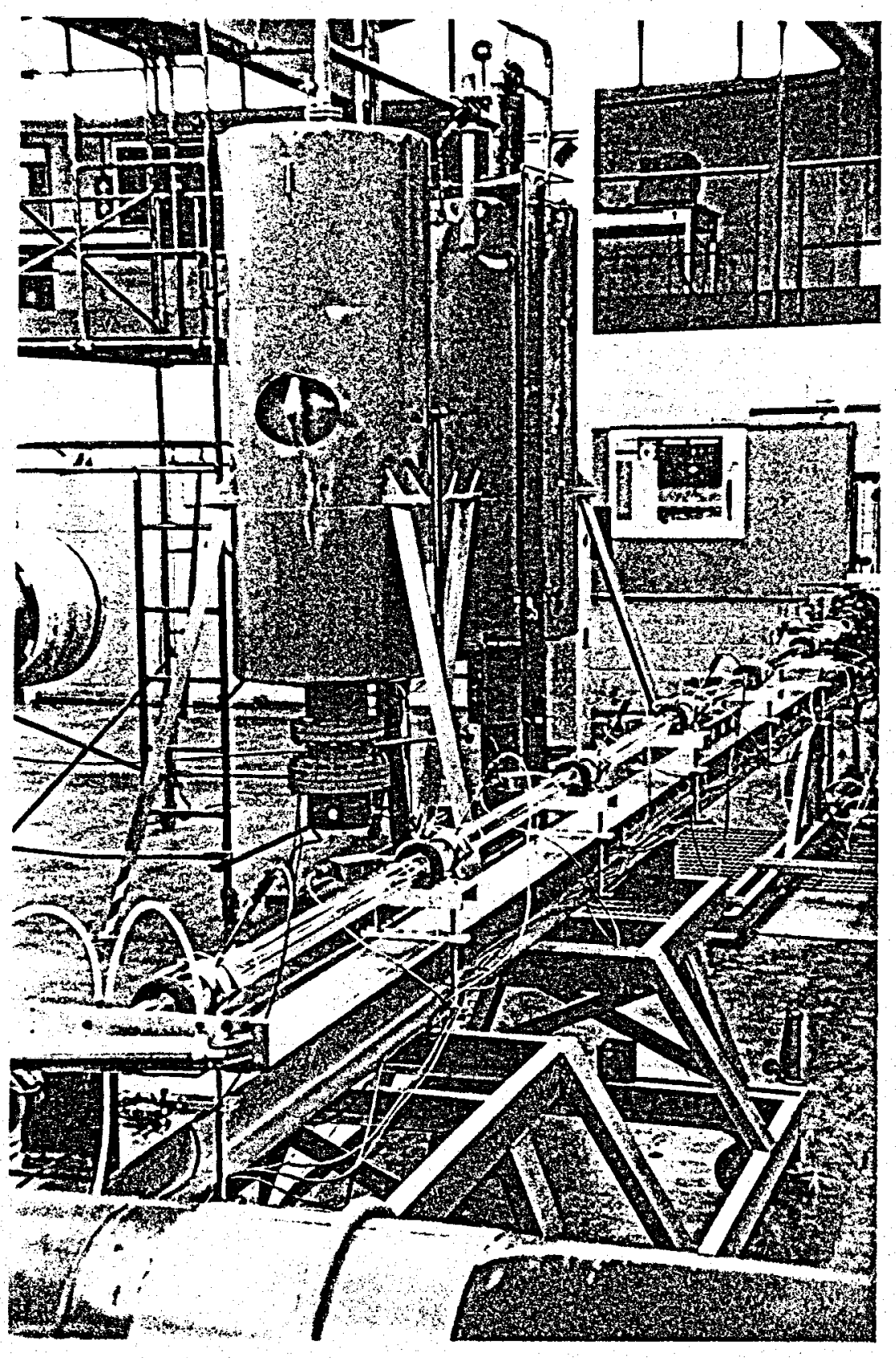

Photo 2.

Booster tank (1eft center), accumulator tank (right center), and test section. Booster heater housing is at the bottom of the booster tank. Note locations of pressure and temperature probes along test section. 


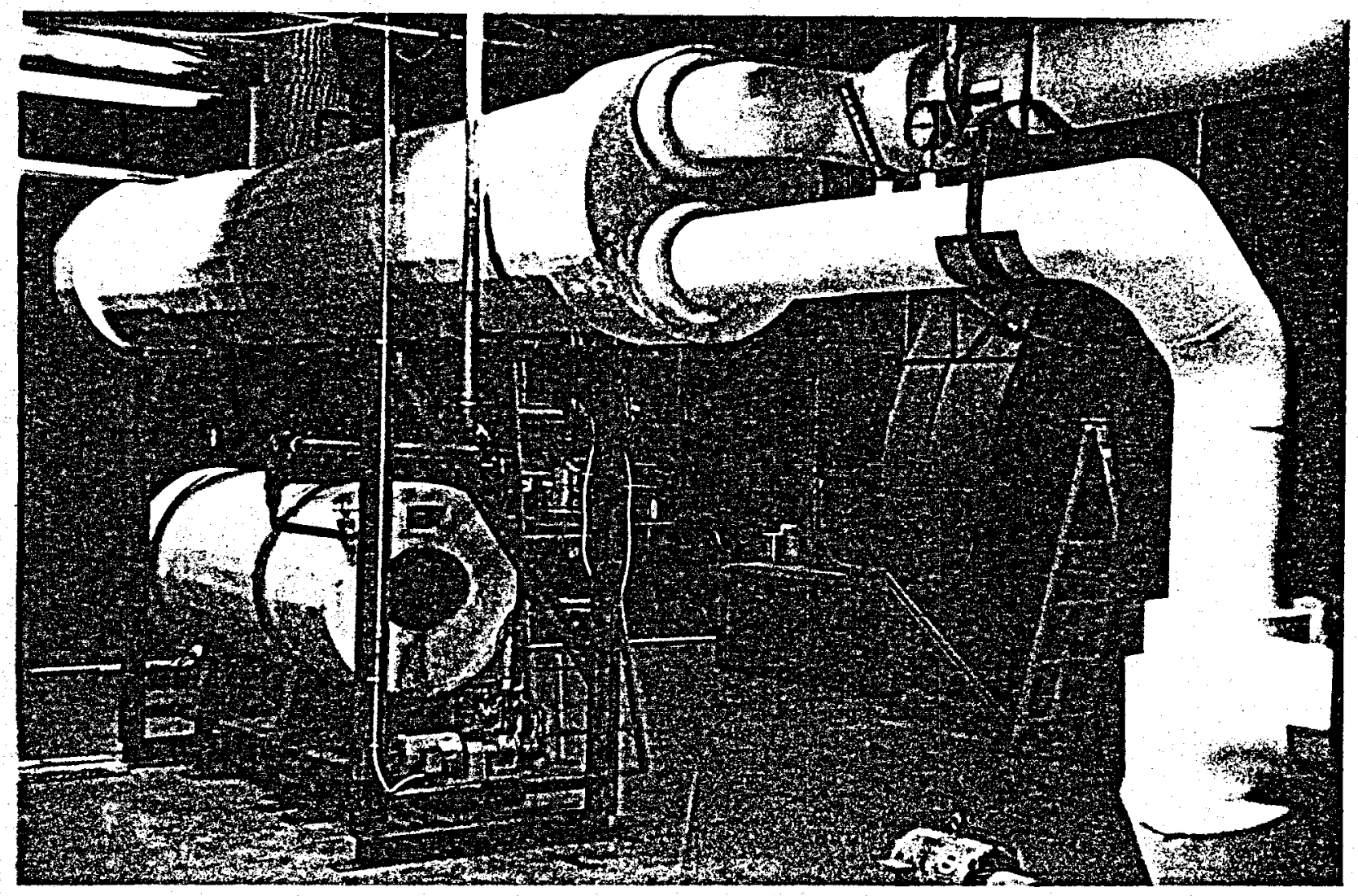

Photo 3.

Condenser (top) and dump tank (bottom); basement level of facility. 
during a run, and also keep the temperature of the solution within the range required by the condenser. With a maximum total temperature difference of $20^{\circ} \mathrm{F}$ for the storage tank $\left(-30^{\circ} \mathrm{F}\right.$ to $-10^{\circ} \mathrm{F}$ or $-34^{\circ} \mathrm{C}$ to $\left.-23^{\circ} \mathrm{C}\right)$, a capacity of 700 gallons $\left(2.95 \mathrm{~m}^{3}\right)$ is required. The final size selected for the tank was 1000 gallons $\left(3.79 \mathrm{~m}^{3}\right)$, to provide an adequate volume of air to eliminate the need for a separate expansion tank. The corrosion enhibitor Borox is added to the solution for corrosion protection. Photo 4 shows the coolant storage tank as well as the circulating pump.

Since the system operates in a blow-down manner, the specifications for the chiller, heater and freon re-distribution pump depend on the selection of an acceptable waiting time between runs. Based on the type of schedule expected in the laboratory, the time was selected as three hours.

The chiller uses the full 3-hour time period to restore the coolant storage tank temperature to its design value before a run (a $20^{\circ}$ maximum temperature reduction). It is also used during any period when the system is not operating on a regular basis to maintain this same temperature. Since the tank is well insulated, the chiller size was determined from the first consideration alone, and it was found that a medium-size packaged unit of 3-ton capacity would be required. The chiller is shown in Photo 5.

The specifications of the freon pump and heaters for the accumulator and booster tanks are interrelated since the pumping and heating operations must be done in sequence within the 3 -hour time span. Thus the restoration period was split into two portions: two hours for pumping liquid freon from the dump tank to the accumulator and booster tanks, and one hour for 


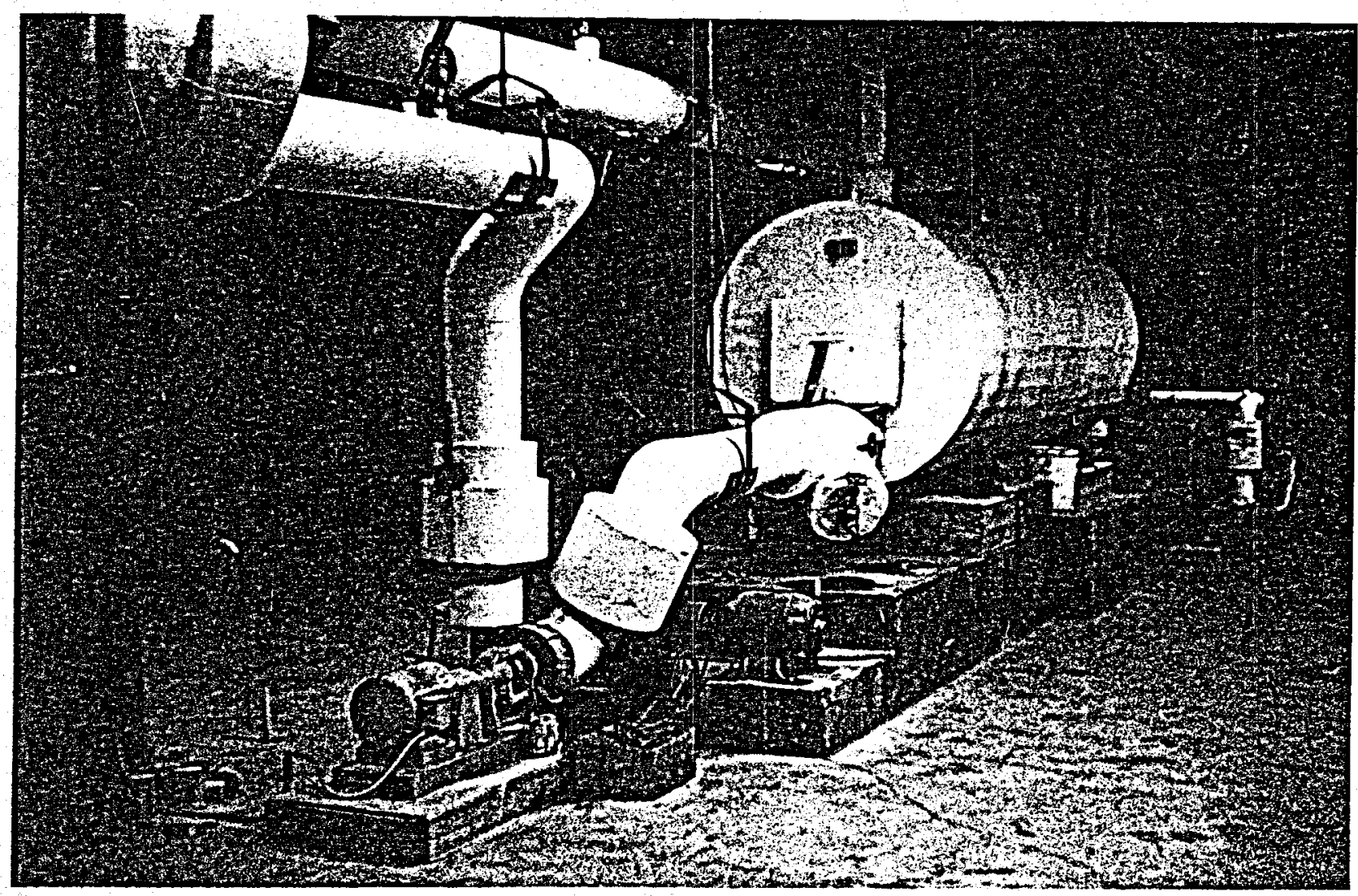

Photo 4.

Coolant storage tank and circulating pump. Condenser partially visible at upper left; chiller in far background at right. 


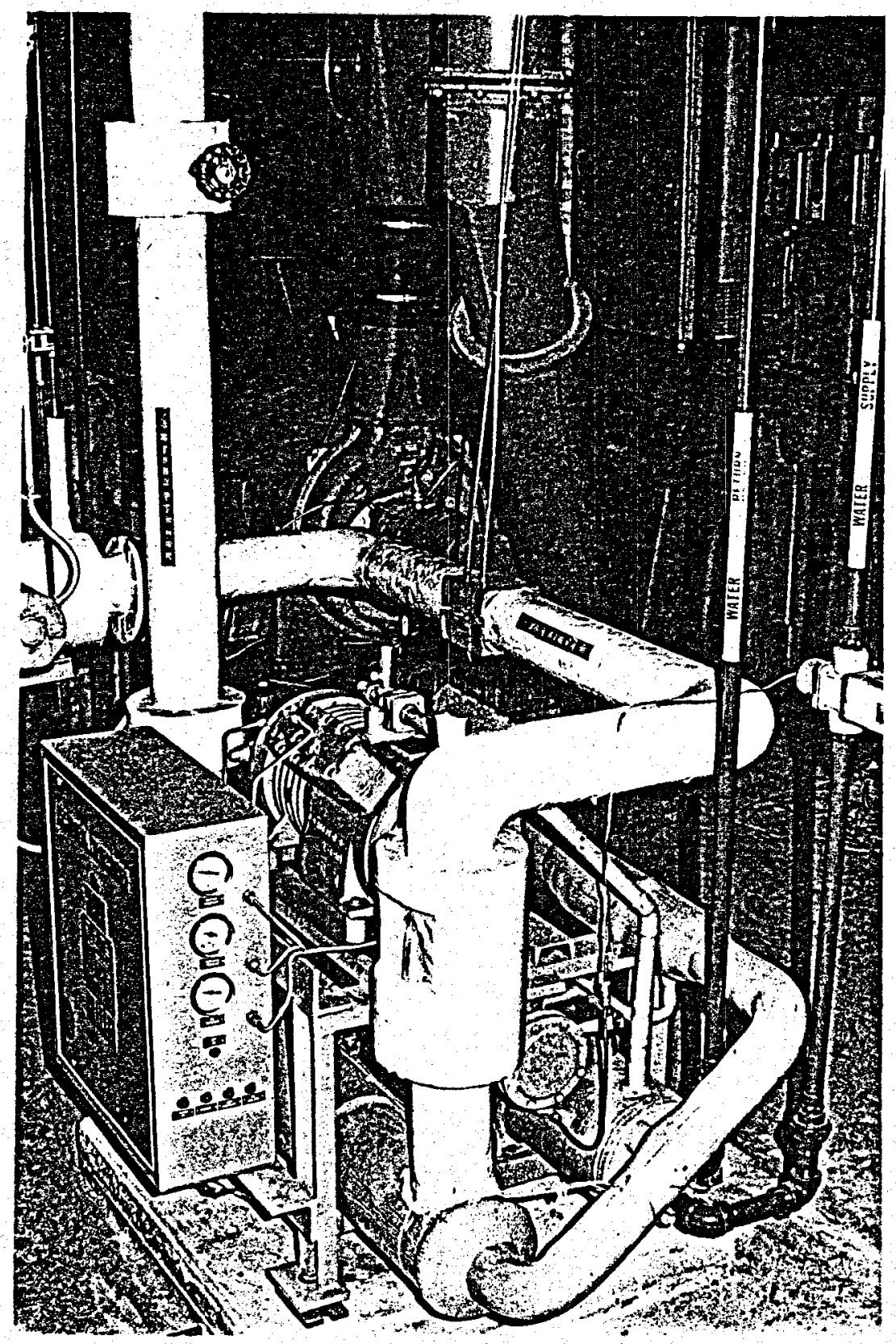

Photo 5.

Chiller unit; prepackaged, commercial system. 
heating the tanks to the desired starting conditions.

Thus, the required size of the circulation pump is 3 GPM The type selected was a positive displacement pump with a helical rotor which operates without contaminating the freon with any type of lubricant.

The heaters were selected as flange-mounted electric resistance heaters of $15 \mathrm{~kW}$ and $6 \mathrm{~kW}$ capacity for the accumulator and booster tanks, respectively. These ratings are based on starting conditions with the accumulator containing $90 \%$ liquid and $10 \%$ vapor under saturation conditions at a pressure of 6.5 bar and the booster containing $90 \%$ vapor and $10 \%$ liquid, saturated at 13 bar.

\subsubsection{Design of Test Section}

A number of different materials were considered for the test section piping. Basic requirements were transparency, smooth inside finish, ease of attachment for all instrumentation, versatility of length selection and adequate flexibility for alignment.

A large variety of plastic materials were examined, but the transparency requirement drastically reduced the number of possibilities. Also, in most cases, chemical resistance to freon could not be definitely determined, and marginal performance at the required temperatures and pressures finally eliminated plastics from further consideration.

As a result, glass was selected as the only possible material. After much investigation, it is discovered that the Corning Glass Works manufactures a system of glass Pyrex pipe, including flanges and gaskets for joining and hardware for mounting and adapting the glass to other fittings. Data supplied by Corning showed this system to have the necessary characteristics 
mentioned above, including the strength and tolerance for thermal shock required for this application. The flanged connections allow sufficient flexibility and ease of adding instrumentation, as discussed later in Section 5.2. The pipe is also available in a variety of lengths and diameters.

\subsubsection{Miscellaneous Hardware}

The rest of the system is comprised of various pipes, valves and assorted fittings. The specifications for these are given in the listing that follows in Section 3.3 .

\subsection{Equipment Specification List}

TANKS

Accumulator Booster

Dump

Methano1 Storage
ASME Rating

Dimensions

125 PSIG e $650^{\circ} \mathrm{F} 30^{\prime \prime} \times 84^{\prime \prime}$

250 PSIG C $650^{\circ} \mathrm{F} 30^{\prime \prime} \times 84^{\prime \prime}$

125 PSIG @ $650^{\circ} \mathrm{F} 30^{\prime \prime} \times 84^{\prime \prime}$

75 PSIG e $-30^{\circ} \mathrm{F} 48^{\prime \prime} \times 144^{\prime \prime}$
Material Weight (1bs)

$\begin{array}{lr}\text { stee1 } & 850 \\ \text { steel } & 950 \\ \text { stee1 } & 800 \\ \text { steel } & 2000\end{array}$

Supplier: Massachusetts Engineering Company, Avon, Massachusetts

\begin{tabular}{|c|c|c|c|c|c|c|c|}
\hline CONDENSER & Type & Cap. & $\begin{array}{l}\text { Inlet } \\
\text { Temp. }\end{array}$ & $\begin{array}{l}\text { Outlet } \\
\text { Temp. }\end{array}$ & GPM & $\begin{array}{l}\text { Cond. } \\
\text { Temp. }\end{array}$ & $\begin{array}{c}\text { Pressure } \\
\text { (She11, Tube) } \\
\end{array}$ \\
\hline & $\begin{array}{l}\text { shell \& tube } \\
8 \text { pass }\end{array}$ & 200 ton & $-20^{\circ} \mathrm{F}$ & $-5^{\circ} \mathrm{F}$ & -450 & $8^{\circ} \mathrm{F}$ & 150 PSIG \\
\hline & shell dimensi & ons: $16^{\prime}$ & $\times 200^{\prime \prime}$ & & & & \\
\hline
\end{tabular}

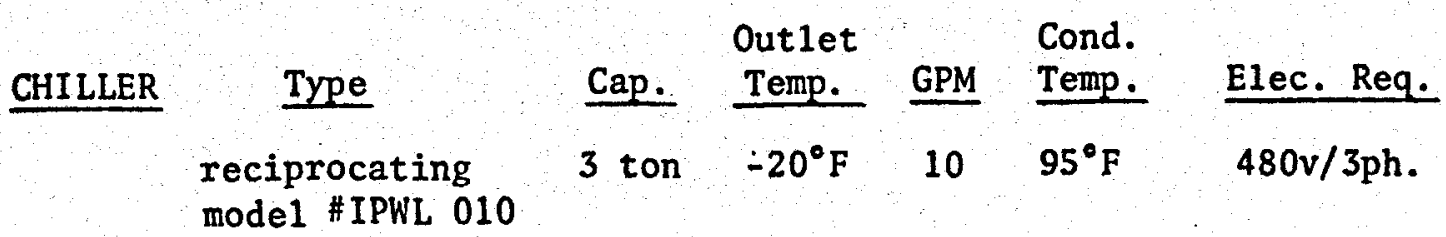

Supplier: Dunham-Bush, Inc., West Hartford, Connecticut 


\begin{tabular}{llllll} 
HEATERS & Type & Cap. & Dimensions & Elec. Req. \\
\cline { 2 - 2 } & elec. & $15 \mathrm{~kW}(2$ stage $)$ & $8^{\prime \prime}-1501 \mathrm{~b}$ flange & $480 \mathrm{v} / 3 \mathrm{ph}$. \\
Booster & elec. & $6 \mathrm{~kW}$ & $10^{\prime \prime}-3001 \mathrm{~b}$ flange & $480 \mathrm{v} / 3 \mathrm{ph}$.
\end{tabular}

$\begin{array}{lccccc}\text { PUMPS } & \text { Type } & \frac{\text { GPM }}{\text { Freon }} & \text { Pressure } & \text { Power } & \text { Elec. Req. } \\ \begin{array}{c}\text { (Distribution) } \\ \text { base-mounted }\end{array} & 3 & 100 \mathrm{PSIG} & 1 / 2 \mathrm{HP} & 440 \mathrm{v} / 3 \mathrm{ph} . \\ \begin{array}{c}\text { Methanol } \\ \text { (Condenser) }\end{array} & \text { base-mounted } & 480 & 60^{\prime} \mathrm{H}_{2} \mathrm{O} & 10 \mathrm{HP} & 440 \mathrm{v} / 3 \mathrm{ph} . \\ \begin{array}{c}\text { Methanol } \\ (\text { Chiller) }\end{array} & \text { circulator } & 10 & 30^{\prime} \mathrm{H}_{2} \mathrm{O} & 1 / 3 \mathrm{HP} & 230 \mathrm{v} / 3 \mathrm{ph} .\end{array}$

Freon Pump: Ramoy mode1 \#33204

Methanol Pumps: Standard equipment - Taco, Inc., Cranston, R. I.

\section{TYPICAL PIPING MATERIALS}

1. Refrigerant Circuit

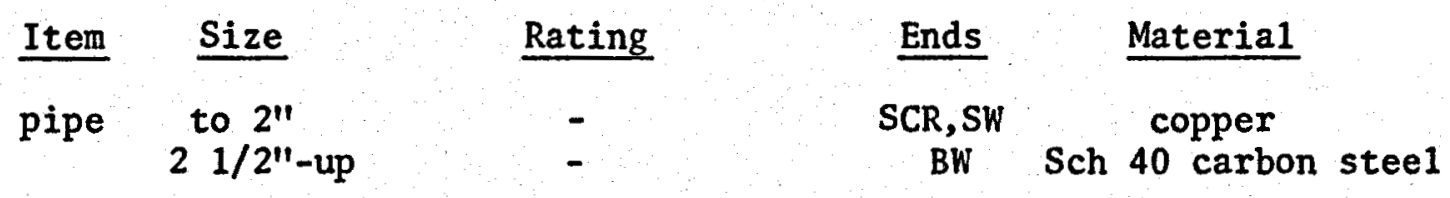

fittings, to $2^{\prime \prime}$ as required, min. $125^{\#} \mathrm{SCR}, \mathrm{SW}$ copper

flanges $21 / 2^{\prime \prime}$-up as required, min. $125^{\#} \mathrm{BW}, \mathrm{WN}$ Sch 40 carbon steel

Note: BW-Butt Weld; WN-Weld Neck; SCR-Screwed; SW-Sweat

2. Methanol Circuit

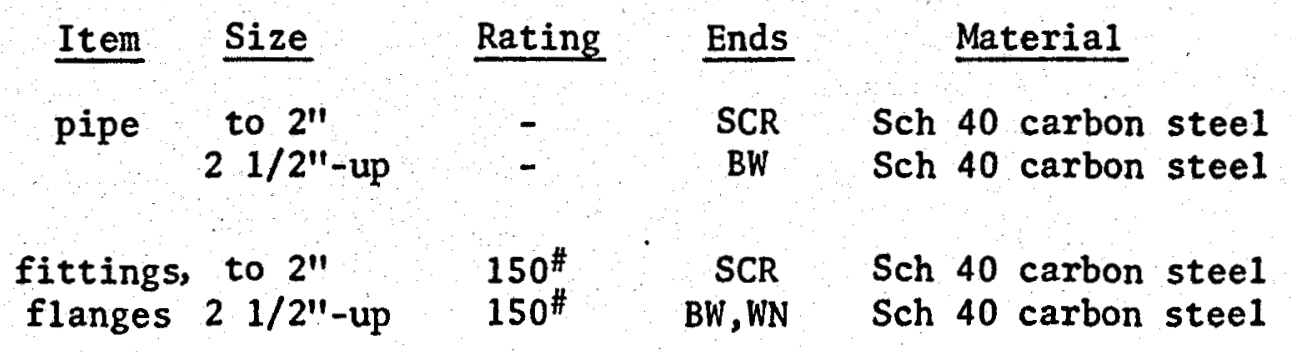


VALVE TYPES

$\begin{array}{ccccc}\text { Type } & \text { Use } & \text { Size } & \frac{\text { Rating }}{\text { Ends }} \\ \text { BF } & \text { R } & 5^{\prime \prime} & 150^{\#} & \text { (flange insert type) } \\ \text { BF } & M & 6^{\prime \prime} & 150^{\#} & \text { FLG } \\ \text { B } & \text { R } & 1^{\prime \prime} & 150^{\#}, 250^{\#} & \text { SCR } \\ \text { B } & \text { R } & 4^{\prime \prime} & 150^{\#} & \text { FLG } \\ \text { B } & M & 11 / 8^{\prime \prime} & 150^{\#} & \text { SCR } \\ \text { P } & \text { M } & 11 / 8^{\prime \prime} & 150^{\#} & \text { SCR }\end{array}$

NOMENCLATURE

Valve Type

BF - Butterf1y

B - Ba11

P - Plug

\section{System}

M - Methano1-Water

$R$ - Refrigerant
Operating Range

$-20^{\circ} \mathrm{F}$ to ambient

$8^{\circ} \mathrm{F}$ to $210^{\circ} \mathrm{F}$

Butterfly valves - Stee1, 316 stainless steel trim, threaded lug; manual detent handle

Ball valves up to $2^{\prime \prime}$ - Bronze body, 316 stainless ball and stem, tefion seat

$21 / 2^{\prime \prime}$ up - Carbon steel body, chrome plated ball and stem 


\section{INSTRUMENTATION}

The instrumentation which is used in the system should be considered in two parts: Instruments for the acquisition of experimental data and those for systems monitoring and control, as was mentioned earlier in Section 2.2. The discussion begun in Section 2.2 wil1 be continued and extended in this section.

\subsection{Instrumentation for Experimental Data}

Under this category we will discuss three types of measurement: temperature measurement, pressure measurement, and mass flow rate measurement.

\subsubsection{Temperature Measurement}

The type of probe selected for measuring temperature was the thermistor, made from a semiconductor material having a resistance which is sensitive to temperature. The equation governing the dependence of the resistance on temperature is:

$$
\phi(T)=\alpha e^{-\beta / T},
$$

where $T$ is the absolute temperature and the constants $\alpha$ and $\beta$ depend on the material. Rather than measure resistance, in our case, a known current is passed through the thermistor and $\phi$ is a voltage measured as a function of temperature.

The specific thermistors were selected based on their sensitivity over the required temperature range and an output which is compatible with 
the voltage-measuring equipment. The manufacturer's specifications were used for the selection process. A method for mounting was designed and implemented, and calibrations were then carried out for each thermistor. Because of the way the thermistor had to be mounted (i.e., in a fluid flow, and along the radius of a circular cross-section), the type selected was a glass-coated bead with adjacent leads. This allowed the thermistor to be mounted as shown in Figure 12, with the leads passing through a sealed tube. The tube is held in a fitting which screws into a Delrin pipe insert and which allows the tube to be positioned radially and locked in place. See Photo 6.

Thermistors with resistance values at $25^{\circ} \mathrm{C}$ of either $1 \mathrm{k} \Omega$ or $2 \mathrm{k} \Omega$ are presently in use. With an applied measuring current of $200 \mu \mathrm{A}$, the resulting voltage is between 0 and 1 volt over the calibration temperature range of 0 to $30^{\circ} \mathrm{C}$. The $1 \mathrm{k} \Omega$ thermistors allow temperatures lower than $0^{\circ} \mathrm{C}$ to be measured when needed, without exceeding $1 \mathrm{~V}$ output.

Calibration of the temperature transducers was carried out using a heated, thermostatically-controlled water bath. Points were taken at approximately $3^{\circ} \mathrm{C}$ intervals over the calibration range. A computer program has been written which allows the HP-85 to read the transducer output voltage at each point. The corresponding temperatures, read on a high-precision mercury-in-glass thermometer are provided by the operator. The computer then correlates the data for $\phi(T)$ using a least-squares analysis. The form of the correlating equation is obtained from the resistance equation above as

$$
\frac{1}{T}=A+B \ln \phi,
$$


$-40-$

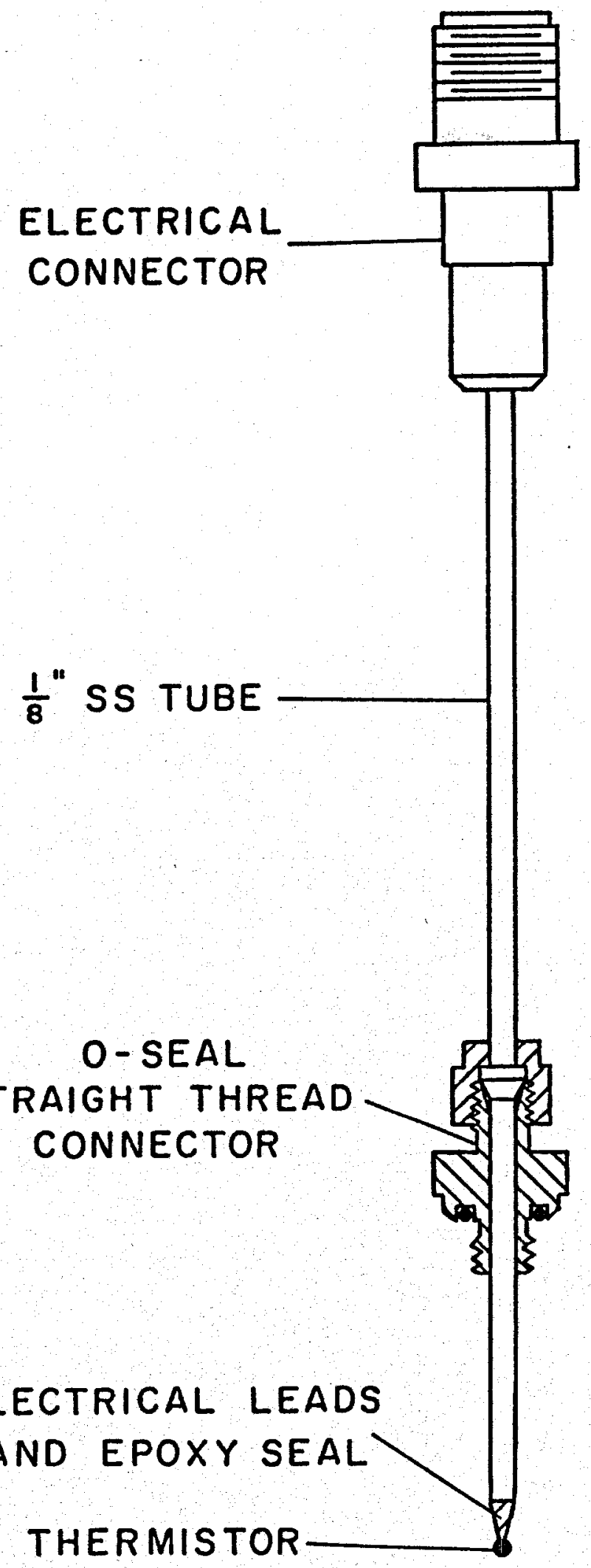

Fig, 12 . THERMISTOR ARRANGEMENT 


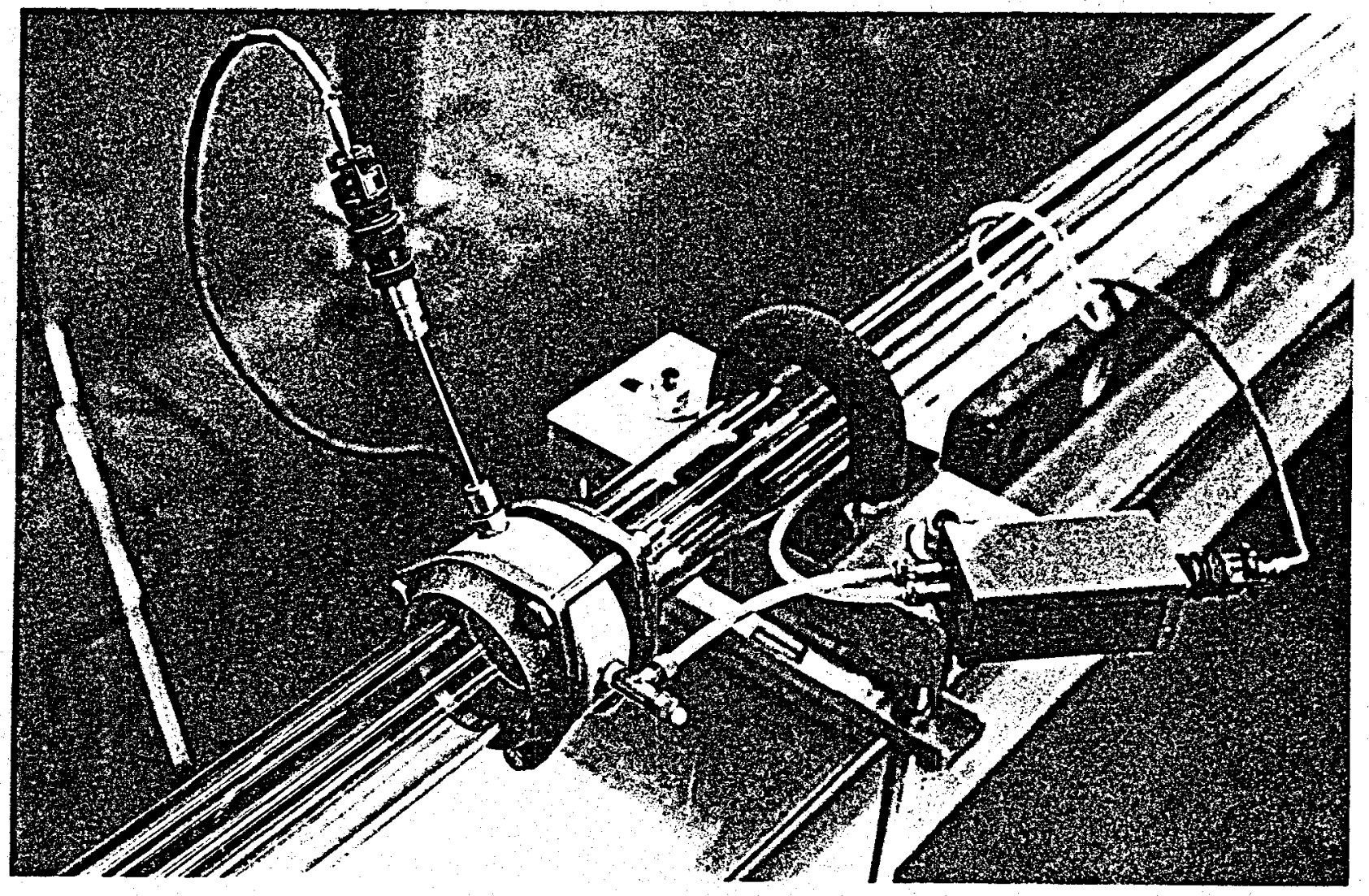

Photo 6.

Typical measuring station. Thermistor probe is at upper left, pressure probe is at right of Delrin insert. Note connecting flanges for glass pipe sections. 
where

$$
A=\frac{\ln \alpha}{B} \text { and } B=-\frac{1}{B}
$$

A sample correlation is given in Figure 13a, showing the input data, resulting correlation equation, standard deviation, and deviation of data from the smooth curve. Specifications for the thermistors are given in the specification list in Section 4.3 .

\subsubsection{Absolute and Differential Pressure Measurement}

The type of probe selected for measuring absolute and differential pressure is an integrated circuit pressure transducer which provides a voltage output that is linear with the applied pressure or pressure difference. The transducer consists of a single-crystal silicon sensor and circuit elements mounted in a ceramic housing. Attached directly to the housing are ports of brass tubing for connection to the pressure source, and electrical connections for a 15-volt excitation signal and output voltage. For this application, it was decided to mount the transducer in a metal box, as shown in Figure 14, which allows the transducer to be isolated from stress created by the external tubing and electrical connections. See Photo 6 .

The differential pressure transducers selected have a range

of $\Delta \mathrm{P}=-5$ to $+5 \mathrm{bf} / \mathrm{in}^{2}(-30$ to $+30 \mathrm{kPa})$ with a voltage output in the range 0 to 12 volts, and an offset of approximately $7 \mathrm{~V}$ when $\Delta \mathrm{P}=0$.

Calibration is performed over the range -30 to $0 \mathrm{kPa}$ by the use of a program on the HP-85 similar to that used in the temperature probe calibrations. In this case, the low pressure port of the transducer is left 
Infut data for Transducer Ho 10

$$
\begin{aligned}
& 2.6 \\
& 3 \cdot 6 \\
& 6 \cdot 3 \\
& 12 \cdot 3 \\
& 15 \cdot 4 \\
& 18 \cdot 4 \\
& 21 \cdot 4 \\
& 24 \cdot 3 \\
& 27 \cdot 3 \\
& 30 \cdot 3 \\
& 33 \cdot 6
\end{aligned}
$$

514

524

409

.36

314

.276

.246

.219

195

.174

.154

Ealibration for Traneducer Ho 10

DRTE : $5 / 19 / 221$

$\mathrm{D} \in \mathrm{BK}, \mathrm{T}=$

$3.799 E-93+2.377 E-04 * \operatorname{LOT}(4, W)$

$\sigma * D e 9 K=8.17 E-67$

Error of T-Transducer 10

+1 liesc

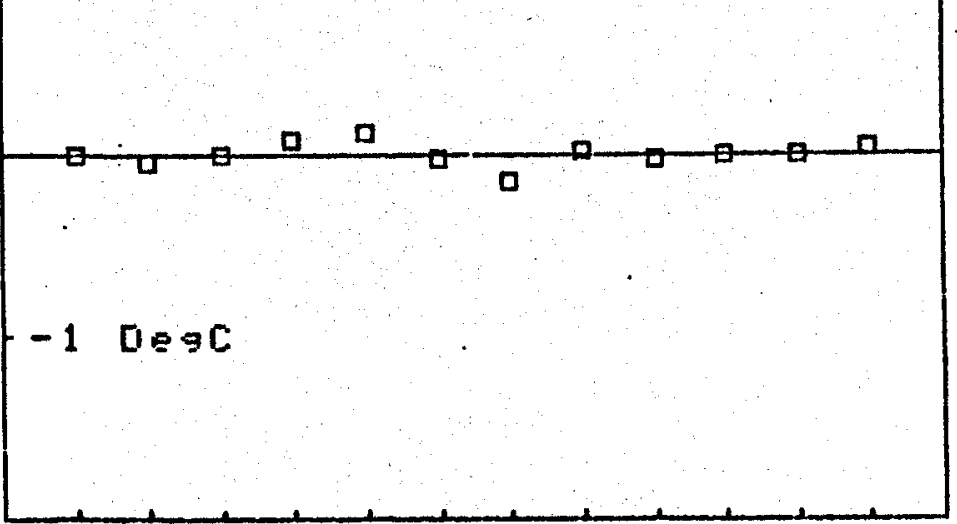

Fig, 13, SAMPLE CALIBRATION FOR (A) TEMPERATURE AND (B) PRESSURE TRANSDUCERS
Infut data:

Pinear

0

$-69.4323677411$

$-139.130251229$

$-207.102282364$

$-276.269134358$

$-347.294596579$

事

Calibration of P-Transducer 5

$\mathrm{P} / m \mathrm{Bar}=-099488.99+90969.40 * 2 \mathrm{~V}$

$\sigma \circ \operatorname{mar}=.365$

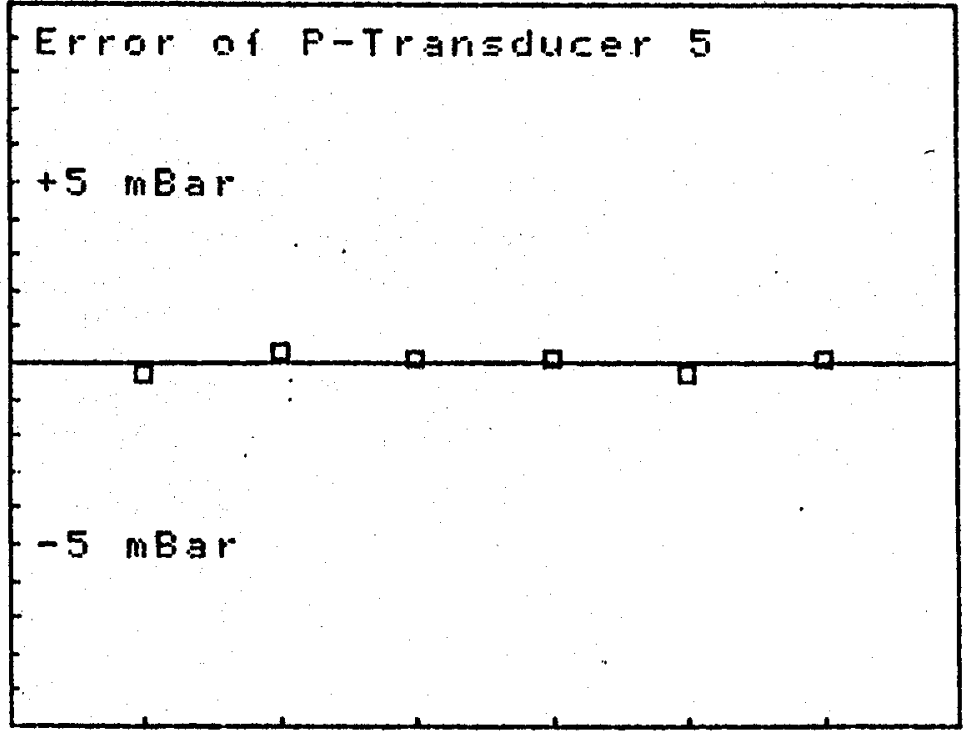

$\stackrel{1}{\dot{c}}$ 


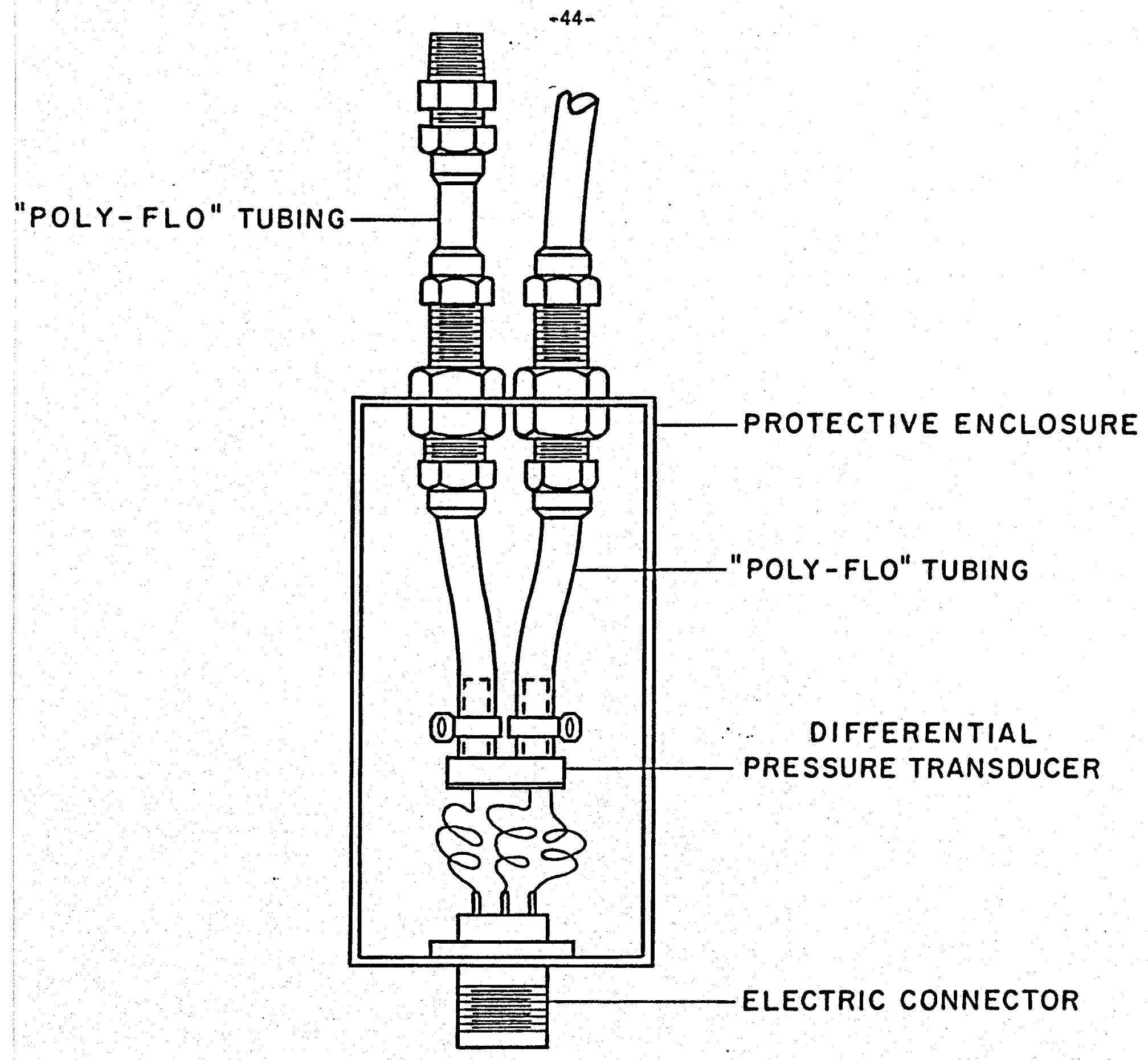

PRESSURE TRANSDUCER MOUNTING

FIG, 14, PRESSURE TRANSDUCER MOUNTING ARRANGEMENT 
open to the atmosphere, and a controlled vacuum is applied to the high pressure port in increments of approximately $7 \mathrm{kPa}$, as read by the operator on a mercury manometer. Thus, the transducer output is kept in the range $\phi=0-7 \mathrm{~V}$. The function $P(\phi)$ is correlated by a least-squares analysis to an equation of the form

$$
P(\phi)=A+B \phi \text {. }
$$

A sample correlation is shown in Figure $13 \mathrm{~b}$. The units of pressure are mbar, converted from $\mathrm{mm} \mathrm{Hg}$ by the computer.

The absolute pressure transducers used have ranges of $0-30$ and $0-60 \mathrm{bf} / \mathrm{in}^{2}(\mathrm{O}-4 \mathrm{bar})$. Calibration is accomplished by applying a known pressure to the transducer, as read using a mercury manometer. The data is correlated using the same computer program as the differential transducer, and the form of the correlating equation is the same. Specifications for the pressure transducers are given in Section 4.3 .

\subsubsection{Mass Flow Rate Measurement}

The flow rate is measured by means of a venturi meter which determines mass flow rate by measuring the change in pressure as a flow of liquid passes through a contraction, or "throat" section in a pipe. Because of a number of special requirements of this meter, it was decided to design and fabricate our own venturi rather than purchase an instrument from a vendor.

Since the only location in the system where liquid and reasonably smooth flow will always exist is between the accumulator tank exit and the inlet to the test section, it was decided to locate the 
venturi in this branch. Because the freon is close to its saturation pressure before entering the test section, in order to maintain liquid flow through the venturi the allowable pressure change in the meter is narrowly limited. Also, because of this, the flow rate which can be measured in a unit of given dimensions (i.e., for a fixed throat size) is limited.

Two steps were taken to solve this problem. First, the meter was located in the vertical section of pipe directly below the accumulator tank, approximately 2 meters above the level of the basement floor. See Photos 7 and 8 . At this point the hydrostatic pressure allows a pressure change of $50 \mathrm{kPa}$ at the meter throat before the fluid flashes into vapor. The second step involved the design of the meter itself. The meter consists of an outer tube and flanges made of stainless steel which fit between adjacent pipe flanges in a conventional manner. The throat section is machined from Delrin, and slides into the outer tube. It is held in place by means of two end plates. Sealing, both internally around the throat pressure chamber and externally at the flanges, is accomplished using 0-rings. A drawing of the outer tube and insert is given in Figure 15. There are three interchangeable throat sections, allowing a flow measurement range of about 1 to $21 \mathrm{~kg} / \mathrm{s}$, corresponding to a test section mass flux of roughly 400 to $10,000 \mathrm{~kg} / \mathrm{m}^{2} \cdot \mathrm{s}$, with throat diameters of $3 / 4,1-1 / 4$ and 2 in. The range from 1200 to $3600 \mathrm{~kg} / \mathrm{m}^{2} \cdot \mathrm{s}$ is covered by the $1-1 / 4$ in diameter section. 


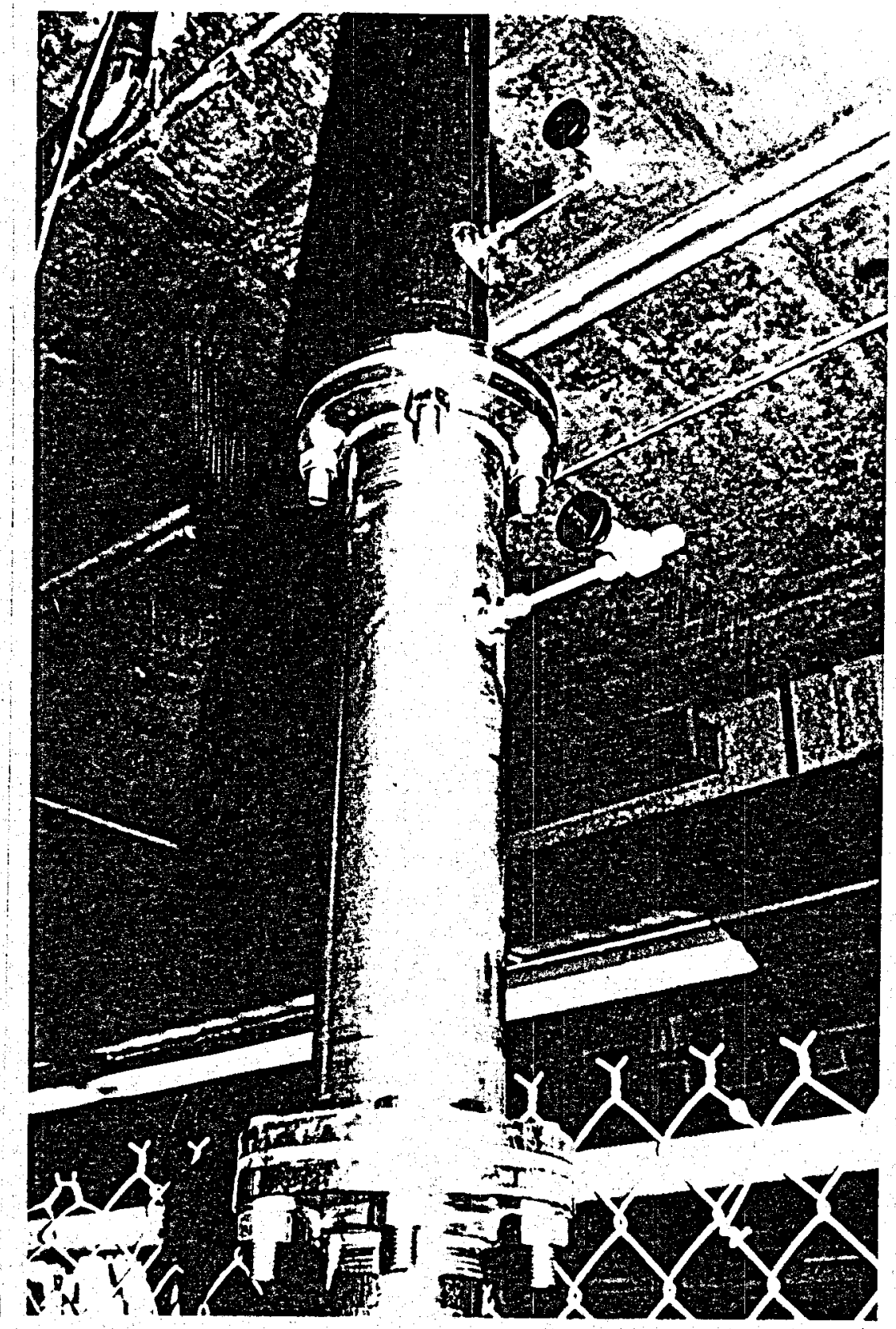

Photo 7.

Venturi flow meter. Located in downcomer beneath accumulator tank; shown before insulation was attached. 


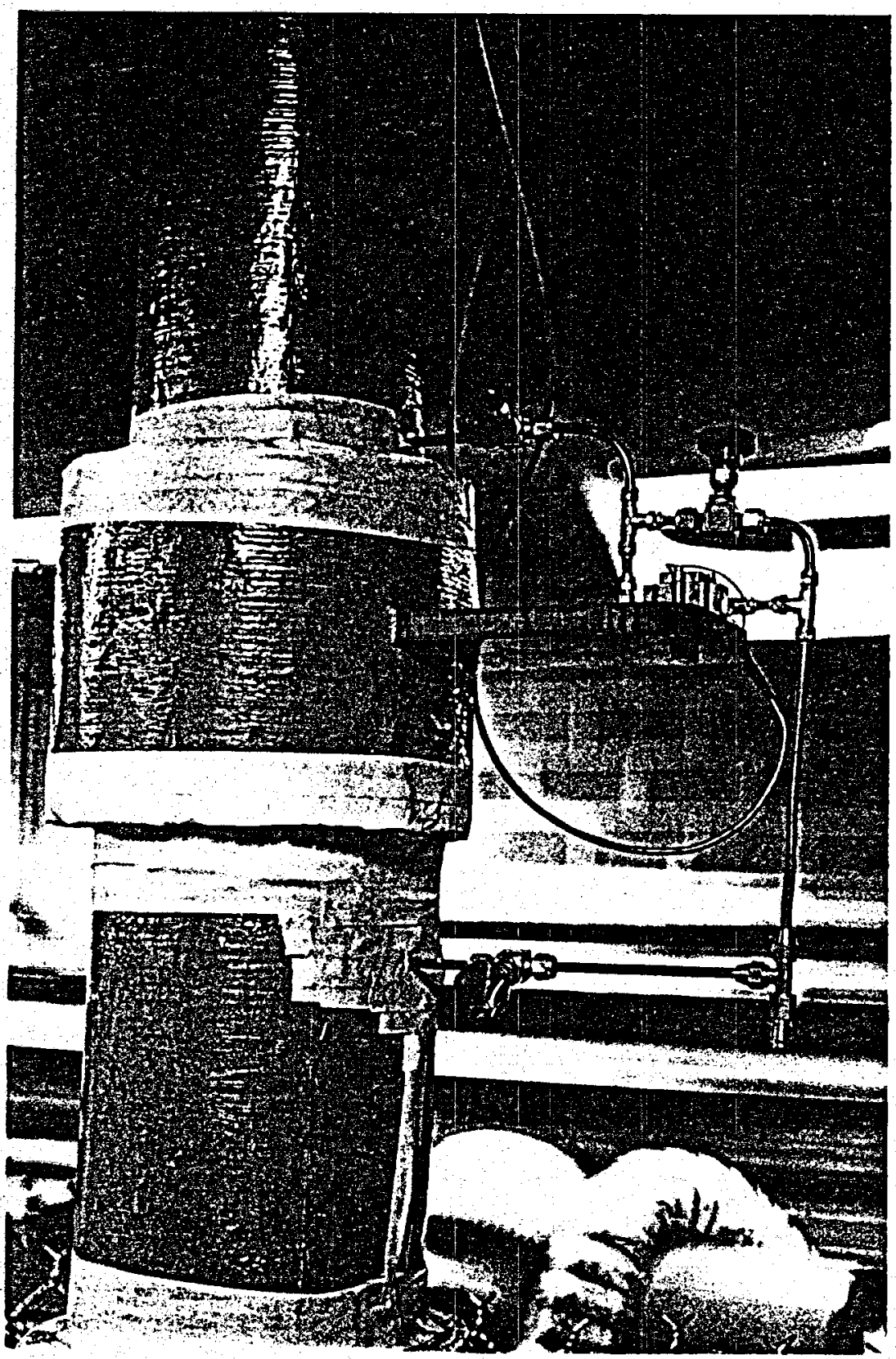

Photo 8.

Venturi flow meter showing differential pressure transducer. 


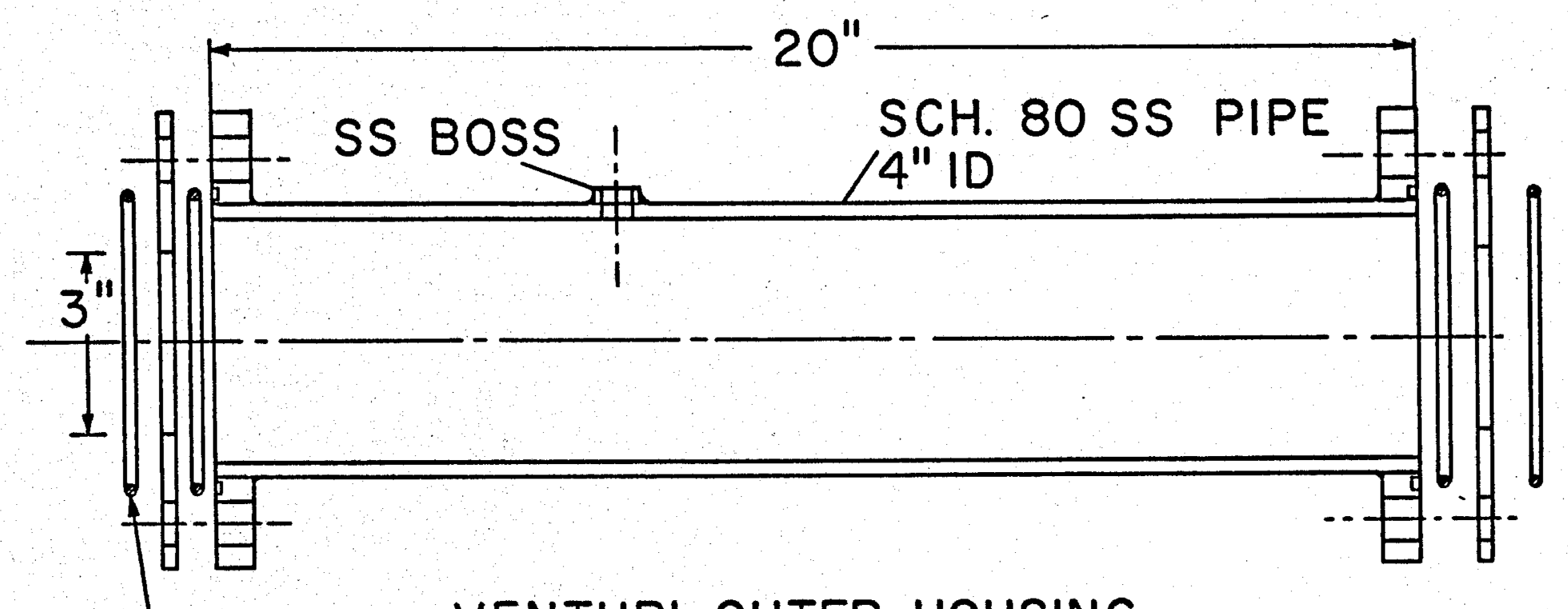

"O"RING

VENTURI OUTER HOUSING

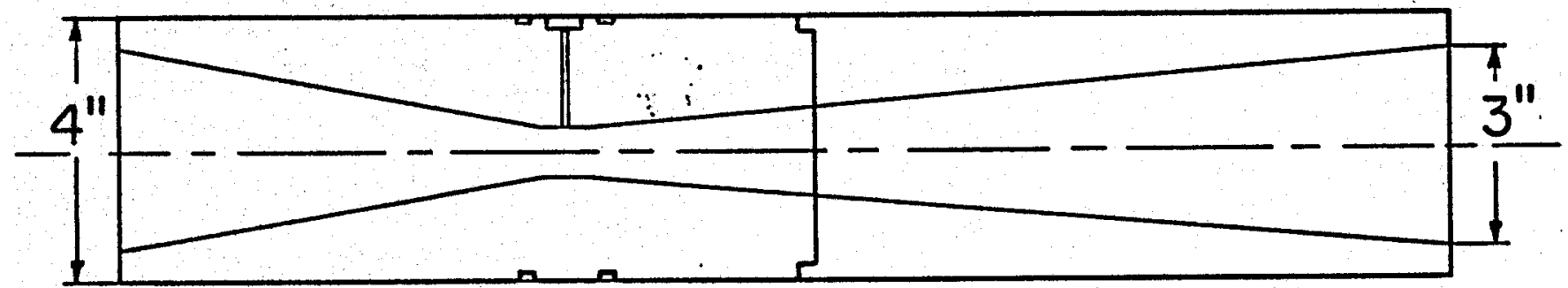

VENTURI THROAT SECTION INSERT

FiG, 15, VENTURI FLOW METER 
$30 \mathrm{kPa}$, safely within the maximum allowable of $50 \mathrm{kPa}$, is accomplished using a differential pressure transducer of the type discussed earlier, except mounted in a zinc housing (as supplied). It is bolted to a vibration isolator at the venturi and connected by the necessary fittings and valves. The inlet pressure tap is located in the upstream pipe section rather than the venturi unit itself. A temperature probe, of the type discussed earlier is located at the same position for accurate determination of the fluid density.

The accuracy of the venturi has been checked by directly measuring the quantity of fluid which leaves the accumulator tank in a given time period with the aid of sight glasses, a cathetometer, and appropriate correction factors, and comparing this to the flow rate measured by the venturi. No correction factor for the standard venturi flow equation has been found necessary, to an accuracy of approximately $2 \%$.

\subsection{Instrumentation for Monitoring and Control}

Instrumentation located throughout the system includes standard mercury-in-glass thermometers, and dial-gage pressure indicators. These are attached using pipe fittings wherever needed, and are only used for visual monitoring. Sight glasses provide a visual check of liquid levels in the tanks.

Temperature measurement for automatic control purposes is accomplished using thermistors of the disc type, mounted by means of adhesive to the outside surface of the walls of the steel tanks, inside the layers of insulation. The connecting cable is simply inserted through the insulation. Thermistors were selected for use in two different temperature ranges: 0 to $100^{\circ} \mathrm{C}$ (high) and -40 to $0^{\circ} \mathrm{C}$ (low). They are calibrated in the same 
manner as discussed previously.

Level indicators are located on individual tanks for automatic control purposes, and consist of differential pressure transducers mounted in a zinc housing. The transducers are connected between the top and bottom of a tank to sense hydrostatic pressure, and hence liquid level. One side of the transducer is connected to the top of the tank by a long tube that naturally is filled with freon vapor which unfortunately will begin to condense when it is warmer than the ambient temperature. To eliminate this problem, we inserted a tube filled with hydraulic oil. The oil is separated from the freon vapor in the tank by an interface device which transmits pressure but does not allow the oil and vapor to mix. The device is essentially a U-tube filled with mercury in its base, and having oil and freon vapor on either side. See Photo 9. The mercury levels remain equal since the oil is incompressible.

\subsection{Instrumentation Specification List}

\section{THERMISTORS}

\begin{tabular}{|c|c|c|c|c|c|c|}
\hline Type & Application & Supplier's Designation & $\begin{array}{l}\mathrm{R}(\Omega) \\
\mathrm{e} 25^{\circ} \mathrm{C} \\
\end{array}$ & $\begin{array}{r}\text { Rang } \\
\cdot \mathrm{C} \\
\end{array}$ & & $\begin{array}{c}\begin{array}{c}\text { Diameter } \\
\text { in }\end{array} \\
\end{array}$ \\
\hline bead & experiment & GB31M2 & 1000 & -10 to & $+30^{\circ} \mathrm{C}$ & .060 \\
\hline bead & experiment & GB32M2 & 2000 & 0 to & $40^{\circ} \mathrm{C}$ & .060 \\
\hline disc & monitor & CB23J1 & 300 & -40 to & 0 & .30 \\
\hline disc & monitor & JB31J1 & 1000 & 0 to & 100 & .10 \\
\hline
\end{tabular}

Supplier: Fenwa11 Electronics, Inc., Framingham, Massachusetts 


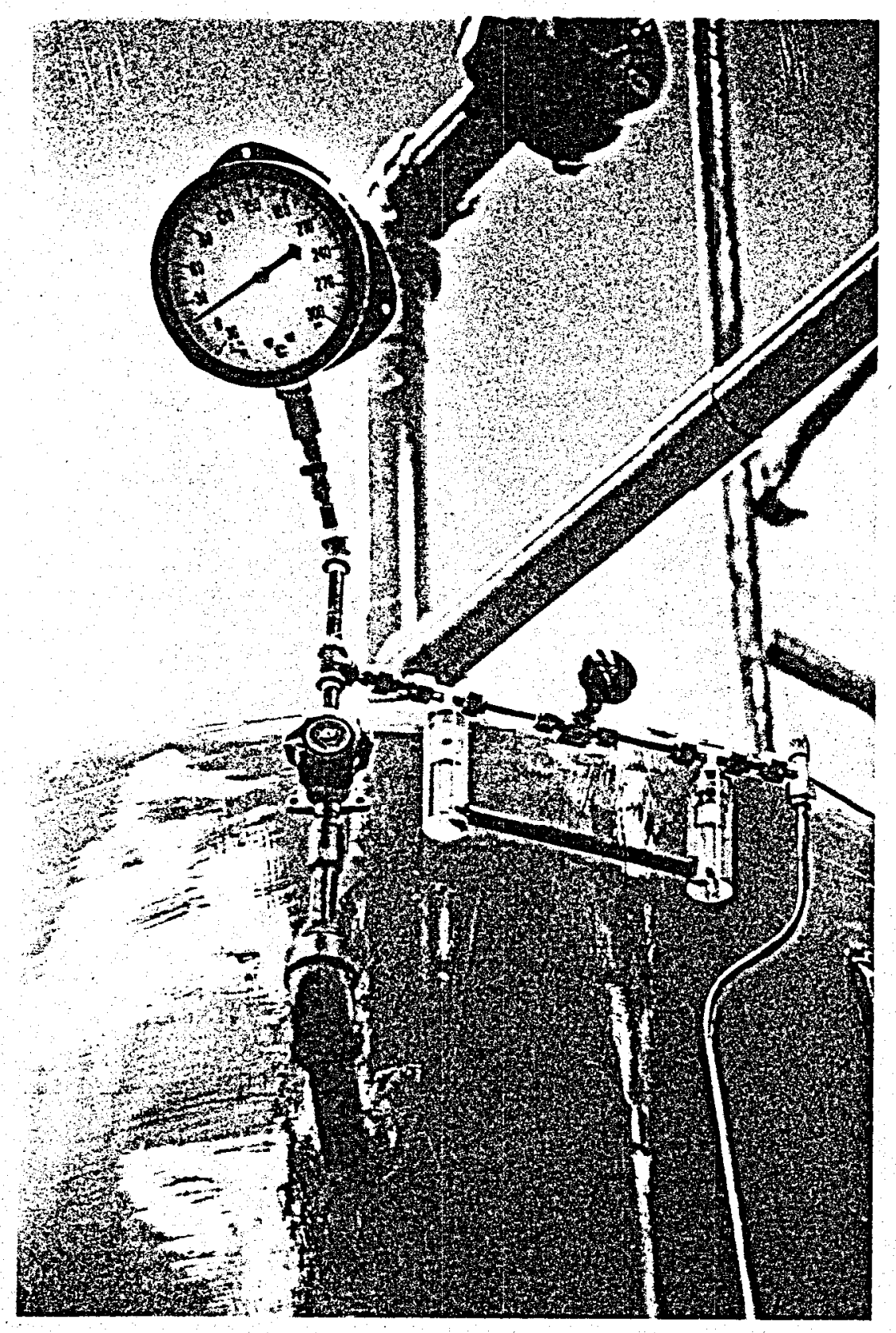

Photo 9.

Freon-oil interface. U-tube has freon vapor in the left cylinder, oil in the right cylinder, and mercury in the connecting tube. Also shown is dial pressure gauge; instruments shown at top of booster tank. 
PRESSURE TRANSDUCERS

\begin{tabular}{llcrrrr}
\multicolumn{1}{c}{ Type } & Application & $\begin{array}{c}\text { Supplier's } \\
\text { Designation }\end{array}$ & $\begin{array}{c}\text { Sensitivity } \\
\text { (mV/psi) }\end{array}$ & $\begin{array}{c}\text { Range } \\
\text { (psi) }\end{array}$ & $\begin{array}{c}\text { Housing } \\
\text { Construction }\end{array}$ \\
differential & experiment & LX1601D & 1000 & -5 to +5 & ceramic \\
absolute, & experiment & LX1603A & 333 & 0 to 30 & ceramic \\
absolute & $\begin{array}{c}\text { experiment } \\
\text { differential }\end{array}$ & LX1610A & 167 & 0 to 60 & ceramic \\
& $\begin{array}{c}\text { monitor and } \\
\text { venturi }\end{array}$ & LX1801DZ & 1000 & -5 to +5 & zinc
\end{tabular}

Supplier: National Semiconductor Corporation, Santa Clara, California

\section{GAUGES AND INDICATORS}

Type, Description

pressure (d)

pressure (d)

pressure (d)

pressure (d)

pressure (d)

pressure (d)

temperature (mg)
temperature (d)
temperature (mg)
temperature (mg)
temperature (mg
temperature (mg)

sight glass

sight glass

sight glass

sight glass

level indicator ( $\mathrm{wm})$ level indicator ( $\mathrm{wm}$ ) dump tank ( $w / o m)$
Location

accumulator tank

booster tank

dump tank

coolant storage tank

condenser inlet (methanol)

condenser outlet (methano1)

accumulator tank

booster tank.

dump tank

chiller outlet

condenser inlet (methanol)

condenser outlet (methanol)

accumulator tank

booster tank

dump tank

coolant storage tank

accumulator tank

booster tank

dump tank
Range

$30^{\prime \prime} \mathrm{H}_{\mathrm{gvac}}$ - $100 \mathrm{psig}$

30 'H $\mathrm{gvac}$ - 300 psig

$30^{\prime \prime} \mathrm{H}_{\mathrm{g} v a c \text {. - } 100 \mathrm{psig}}$

$30^{\prime \prime} \mathrm{H}_{\mathrm{gvac}}$ - 30 psig

$30^{\prime \prime} \mathrm{Hg}$ vac. - 60 psig

30 'H $\mathrm{g}$ vac. - 60 psig

$$
\begin{array}{r}
0-160^{\circ} \mathrm{F} \\
0-220^{\circ} \mathrm{F} \\
0-160^{\circ} \mathrm{F} \\
-40-110^{\circ} \mathrm{F} \\
-40-110^{\circ} \mathrm{F} \\
-40-110^{\circ} \mathrm{F}
\end{array}
$$

0 - 60 in (length)

$0-54$ in

$0-26$ in

$0-34$ in

$0-72 "$ (tank height)

$0-84^{\prime \prime}$

$0-36^{\prime \prime}$

d - dial, mg - mercury-in-glass, wm - with mercury interface, w/om - without mercury interface 


\section{TEST SECTION ARRANGEMENT}

\subsection{General Arrangement}

The test section was shown earlier in schematic form in Figure 2 and in Photos 1 and 2. The test section proper is located between two isolation valves. With the exception of mass flow rate, all experimental measurements and observations are made between these two valves. They are of the butterfly type and are pneumatically controlled for fast operation either by hand or automatically from the computer. The valves are always either fully open or closed and are not used to condition the flow in the test section in any way. The upstrean valve isolates the settling chamber from the pipe leading from the venturi flow meter, whereas the downstream valve isolates the diffuser from the return pipe to the condenser. The valves are shown in Photos 10 and 11.

The settling chamber is made from 5 -in diameter steel pipe. An insert, machined from Delrin, provides a smooth transition to the 2-in diameter glass portion of the test section, which consists of a series of tubes of various lengths connected to one another by means of clamps fitted at flanged ends. The lengths range from $1 \mathrm{ft}$ to $10 \mathrm{ft}$, depending on the particular measurements being taken. The first glass section is flanged directly to the settling chamber.

At the opposite end of the test section, the last glass section is connected to an adapter with a flexible rubber sleeve to allow alignment of the tubes and changes in length caused by thermal effects. The sleeve is connected to a fixed support and a second rubber sleeve to isolate the glass sections from vibration of the condenser-pipe assembly. The flow 


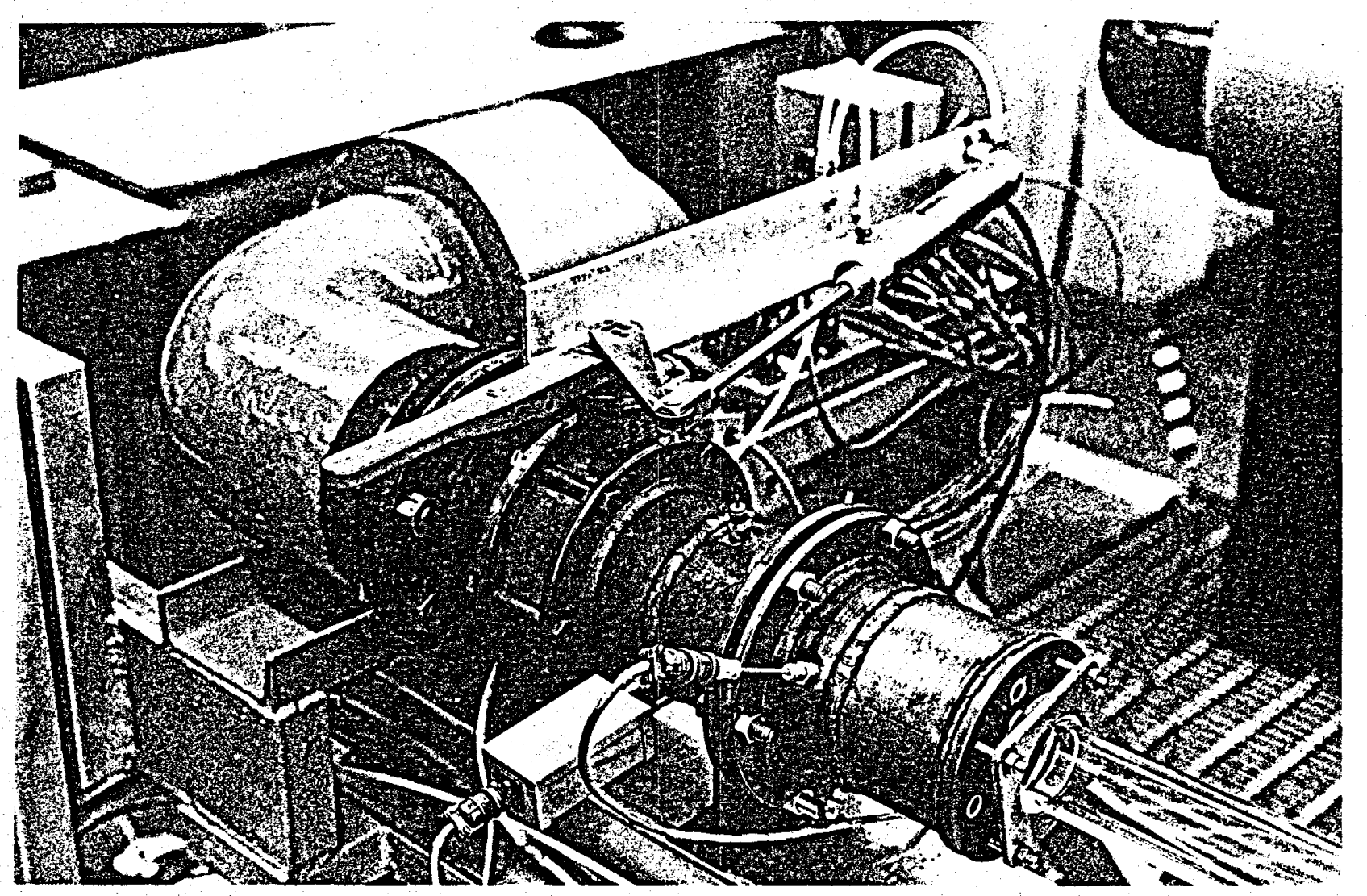

Photo 10.

Upstream valve. Note pneumatic actuator and settling chamber instruments. 


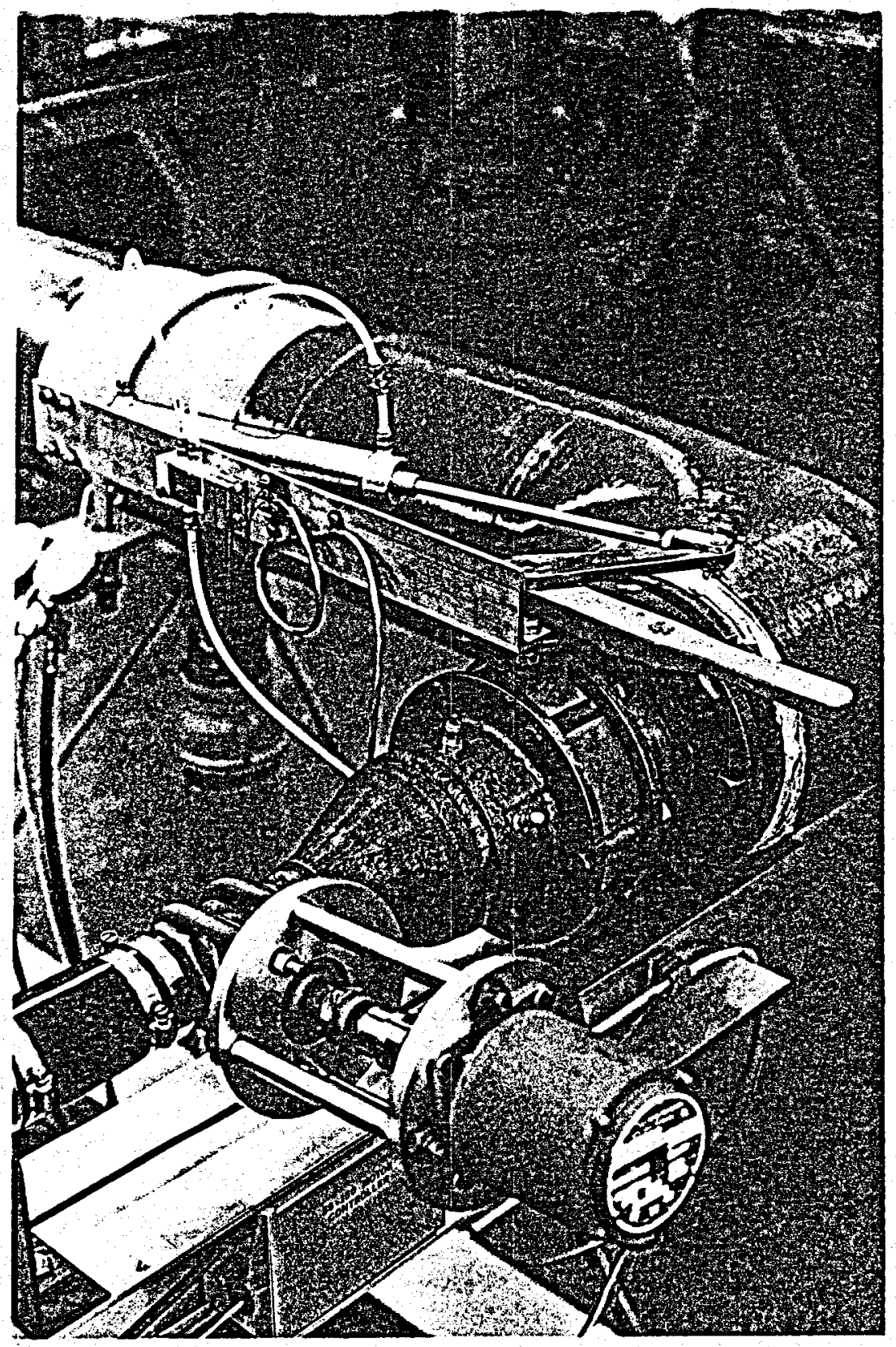

Photo 11.

Downstream valves. The throttling control valve (gate valve) is in the 2 -in diameter section; the isolation valve (butterfly valve) is in the 5-in diameter section. Both are automatically controlled. 
through the test section is controlled by a standard gate valve (the throttling valve) and the diffuser. These follow the second sleeve and are connected to the condenser by means of the return pipe. The diffuser provides an expansion in diameter from 2-in to 5-in, and is a standard steel pipe fitting.

The settling chamber and the fixed support mentioned above are mounted on a 6-in square aluminum I-beam which runs the full length of the test section. The glass sections are supported on this beam by means of adjustable stands which clamp onto the beam and allow alignment of the glass. The I-beam, and hence the test section, is supported separately from the connecting piping to eliminate vibration. The total length of the transparent section can be set at $10 \mathrm{ft}, 24 \mathrm{ft}$, or $40 \mathrm{ft}$ when horizontal, and $10 \mathrm{ft}$ or $24 \mathrm{ft}$ when vertical.

\subsection{Accommodation of Probes and Transducers}

Pressure and temperature transducers are connected along the test section in basically the same way. Delrin inserts fit between the ends of the glass sections. These inserts have an inside diameter which matches that of the glass pipe and face grooves to accommodate the standard Teflon gaskets used with this type of pipe. The outside diameter is such that the spacer is also held centered by the flange bolts.

Pressure transducers are connected by plastic tubing to a brass fitting which screws into wells in the insert, with a small hole connecting the well to the inside wall of the spacer. Hence, static pressure is measured at the wall. Both absolute and differential transducers are 
connected using this arrangement.

Temperature probes are also mounted in a brass fitting which screws into the insert, but which also allows the probe to be positioned radially.

The sketches in Figure 16 show both arrangements. A temperature and absolute pressure transducer can also be connected at the settling chamber and diffuser, but with fittings screwed into the steel pipe wall.

The Delrin inserts discussed above have an extra probe location to accept the sliding type of probe. This location could be used in the measurement of void fraction or stagnation pressure.

\subsection{Flow Contro1}

Flow control is accomplished by means of four devices: a throttle plate, a throttle valve, and two isolation valves. . The latter are used only as shut-off valves, as discussed above, and will not be discussed further here.

The throttle plate is an aluminum disc with a number of holes drilled to provide a specified total flow area. The disc is clamped in an aluminum holder which fits between two glass sections, in the same manner as the Delrin inserts. A drawing of the disc and holder is given in Figure 17. It is possible to replace the disc with a contoured nozzle, shown in Figure 16, depending on the type of flow to be studied. Allowance has been made in both designs for the measurement of pressure at the face of the plate or nozzle using the same type of transducer fitting discussed earlier. Control of the flow is accomplished by causing the liquid to choke at the plate or nozzle. In this way, the flow rate can be held nearly 

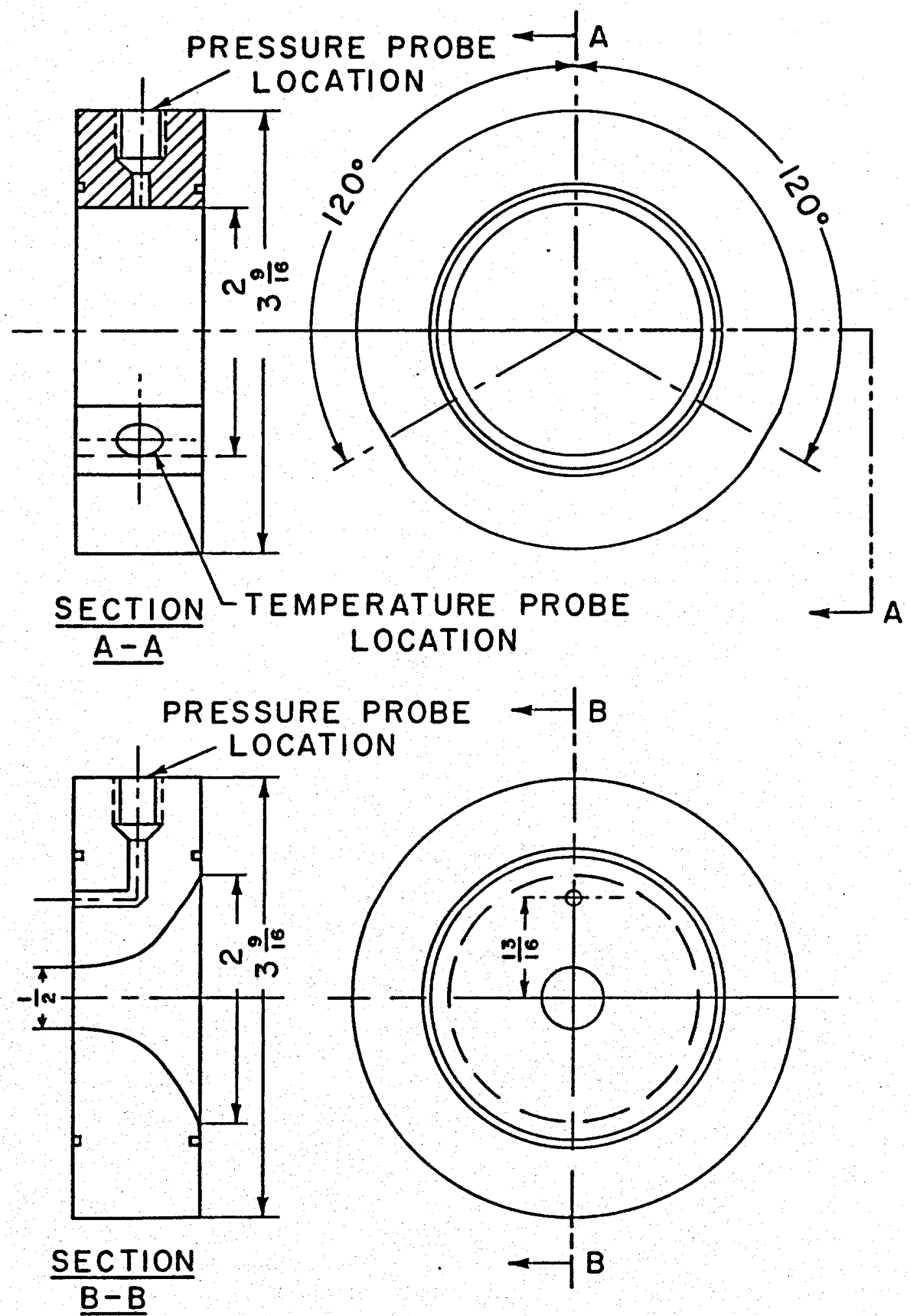

FIG. 16, DELRIN INSERTS FOR TEMPERATURE AND PRESSURE PROBE ATTACHMENTS 


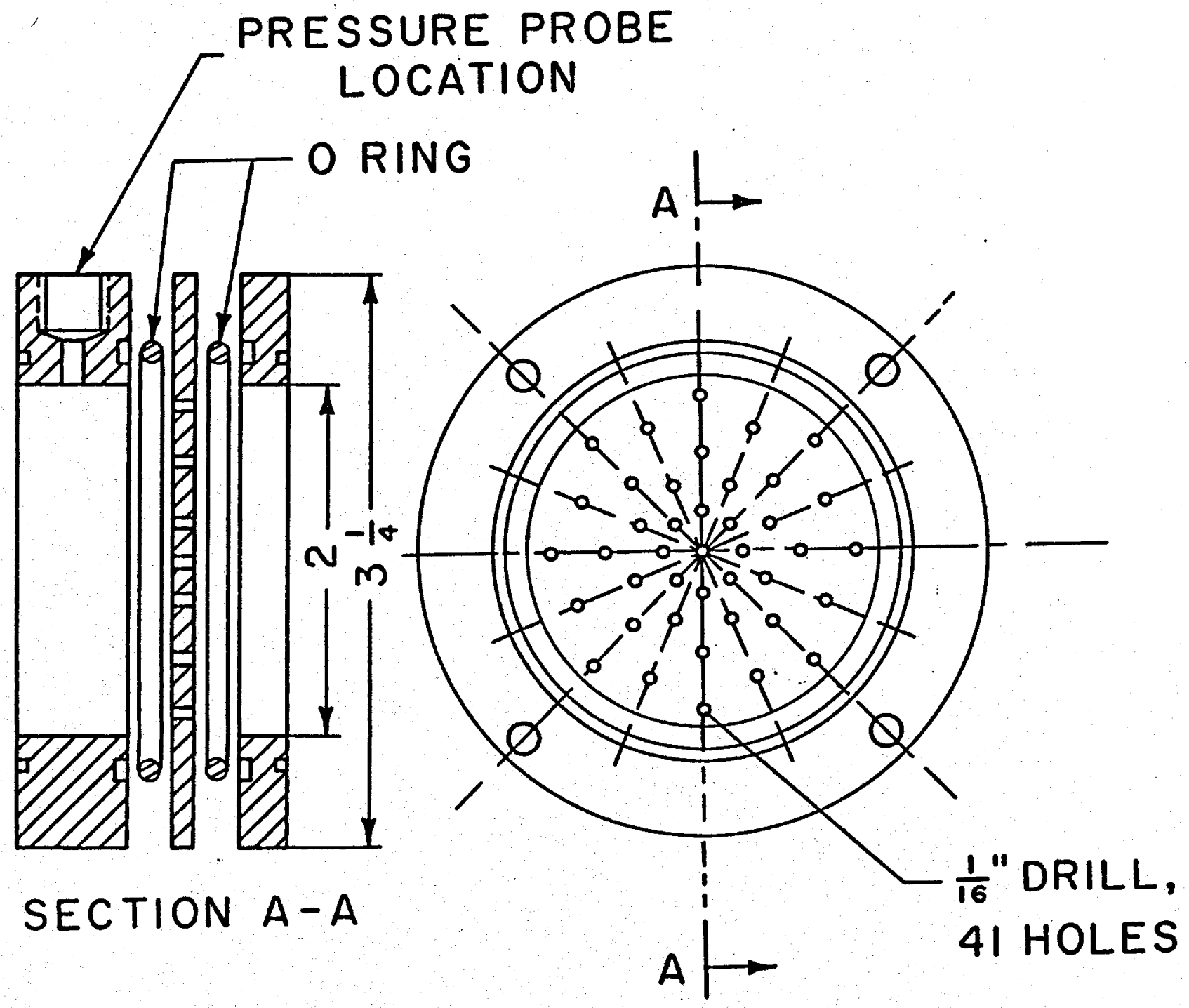

Fig, 17, THROTTLE PLATE AND HOLDER 
constant during the run, regardless of changes which occur in the flow further downstream. The throttling valve can then be adjusted to control the amount of flashing which occurs, or equivalently, the type of flow which occurs in the test section, without changing the mass flow rate [01ia, 1982$]$. Also, the pressure in the diffuser is maintained sufficiently low (by the operation of the condenser) so that the two-phase flow in the test section is choked at the throttle valve. Thus, conditions in the test section can be held constant during a run, despite changes which occur in other parts of the system, since the flow occurs between two choked conditions. With a throttle plate or nozzle of a given flow area in place, the mass flow rate can be varied over a limited range by adjusting the pressure in the accumulator tank. If a larger variation is required, a plate with a different flow area is used. Figure 18 shows the range of mass flow rates which can be achieved by choking the liquid flow. The applied boost is the pressure applied to the accumulator above the saturation pressure in that tank. In Figure 18, the quantity $D$ is the diameter of the nozzle or equivalent diameter of the throttle plate. The principle of choked liquid flow is explained in detail, for example, in Maeder et al, 1981 and Bilicki and Kestin, 1982. 


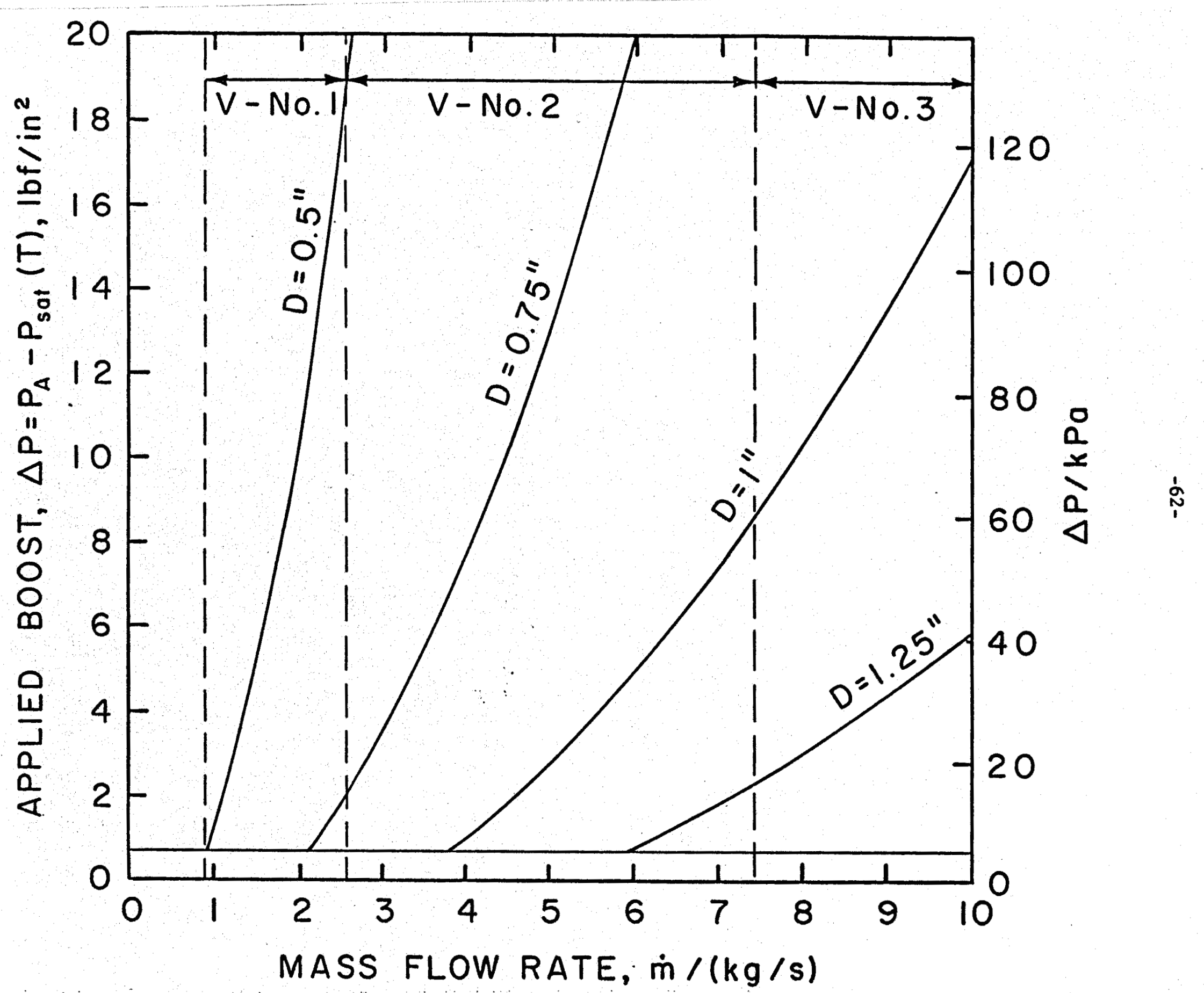

FIG, 18, BOOST PRESSURE VERSUS MASS FLOW RATE FOR SEVERAL EQUIVALENT NOZZLE DIAMETERS 
6. MONITORING, SET-UP, AND DATA ACQUISITION

Since the facility was designed as an intermittent one with running times of one-half to three minutes, it is clear that for all operations of the facility including the acquisition of data and the running of the experiment, automation was highly desirable, if not an absolute necessity. After investigating a number of options, we decided to choose the Hewlett-Packard HP-85 computer as the basic controller for the system. This not only satisfies our requirements for control and data acquisition, but also makes available to the research group a reasonably powerful computer for data evaluation and theoretical studies.

\subsection{Selection of Basic System and Functions}

For the connection between measuring instruments and the remotely operated devices such as valves and motors and the HP-85 computer, a number of different interfaces are available.

The selection of the HP-IB interface bus was based on its very impressive acquisition rate of $20 \mathrm{kBytes} / \mathrm{s}(\mathrm{kB} / \mathrm{s})$, and its great versatility for accepting additional instrumentation and control devices.

Basically, the chosen system is required to satisfy four functions:

- Between runs it monitors such essential parameters as refrigerant pressure and temperature, methanol-water mixture temperature, fluid levels, and, if necessary, issues control signals to keep these parameters within set limits.

- When the system is being prepared for a run at the preset time (the target time), it issues orders to pump the working fluid, R-114, into 
the proper vessels in the proper amounts, prepares the R-114 conditions by switching heaters on and off, and reports when the desired conditions have been reached.

- At the target time, control is taken over by the operator who then transfers the control, in turn, to the next program which takes calibration measurements, opens the necessary valves to establish the proper flow conditions in the test section, and takes the measurements in a variety of ways to be explained later. It also transcribes data onto the permanent record on tape in digital code.

- The computer then takes these data off the tape, checks them for consistency, and evaluates them, putting them into a form which can be easily interpreted. This last function is designed in a very flexible fashion, to be tailored to the particular research to be performed.

\subsection{The Controller}

The HP-85 computer when operating as a controller is equipped with an internal memory of $32 \mathrm{kB}$ with a number of enhancement read-only memories (ROMs) and the interface to the HP-IB bus. Its standard equipment includes: keyboard for manual input and programming, a CRT for alphanumeric and graphic output, and a small printer for printed and graphics output. The computer uses enhanced BASIC as the computer language and together with the selected interface has a basic data acquisition speed of $20 \mathrm{kB} / \mathrm{s}$.

\subsection{The Interface Bus}

The HP-IB interface bus is a 16 bit bus: eight bits are used for 
data transmission; three bits are used for acquisition control ("handshake"), and five bits are used for control of the bus itself and the instruments connected to it. See Photo 12.

\subsection{The Multiprogrammer and Its Cards}

At the present time, we have connected to the bus a precision multimeter (used for calibration of pressure and temperature transducers and any other devices used for measurement) and a multiprogrammer with its proper interface which allows the transmission of digital signals received from or transmitted to the analog devices, switches, etc.

The multiprogrammer, which can be expanded at a later date to three times its present capacity, allows up to 15 specialized measurement or control cards to be selectively connected to the bus. While some of these cards are standard Hewlett-Packard equipment, most of them have been designed and built by our own personnel to suit the specific purposes at hand (i.e., in Figure 19, the cards at $A, B, C, D$ and $F$ ).

of particular interest, should be cards B,C and D which translate up to 7 multiplexed analog channels into digital information using a ramp-type A-to-D converter. The ramp-type A-to-D converter was chosen in order to make these cards reasonably insensitive to extraneous noise.

The signals measured by these cards, for instance, can be either resistance measurements, such as from the thermistor temperature transducers, or voltage measurements as derived from pressure transducers.

Card F, a multiplexed card feeding directly into a high speed A-to-D converter, is designed to provide high-speed measurements of voltage in the range from 0 to 10 volts of 8 channels. The basic data transmission 


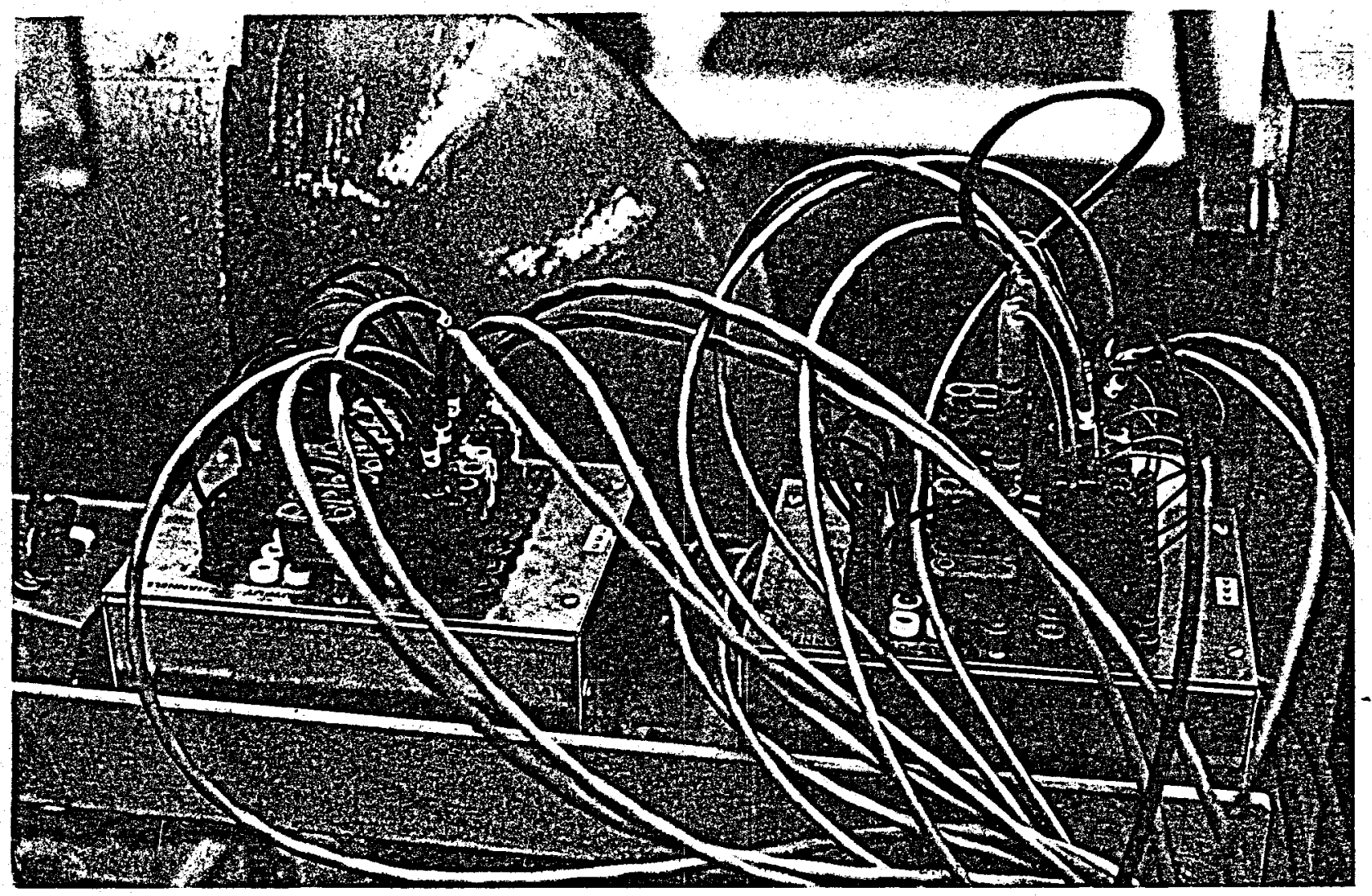

Photo 12.

Electronic interface between measuring instruments and HP -85 computer. 


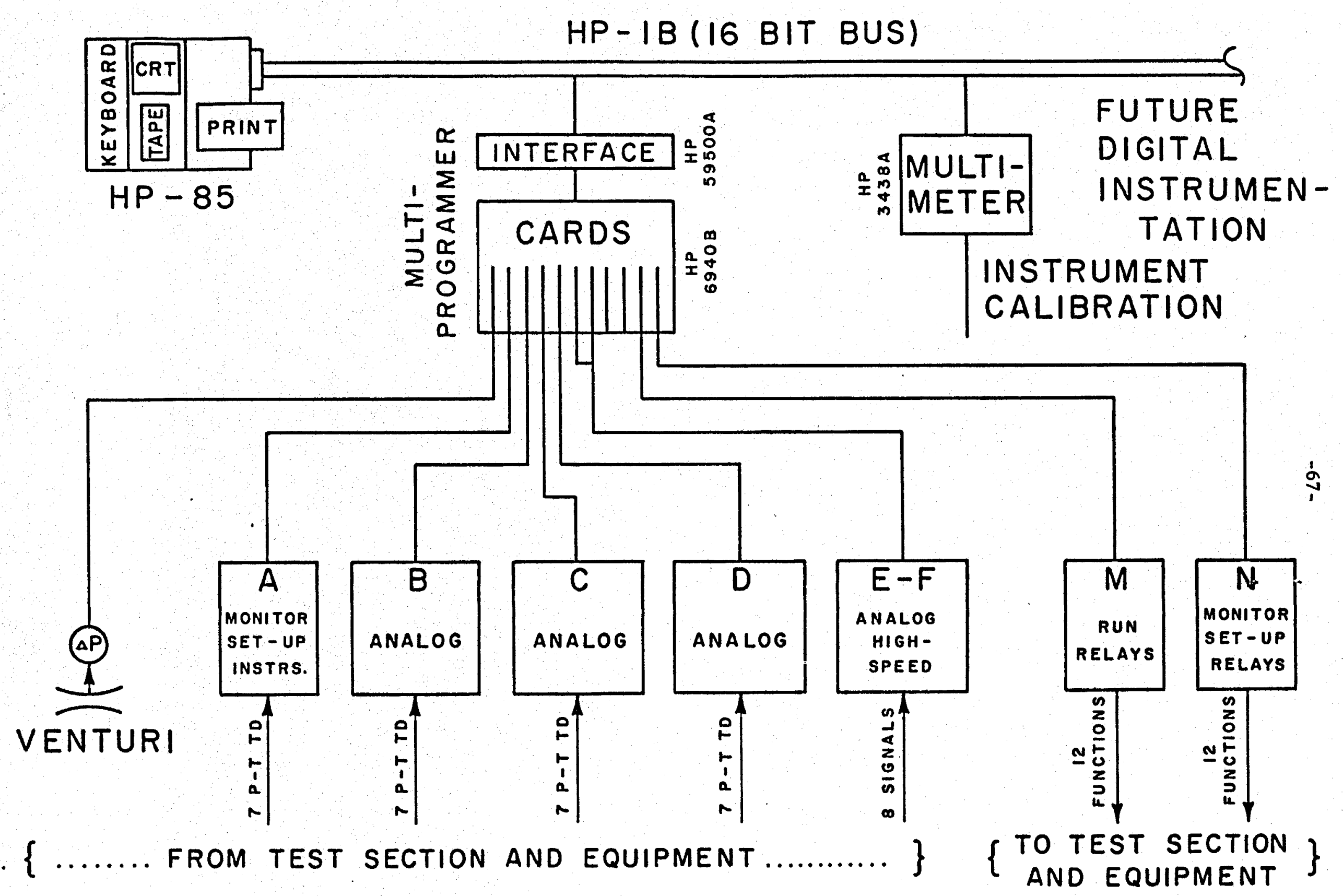

Fig. 19. AUTOMATIC DATA ACQUISITION AND PROCESSING SYSTEM 
rate of this "fast handshake" data transmission system is 300 microseconds. It has been incorporated for the acquisition of unsteady information such as turbulence and transient flow measurements.

Multiprogrammer cards $M$ and $N$ are output cards that selectively operate 24 relays, thereby controlling valves, motors, pumps and other such devices under the action of the controller.

In order to enable the multiprogrammer to operate in the fast handshake mode, i.e., to permit the acquisition of turbulence data, its electronics needed to be modified. This was accomplished by eliminating some unnecessary data transmission delays in the multiprogrammer interface and providing a trigger for the high-speed A-to-D converter which will advance the multiplex and start the next conversion just as soon as the previous signal is ready for transmission. 


\section{PRELIMINARY RESULTS OF PRESENT OPERATIONS}

We expect to issue several reports on the detailed findings of our studies, but wish to present here a sampling of the results obtained to-date.

\subsection{Range of Operation}

The test facility has been operated over the following ranges:

$$
\begin{array}{lc}
\text { Reynolds number, Re: } & 6.7 \times 10^{4} \text { to } 1.7 \times 10^{7} \\
\text { Pseudo Mach number, Ma': } & 0 \text { to } 1.0 \\
\text { Froude number, Fr: } & 0.19 \text { to } 4.6 \times 10^{4} \text {. }
\end{array}
$$

We use the following definitions for these dimensionless parameters:

$$
\begin{aligned}
\operatorname{Re} & =\rho w D / \mu=\dot{\mathrm{m} D} / \mathrm{A \mu}, \\
\mathrm{Ma}^{\prime} & =w / \mathrm{a}^{*}, \\
\mathrm{Fr} & =w^{2} / \mathrm{gD} .
\end{aligned}
$$

\subsection{Two-Phase Friction Factors}

Various experiments have been conducted on the horizontally-configured test section, and a full range of flow conditions has been attained. For the sample of results given here, the test section was arranged with a $4-\mathrm{ft}$ front section followed by one $10-\mathrm{ft}$ and two $4-\mathrm{ft}$ sections, and with an orifice to throttle the flow at the start of the test section. Test runs have been made under conditions from pure liquid flow to choked two-phase flow (i.e., two-phase flow with a specific volume ratio, $R=v / v_{f}=50$ ). 
This covers the entire range of present interest and demonstrates the range of flows which can be produced.

As a means of validating the design and performance of the test section, several runs were conducted with the working fluid in the pure liquid state. The pressure drop was measured, normalized to the dynamic pressure, $Q=0.5 \mathrm{\rho w}^{2}$, and plotted as a function of pipe length from the inlet. The result is shown in Figure 20. We believe the measured data are accurate to $\pm 2 \%$. The best straight line through the data deviates from the results expected for a perfectly smooth pipe by about $+5 \%$. This amount of extra friction can be accounted for with a pipe wall roughness of about $5 \mathrm{\mu m}$, according to the Moody diagram, and is reasonable given the type of pipe and couplings being used in this system. These results, we believe, validate the design.

The system has been operated under conditions from compressed liquid to choked two-phase flow. The full range of flows can be seen from Figure 21 which is essentially a Fanno curve drawn in enthalpy-entropy coordinates. The quantity, $T\left(s-s_{f}\right)$ has been chosen as a measure of dissipation, compared to the change in kinetic energy, $h-h_{f}$. The terms, $h_{f}$ and $s_{f}$, are the enthalpy and entropy, respectively, of the saturated liquid, and thus the point, $s-s_{f}=0$ and $h-h_{f}=0$, corresponds to pure liquid flow. From the sampling of points shown, taken from a number of test runs, it can be seen that the flow approaches the case of choked two-phase flow where the curve has a vertical tangent.

We have examined the pressure drop along the test section in twophase flow and compared the results with single-phase, liquid flow. The 


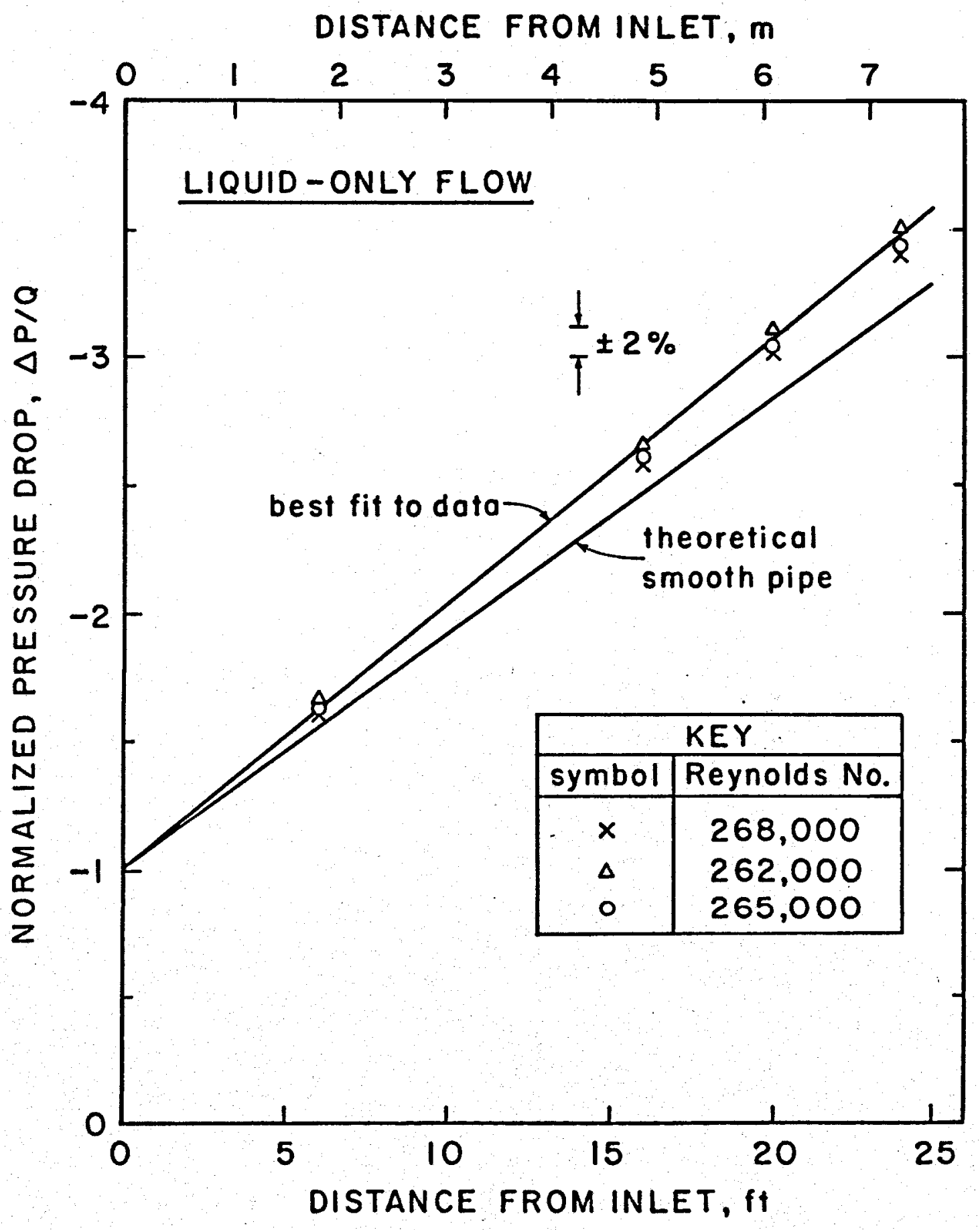

FIG, 20, PRESSURE DROP AS A FUNCTION OF DISTANCE ALONG THE PIPE FOR PURE LIQUID FLOW 


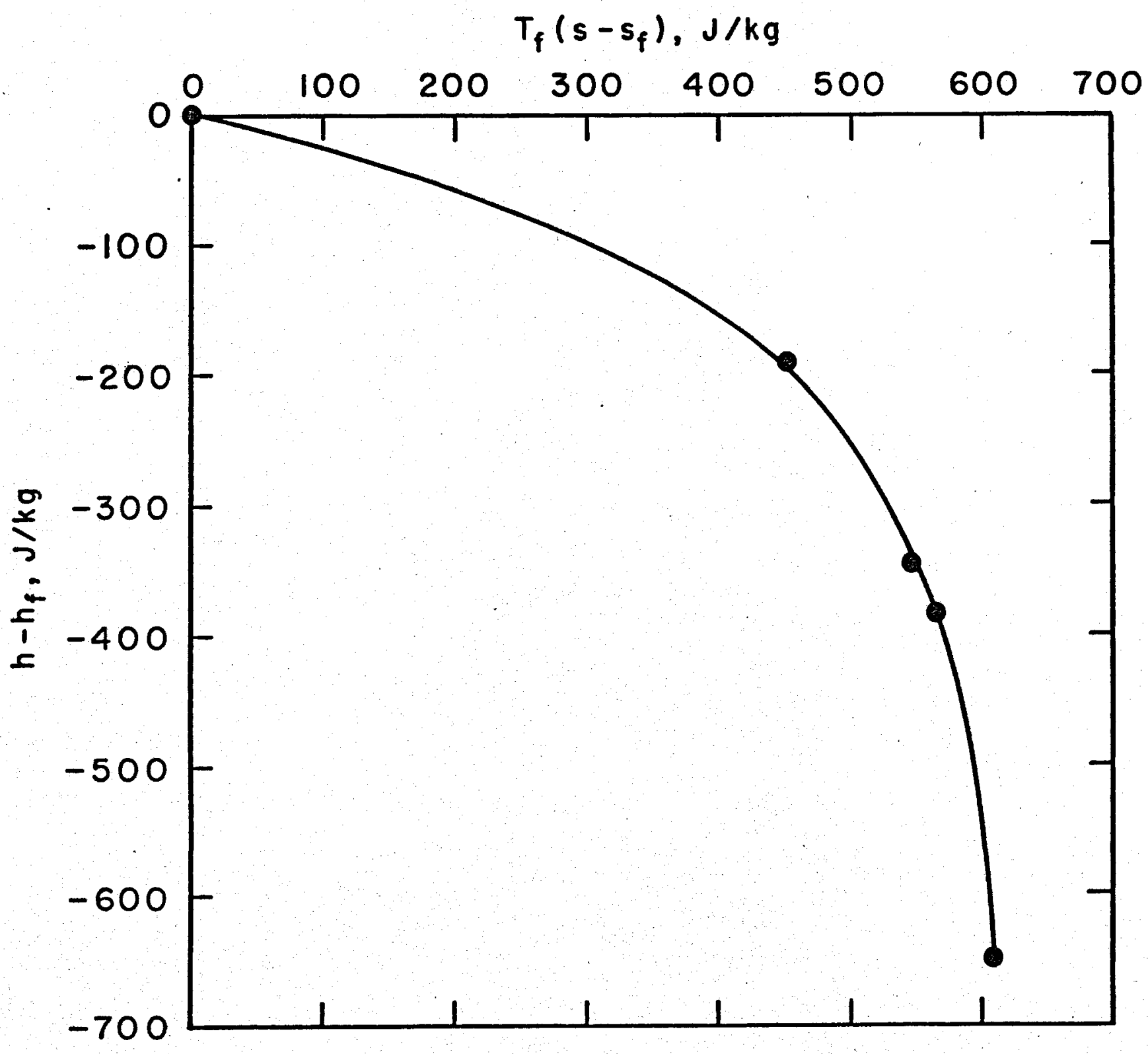

Fig, 21. FANNO-CURVE FOR TYPICAL FLOW CONDITIONS 
dissipated energy, $\mathrm{T}$ ds, has been expressed as the product of the kinetic energy and a friction factor, $f$, i.e.,

$$
T d s=f \frac{w^{2}}{2} \frac{d \ell}{D},
$$

over a dimensionless length of pipe, dl/D. For comparison, we compute a pseudo-1iquid friction factor, $f_{0}$, by assuming the total mass flow through the pipe is only 1iquid. From this, a friction factor is found by means of the Moody diagram for a smooth pipe. We then calculate $f_{0} \bar{R}$, where $\bar{R}=\bar{v} / v_{f}$, with $\bar{v}$ being an average specific volume over a specified length for the two-phase flow. A graph of $f_{0} \bar{R}$ versus $\bar{v} / v_{f}$ is then drawn. A profile of $f_{0} \bar{R}$ versus $\bar{v} / v_{f}$ can then be drawn as a straight line. Experimental results obtained for two-phase runs, $\overline{f R}$, (i.e., the average of $f$ times $R$ over a length) may be plotted on the same graph, as shown in Figure 22. These indicate that the two-phase friction coefficient defined in equation $(7.4)$ is close to the liquid-only coefficient at moderate values of $\bar{v} / v_{f}$. Also shown in Figure 22 is a profile of $f_{0} \bar{R}$ where $f_{0}$ has been calculated based on all vapor flow (dashed line).

Preliminary results seem to indicate that the data may approach this. curve at higher values of $\bar{v} / v_{f}$, and may be confined to the region bounded by the two straight lines corresponding to the cases of pure liquid and pure vapor flows. Additional measurements are needed to confirm these trends.

\subsection{Flow-Pattern Observations}

A variety of so-called "flow patterns" have been observed during the runs conducted to-date. These are represented schematically in Figure 23 


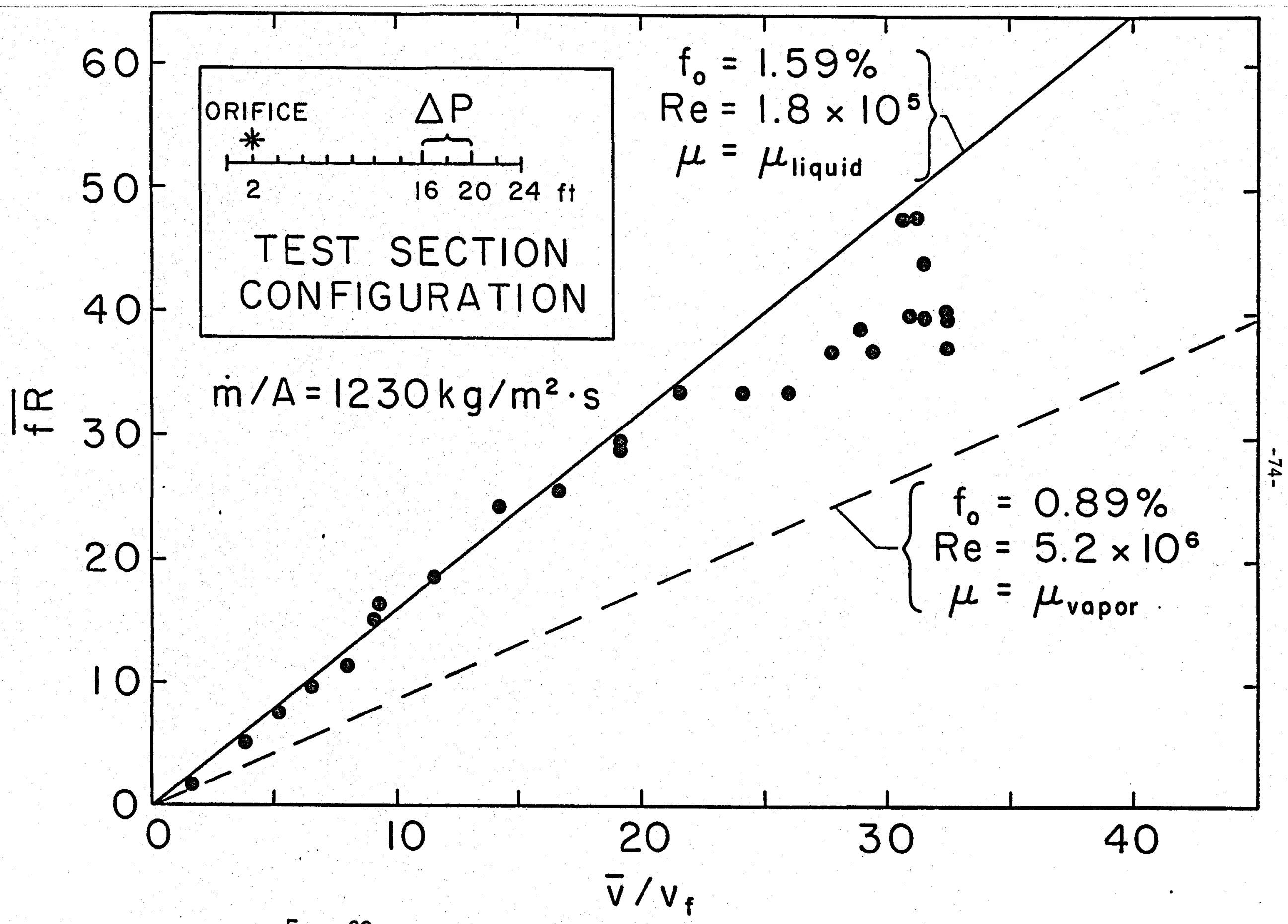

FIG, 22. FRICTION EFFECTS AS A FUNCTION OF VOLUME RATIO 
FLOW DIRECTION
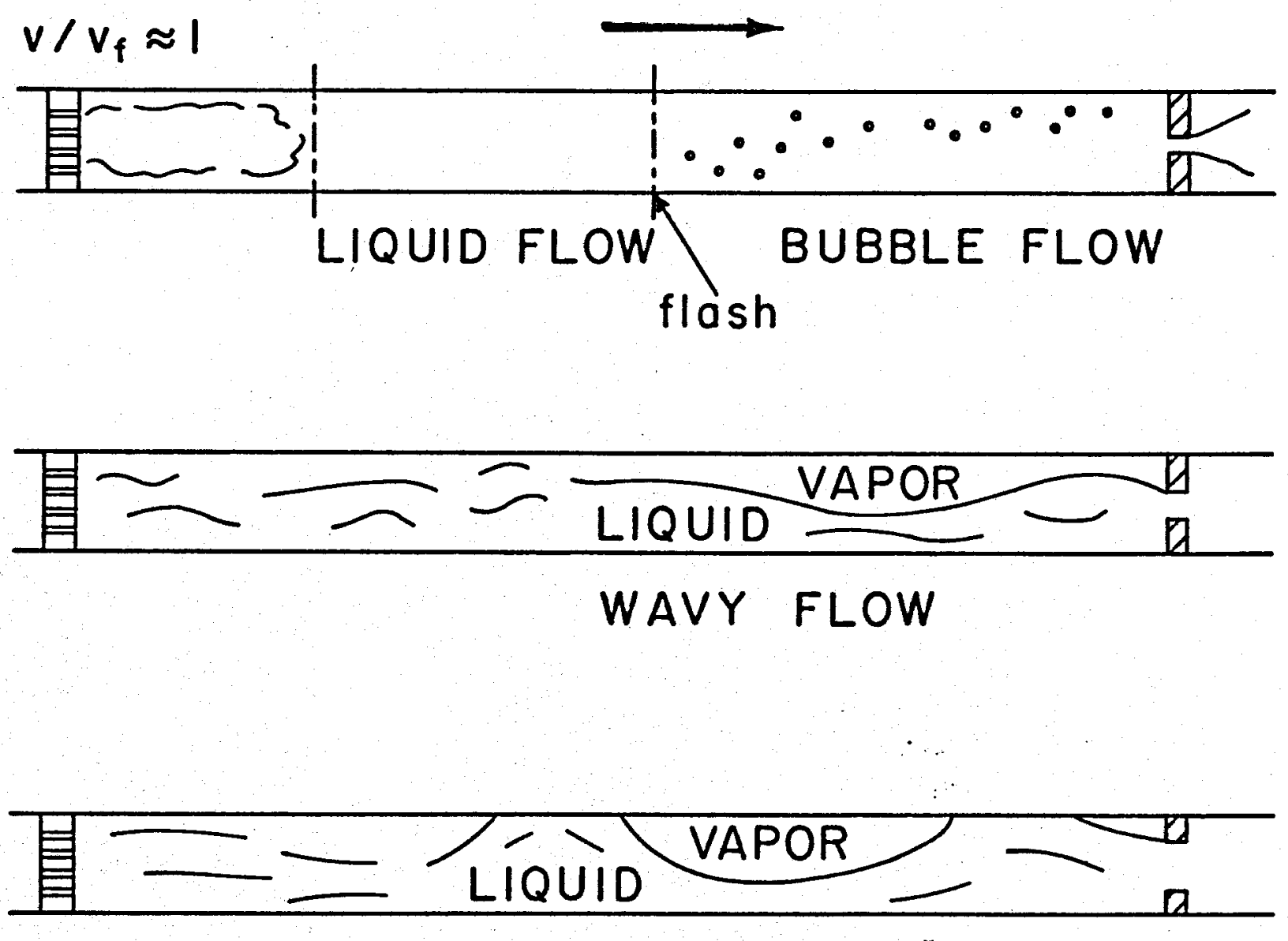

BREAKING WAVES

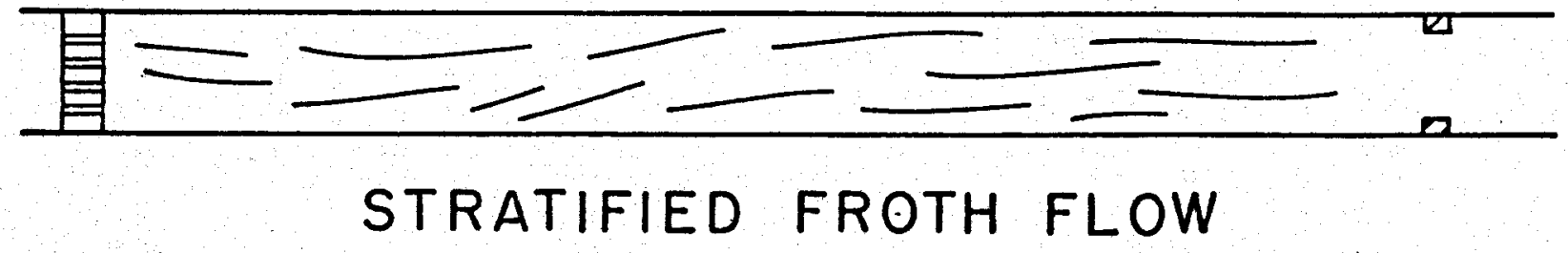

FIG, 23, TWO-PHASE FLOW PATTERNS 
where the throttling orifice (at the left or upstream end) and the throttle valve (at the right or downstream end) are also shown. In spite of the widely recognized fact that the description and classification of such patterns is to a certain extent subjective, it is generally accepted that they reveal essential aspects of two-phase flow.

Figure 23 (a) shows a plume of vapor emerging from the orifice followed by condensation to fully-liquid flow. This is a characteristic of choked liquid flow at this point. When the fluid pressure falls to the saturation value, flashing occurs with bubble formation. Migration of the bubbles toward the top of the pipe seems to lead to the formation of wavy flows, as seen in Figure $23(b)$ and (c). Eventually a "stratified froth" flow becomes established (Figure $23(\mathrm{~d})$ ) that is very nearly homogeneous. In all cases, the transition region after the orifice is confined to a short length of pipe, beyond which fully-developed flow takes place.

At any given time, we have observed combinations of the types of flow shown in Figure 23 in different sections of the pipe, e.g., (a) - (b), (b)-(c), and (c)-(d). Furthermore, the transitions between flow patterns of different types have been observed. As the flow develops from (a) to (d), the ratio $v / v_{f}$ increases from about 1 to 50 , whereas the Froude number, upon which the flow pattern strongly depends, increases to about 4000 , which constitutes a highly supercritical flow condition.

\section{Acknowledgements}

This work is being supported by the U.S. Dept. of Energy, Division of Geotherma1 Energy, through Contract DE-ACO2-79ET27225, administered through the Los Alamos National Laboratory under subcontract LASL4-X60-6306P-1. Cataudella Associates of Providence, R.I., were 
retained as architect-engineers in order for the facility to meet required codes and safety regulations. The encouragement and support of

Dr. R. J. Hanold, Los Alamos National Laboratory, and Mr. C. B. McFarland, U.S. Dept. of Energy, is gratefully acknowledged. 


\section{REFERENCES}

Bilicki, Z., DiPippo, R., Michaelides, E.E., and Kestin, J., 1980.

"Geothermal Two-Phase Flow: A Selective Annotated Guide to the Literature", Brown University Rep. No. GEOFLO/7, DOE/ET/27225-11, Providence, R.I.

Bilicki, Z. and Kestin, J., 1980. "Flow in Geothermal Wells, Part 4. Transition Criteria for Two-Phase Flow Patterns", Brown University Rep. No. GEOFLO/6, DOE/ET/27225-9, Providence, R.I.

Bilicki, 2. and Kestin, J., 1982. "Two-Phase Flow in a Vertical Pipe and The Phenomenon of Choking: Homogeneous Diffusion Mode1, Part I: Homogeneous Flow Models", Brown University Rep. No. GEOFLO/13, LA-UR-82-598, Providence, R.I.

DiPippo, R., 1980. Geothermal Energy as a Source of Electricity: A Worldwide Survey of the Design and Operation of Geothermal Power Plants, U.S. Dept. of Energy, DOE/RA/28320-1, Washington, D.C.

DiPippo, R. and Avelar, E.M., 1979. "Compound Hybrid Geothermal-Fossil Power Plants", Geothermal Resources Council TRANSACTIONS, 3, p. 165.

DiPippo, R., Khalifa, H.E., Correia, R.J., and Kestin, J., 1979. "Fossil Superheating in Geothermal Steam Power Plants", Geothermal Energy Magazine, 2, p. 17.

Kestin, J. (Ed.-in-Chief), 1980. Sourcebook on the Production of Electricity from Geotherma1 Energy, U.S. Dept. of Energy, DOE/RA/28320-2, Washington, D.C.

Kestin, J., DiPippo, R., and Khalifa, H.E., 1978. "Hybrid GeothermalFossil Power Plants", Mech. Eng., 100, p. 28.

Maeder, P.F., DiPippo, R., Delor, M. and Dickinson, D.A., 1981. "The Physics of Two-Phase Flow: Choked Flow", Brown University Rep. No. GEOFLO/10, DOE/ET/27225-15, Providence, R.I. 
Maeder, P.F. and Michaelides, E.E., 1980. "Prediction of the Entropy Production and Pressure Losses in Two-Phase Flow from the Mixing Length Theory", Brown University Rep. No. GEOFLO/2, DOE/ET/27225-5, Providence, R.I.

01ia, H., 1982. "Expansion of Liquids through Nozzles and Orifices into the Two-Phase Region", Master of Science Thesis, Brown University, Providence, R.I. 

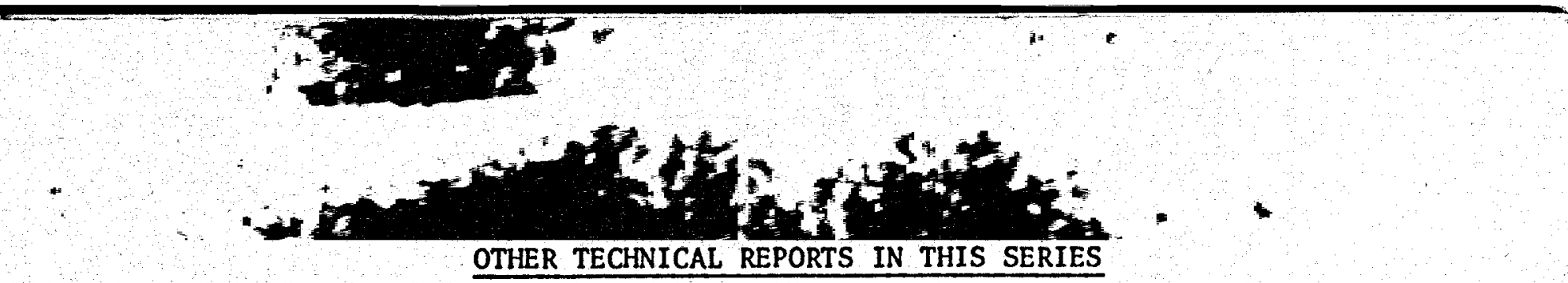

Brown Rep. No.

GEOFLO/1

GEOFLO/2

GEOFLO/3

GEOFLO/4

GEOFLO/5

GEOFLO/6

GEOFLO/7

GEOFLO/ 8

GEOFLO/9

GEOFLO/ 10

GEOFLO/11

GEOFLO/ 12

GEOFLO/13

GEOFLO/ 14

GEOFLO/ 15
Title

"Waste Heat Rejection in Geothermal Power Plants"

"Prediction of the Entropy Production and Pressure Losses in TwoPhase Flow from the Mixing Length Theory"

"Flow in Geothermal Wells: Part I. Fundamentals of Two-Phase Flow by the Method of Irreversible Thermodynamics"

"Flow in Geothermal Wells: Part II. Working Equations for OneDimensional Flow Through a Circular Vertical Channel"

"Flow in Geothermal Wells: Part III. Calculation Model for SelfFlowing Well"

"Flow in Geothermal Wells: Part IV. Transition Criteria for TwoPhase Flow Patterns"

"A Selective Annotated Guide to the literature"

"Executive Summary: The Next Steps in Two-Phase Flow"

"Average Field Equations for Multiphase Flows"

"The Physics of Two-Phase Flow: Choked Flow"

"Two-Phase Flow in Horizontal Pipes"

"Continuum Modeling of Two-Phase Flows"

"Two-Phase flow in a Vertical pipe and the Phenomenon of Choking: Homogeneous Diffusion Model, Part I. Homogeneous Flow Models"

"Two-Phase Flow in a Vertical Pipe and the Phenomenon of Choking: Homogeneous Diffusion Mode1, Part II. The Case of Downflow"

"The Effect of Expansion-Ratio Limitations on Positive-Displacement, Total-Flow Geothermal Power Systems" 